University of Tennessee Health Science Center

UTHSC Digital Commons

$12-2009$

\title{
Contribution of the Membrane-Proximal Region of the Vesicular Stomatitis Virus Glycoprotein to Host Cell Entry and Membrane Fusion
}

\author{
Elizabeth Lane Matheny \\ University of Tennessee Health Science Center
}

Follow this and additional works at: https://dc.uthsc.edu/dissertations

Part of the Virus Diseases Commons, and the Viruses Commons

\section{Recommended Citation}

Matheny, Elizabeth Lane, "Contribution of the Membrane-Proximal Region of the Vesicular Stomatitis Virus Glycoprotein to Host Cell Entry and Membrane Fusion" (2009). Theses and Dissertations (ETD). Paper 159. http://dx.doi.org/10.21007/etd.cghs.2009.0205. 


\title{
Contribution of the Membrane-Proximal Region of the Vesicular Stomatitis Virus Glycoprotein to Host Cell Entry and Membrane Fusion
}

\begin{abstract}
Vesicular stomatitis virus (VSV) is an enveloped, nonsegmented, negative-sense, RNA virus belonging to the Rhabdoviridae family. VSV is considered the prototypic Rhabdovirus due to its simple genetic organization, broad host cell tropism, and ability to be easily grown in cell culture. Therefore, VSV has been used as the prototype to study viral entry, transcription, replication, and assembly. Viral entry, a critical step in the lifecycle of the virus, is mediated by the outer surface protein, $G$ and will be the focus of this dissertation.

We hypothesize that the highly conserved residues in the membrane-proximal region of VSV G protein are critical to membrane fusion through participation in low pH-induced conformational changes and stability of theses structures. This hypothesis was tested initially through the use of site directed mutagenesis and then by studying rapidly acquired second site mutations. Residues that are conserved completely or conserved for their biochemical properties were either deleted or mutated to alanines. The mutated $G$ proteins were examined through the use of transient transfection assays for their surface expression levels, fusion capacity, and ability to undergo $\mathrm{pH}$ dependent conformational changes. Mutation of a conserved $\mathrm{HPH}$ motif (H423/P424/H425) resulted in a dramatic decrease in surface expression. $\Delta \mathrm{H} 423 /$ $\mathrm{P} 424 / \mathrm{H} 425$ was completely fusion defective as assessed by syncytium formation assays that measured cell-cell fusion. Likewise, the cell-cell fusion activity for $\Delta \mathrm{H} 425$ was affected in that the $\mathrm{pH}$ threshold required to trigger the fusion event was decreased. These findings support previous reports suggesting a requirement for histidine protonation in order for the $\mathrm{pH}$ dependent conformational changes needed for membrane fusion to occur. Recombinant viruses encoding the mutated $\mathrm{G}$ proteins were recovered and all of the viruses expressing $G$ proteins with reduced cell-cell fusion capacity, as compared to wild type, grew to lower titers, with the exception of one mutant: D435A/D436A/E437A. Mutation of the DDE motif resulted in a $\mathrm{G}$ protein with a reduced capacity to fuse in transiently transfected cells. However, recombinant virus encoding D435A/D436A/E437A was recovered and unexpectedly grew to wild type titers, suggesting that the virus is overcoming the fusion defect caused by the mutation. Wild type VSV virions have been shown to express a truncated G protein on their surface, called G-stem (GS). GS was detected on the virion of this mutant at levels higher than that of wild type suggesting the truncated $G$ protein was contributing to enhancing the infectivity of the virus.

Mutation of conserved phenylalanines (F440A/F441A) also resulted in a similar phenotype as the $\Delta \mathrm{H} 425$ mutant. Reduced surface expression was observed when this mutated $\mathrm{G}$ protein was transiently expressed in cells and a decrease in the threshold $\mathrm{pH}$ required for fusion was also observed.

Recombinant VSVs encoding the mutated G proteins were recovered to analyze the impact of the mutations on the ability of the viruses to grow and spread. Interestingly, viruses encoding the $\Delta \mathrm{H} 425$ and the F440A/F441A mutant $G$ proteins rapidly acquired additional mutations that made the viruses better able to grow and spread as indicated by increased titers and plaque sizes. Plaque isolates were obtained and subjected to sequence analysis revealing several variants: $\Delta \mathrm{H} 425 / \mathrm{S} 438 \mathrm{I}, \Delta \mathrm{HI} 426 \mathrm{~S} / \mathrm{S} 438 \mathrm{I}, \mathrm{F} 440 \mathrm{~V} /$ F441A, F440T/F441A, F440A/F441A/S438I, and F440A/F441A/CT9. To identify the advantage the additional mutations were providing the recombinant viruses (if any), the mutations were cloned into expression vectors and the mutant $\mathrm{G}$ proteins were examined for their surface expression levels and fusion capacity. The mutations appeared to enhance cell surface expression levels, with the exception of the $\Delta \mathrm{H} 425 / \mathrm{S} 438 \mathrm{I}$ and F440A/F441A/CT9 mutants. The F440A/F441A mutants still were reduced in cellcell fusion activity at $\mathrm{pH} 6.0$ as compared to wild type $\mathrm{G}$. However, the $\Delta \mathrm{H} 425$ mutants' fusion activity was partially restored at $\mathrm{pH} 6.0$. Results from these experiments suggest that when both the $\Delta \mathrm{H} 425$ and F440A/F441A mutant $\mathrm{G}$ acquire a S438I mutation the fusion capacity at $\mathrm{pH} 6.0$ is restored. The findings
\end{abstract}


in these studies indicate residues in the membrane-proximal region of VSV G are critical to the fusion process, suggesting a likely contribution to the stabilization of the pre- and postfusion structures.

\section{Document Type}

Dissertation

Degree Name

Doctor of Philosophy (PhD)

\section{Program}

Molecular Sciences

\section{Research Advisor}

Michael A. Whitt, Ph.D.

\section{Keywords}

Vesicular Stomatitis Virus, Viral Entry, Viral Fusion, VSV G

\section{Subject Categories}

Diseases | Medicine and Health Sciences | Organisms | Virus Diseases | Viruses 
Contribution of the Membrane-Proximal Region of the Vesicular Stomatitis Virus Glycoprotein to Host Cell Entry and Membrane Fusion

\author{
A Dissertation \\ Presented for \\ The Graduate Studies Council \\ The University of Tennessee \\ Health Science Center
}

\author{
In Partial Fulfillment \\ Of the Requirements for the Degree \\ Doctor of Philosophy \\ From The University of Tennessee
}

By

Elizabeth Lane Matheny

December 2009 
Copyright $(C 2009$ by Elizabeth Lane Matheny All rights reserved 


\section{Dedication}

This dissertation is dedicated to my late father Edward Matheny, my mother Dana Matheny, and brother Sean Matheny for their unyielding support and belief in me throughout the years. 


\section{Acknowledgements}

I would like to thank my advisor Michael A. Whitt for the opportunity to work in his lab and the training I received. Also, thanks to my committee members Allen Portner, PhD., Charles J. Russell, Ph.D., Susan E. Senogles, Ph.D., and James Patrick Ryan, Ph.D. for providing excellent insights, ideas, and guidance during my research.

My gratitude is also extended to present and past members of the Whitt laboratory. Erika Dillard, Chad Mire Ph.D., Himangi Jayakar Ph.D., Jeetendra Eswararka Ph.D., Makiko Wantannabe Ph.D., and Carolyn Matthews for their support and help. Additionally, I would like to thank other members of the Molecular Sciences department for offering input, guidance, and support. 


\begin{abstract}
Vesicular stomatitis virus (VSV) is an enveloped, nonsegmented, negative-sense, RNA virus belonging to the Rhabdoviridae family. VSV is considered the prototypic Rhabdovirus due to its simple genetic organization, broad host cell tropism, and ability to be easily grown in cell culture. Therefore, VSV has been used as the prototype to study viral entry, transcription, replication, and assembly. Viral entry, a critical step in the lifecycle of the virus, is mediated by the outer surface protein, $G$ and will be the focus of this dissertation.

We hypothesize that the highly conserved residues in the membrane-proximal region of VSV G protein are critical to membrane fusion through participation in low $\mathrm{pH}$ induced conformational changes and stability of theses structures. This hypothesis was tested initially through the use of site directed mutagenesis and then by studying rapidly acquired second site mutations. Residues that are conserved completely or conserved for their biochemical properties were either deleted or mutated to alanines. The mutated $G$ proteins were examined through the use of transient transfection assays for their surface expression levels, fusion capacity, and ability to undergo $\mathrm{pH}$ dependent conformational changes. Mutation of a conserved HPH motif (H423/P424/H425) resulted in a dramatic decrease in surface expression. $\Delta \mathrm{H} 423 / \mathrm{P} 424 / \mathrm{H} 425$ was completely fusion defective as assessed by syncytium formation assays that measured cell-cell fusion. Likewise, the cell-cell fusion activity for $\Delta \mathrm{H} 425$ was affected in that the $\mathrm{pH}$ threshold required to trigger the fusion event was decreased. These findings support previous reports suggesting a requirement for histidine protonation in order for the $\mathrm{pH}$ dependent conformational changes needed for membrane fusion to occur. Recombinant viruses encoding the mutated $\mathrm{G}$ proteins were recovered and all of the viruses expressing $\mathrm{G}$ proteins with reduced cell-cell fusion capacity, as compared to wild type, grew to lower titers, with the exception of one mutant: D435A/D436A/E437A. Mutation of the DDE motif resulted in a $\mathrm{G}$ protein with a reduced capacity to fuse in transiently transfected cells. However, recombinant virus encoding D435A/D436A/E437A was recovered and unexpectedly grew to wild type titers, suggesting that the virus is overcoming the fusion defect caused by the mutation. Wild type VSV virions have been shown to express a truncated G protein on their surface, called G-stem (GS). GS was detected on the virion of this mutant at levels higher than that of wild type suggesting the truncated $G$ protein was contributing to enhancing the infectivity of the virus.
\end{abstract}

Mutation of conserved phenylalanines (F440A/F441A) also resulted in a similar phenotype as the $\Delta \mathrm{H} 425$ mutant. Reduced surface expression was observed when this mutated $\mathrm{G}$ protein was transiently expressed in cells and a decrease in the threshold $\mathrm{pH}$ required for fusion was also observed. Recombinant VSVs encoding the mutated G proteins were recovered to analyze the impact of the mutations on the ability of the viruses to grow and spread. Interestingly, viruses encoding the $\Delta \mathrm{H} 425$ and the F440A/F441A mutant $G$ proteins rapidly acquired additional mutations that made the viruses better able to grow and spread as indicated by increased titers and plaque sizes. Plaque isolates were obtained and subjected to sequence analysis revealing several 
variants: $\Delta$ H425/S438I, $\Delta$ HI426S/S438I, F440V/F441A, F440T/F441A, F440A/F441A/S438I, and F440A/F441A/CT9. To identify the advantage the additional mutations were providing the recombinant viruses (if any), the mutations were cloned into expression vectors and the mutant $G$ proteins were examined for their surface expression levels and fusion capacity. The mutations appeared to enhance cell surface expression levels, with the exception of the $\Delta \mathrm{H} 425 / \mathrm{S} 438 \mathrm{I}$ and F440A/F441A/CT9 mutants. The F440A/F441A mutants still were reduced in cell-cell fusion activity at $\mathrm{pH}$ 6.0 as compared to wild type G. However, the $\Delta \mathrm{H} 425$ mutants' fusion activity was partially restored at $\mathrm{pH}$ 6.0. Results from these experiments suggest that when both the $\Delta \mathrm{H} 425$ and $\mathrm{F} 440 \mathrm{~A} / \mathrm{F} 441 \mathrm{~A}$ mutant $\mathrm{G}$ acquire a S438I mutation the fusion capacity at $\mathrm{pH}$ 6.0 is restored. The findings in these studies indicate residues in the membrane-proximal region of VSV G are critical to the fusion process, suggesting a likely contribution to the stabilization of the pre- and postfusion structures. 


\section{Table of Contents}

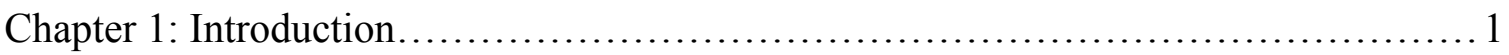

Enveloped Viruses: Host Cell Entry .......................................... 1

A Brief Introduction to Enveloped Viruses............................ 1

Viral Fusion Proteins..................................................... 1

Three Classes of Viral Fusion Proteins ....................................... 2

Class I Viral Fusion Proteins........................................ 2

Influenza Virus HA.............................................. 4

Class II Viral Fusion Proteins........................................... 6

Semliki Forest Virus E1 Mediated Fusion................................. 6

Class III Viral Fusion Proteins.......................................... 7

Vesicular Stomatitis Virus............................................. 8

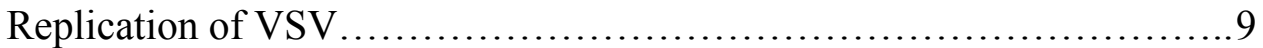

Vesicular Stomatitis Virus Glycoprotein............................... 10

pH Dependent Conformational Changes............................... 10

Role of Histidine Protonation in pH Dependent

Conformational Changes............................................ 14

Membrane-Proximal Regions of Viral Fusion Proteins..........................14

HIV-1 gp41 Mediated Fusion....................................... 15

HIV-1 gp41 MPER .............................................. 16

Paramyxovirus F Stem..............................................16

Semliki Forest Virus E1 Stem....................................... 17

VSV G Stem......................................................

Thesis Statement ......................................................... 18

Chapter 2: Materials and Methods...............................................20

Mutagenesis................................................................... 20

Plasmids and Oligonuclotide-Directed Mutagenesis....................20

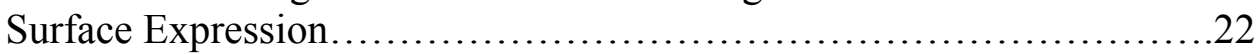

Initial Characterization of Mutants....................................... 22

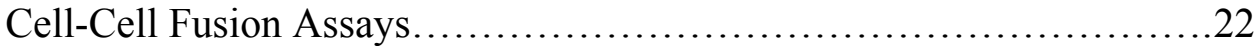

Metabolic Labeling, Transport Kinetics, and

Trypsin-Sensitivity Assays......................................... 23

Characterization of rVSV Encoding Mutant G Proteins..........................24

Recovery of Virus Containing Mutated G Proteins.......................24

Plaque Assay .......................................................24

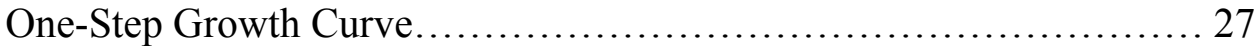

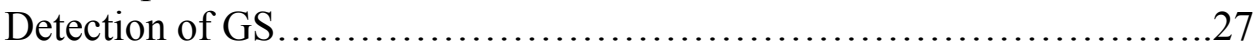

Selection of Plaque Isolates......................................... 27 
Chapter 3: Mutational Analysis of the Membrane-Proximal Region of VSV G....

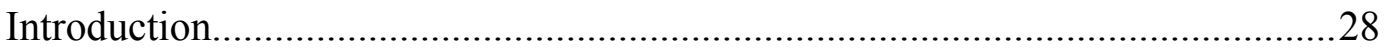

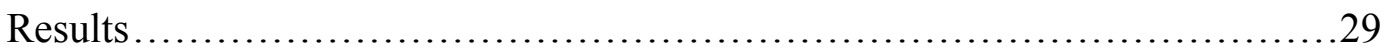

Mutagenesis of the Membrane-Proximal Region of G.................29

Surface Expression of VSV G Mutants............................. 31

Cell-Cell Fusion Activity of Mutants................................. 34

Analysis of $\mathrm{pH}$ Dependent Conformational Changes.................... 36

Recovery of Recombinant Mutant VSV .......................... 40

One-Step Growth Curve........................................... 40

Surface Expression and Fusion in Virally Infected Cells................. 44

Presence of Cleaved G on the Recombinant VSV Virion................ 44

Discussion............................................................. 49

Chapter 4: Examination of Variants with Enhanced Growth Phenotypes...............55

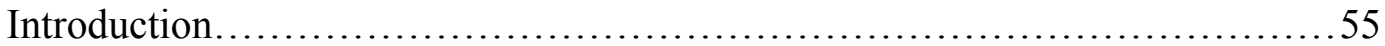

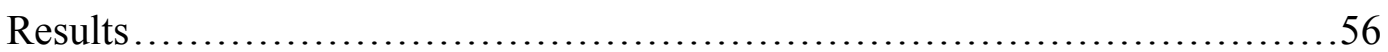

Identification of Rapidly Acquired Mutations..........................56

Isolation of Plaques to Identify Additional Mutants....................57

Standard Plaque Assay.............................................5 57

Surface Expression in Transiently Transfected Cells...................6 62

Cell-Cell Fusion in Transiently Transfected Cells......................62

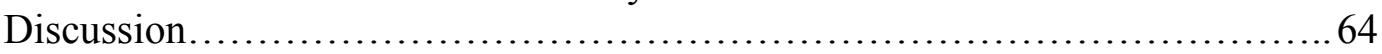

Chapter 5: General Discussion............................................. 71

Involvement of G Protein in VSV Infection................................ 71

VSV G Mediated Entry........................................ 71

Prototypic Class III Fusion Protein.................................. 72

VSV G Mediated Membrane Fusion Model................................ 72

Rapid Acquisition of Growth Enhancing Mutations........................... 74

Role of GS in VSV Infection............................................ 75

Future Experiments............................................... 76

List of References............................................................ 81

Vita................................................................... 91 


\section{List of Figures}

Figure 1-1

Class I and class II mediated fusion schematic..................5

Figure 1-2

Crystal structures of VSV G.

Figure 2-1

Schematic representing recovery scheme for

rVSV encoding mutated G proteins.

Figure 3-1

Sequence alignment of closely related

vesiculoviruses and mutations made.

Figure 3-2

Cell surface expression of glycoprotein mutants.

Figure 3-3

Transport kinetics of mutants with reduced surface expression... 35

Figure 3-4

Cell-cell fusion in transiently transfected cells 37

Figure 3-5

Quantitation of cell-cell fusion. 38

Figure 3-6

$\mathrm{pH}$ dependent protease sensitivity.

Figure 3-7

One-step growth curve measuring virus infectivity.

Figure 3-8

Plaques of wt and mutant VSV.

Figure 3-9

Surface expression in virally infected cells.

Figure 3-10

Cell-cell fusion in virally infected cells. .48

Figure 3-11

Presence of cleaved $\mathrm{G}$ protein on the virion .50

Figure 4-1

Selection of plaque isolates. .58

Figure 4-2

Sequence alignments of plaque isolates.

Figure 4-3

Plaque sizes.

Figure 4-4

Surface expression in transiently transfected cells.

Figure 4-5

Cell-cell fusion activity. .65

Figure 4-6

Quantitation of cell-cell fusion activity. 67 
Figure 5-1

Figure 5-2
Model for VSV G mediated membrane fusion...................73

Potential role of GS in VSV G mediated fusion..................77 


\section{Chapter 1: Introduction}

\section{Enveloped Viruses: Host Cell Entry}

Vesicular stomatitis virus (VSV) is an enveloped, nonsegmented, singlestranded, negative sense RNA virus in the Rhabdoviridae family. VSV serves as the prototypic Rhabdovirus due to its broad host range, simple genetic organization, and ability to be easily grown in cell culture. VSV has been used as a tool to better understand various phases of enveloped viral life cycles. The focus of this work will primarily be the role of the outer surface protein $(\mathrm{G})$ in membrane fusion and viral entry. In particular, the studies are aimed at examining the contribution of the membraneproximal region of $\mathrm{G}$ in virus-cell membrane fusion. All enveloped viruses must undergo a fusion event with the host cell membrane for successful entry. Enveloped viruses have evolved various mechanisms to achieve the common goals of membrane fusion and host cell entry, as will be discussed further.

A Brief Introduction to Enveloped Viruses. Enveloped viruses are made up of a host cell derived lipid membrane surrounding their nucleocapsid, with glycoproteins embedded in this outer membrane. A common feature of all enveloped viruses is the need for viral membrane fusion with a host cell membrane enabling the release of the viral genetic information into the cell cytoplasm. Fusion is mediated by the glycoproteins (or fusion proteins) protruding from the envelope of the virus. Viruses have evolved many means by which to enter host cells to initiate cycles of replication to further spread. Fusion can either take place between the outer membrane of the host cell or an endocytic membrane (Smith and Helenius 2004; Earp, Delos et al. 2005). Fusion between the viral membrane and a host membrane is either $\mathrm{pH}$ independent or $\mathrm{pH}$ dependent. Some viruses, such as measles virus (Paramyxovirus), can bind and fuse at the cell surface, while other viruses such as influenza virus and VSV hijack the host cell endocytic pathway for entry into the cell (Helenius and Kartenbeck 1980; Matlin, Reggio et al. 1982). Fusion for viruses, such as VSV, that utilize the endocytic pathway is triggered by the drop in $\mathrm{pH}$ in the endosome or processing by proteases that are active at low $\mathrm{pH}$ within the endosome, while the viruses that fuse at the cell surface do not require a low $\mathrm{pH}$ trigger, but instead rely on receptor or receptor/co-receptor recognition. Information presented here will be focus mechanisms of enveloped virus entry mediated by viral fusion proteins.

Viral Fusion Proteins. Envelope fusion proteins are responsible for receptor recognition, host cell entry, and in some cases, play a role in egress from the host cell. Viral envelope proteins have been widely studied in an effort to better elucidate the life cycle of important human pathogens, such as influenza virus, HIV-1, and Ebola virus. Viral fusion, as previously mentioned, is a process by which the viral membrane and a host cell membrane are brought into close proximity, leading to lipid mixing, formation of a fusion pore, and finally release of the viral genetic information into the host cell cytosol. 
Although viral fusion proteins vary widely in their structures and mechanisms of action, a few common features are seen (Hernandez, Hoffman et al. 1996). Fusion proteins are all similar in that they are type I transmembrane proteins which are made up of a large ectodomain, a single transmembrane spanning domain, and a cytoplasmic tail. Other commonalities include; they are all trimers and they all have a fusion peptide, which is a short hydrophobic or non-polar sequence that is required for mediating fusion (White, Delos et al. 2008). All fusion proteins undergo large conformational changes that drive this process. These large scale changes in conformation provide the needed free energy for mixing of two lipid bilayers, which is an energetically expensive event. In fusion proteins studied thus far, the basic mechanism allowing for membrane mixing, resulting in fusion pore formation and transfer of the nucleocapsid in to the cytosol, is through the formation of a hairpin structure in the final conformation of the protien (Kielian and Rey 2006).

Fusion proteins have been divided in two well characterized groups (class I and class II) (Lescar, Roussel et al. 2001) based on the structural features and transitions leading to virus-host-cell fusion (Table 1-1). Some examples of viruses with class I fusion proteins are Coronaviruses, Filoviruses, Arenaviruses, Orthomyxoviruses, Paramyxoviruses, and Retroviruses (Skehel and Wiley 1998; Eckert and Kim 2001; White, Delos et al. 2008). Influenza virus HA is the prototypic class I fusion protein, while the fusion proteins from Alphaviruses and Flaviviruses make up class II fusion proteins. Recent structural determination of the glycoprotein $(\mathrm{G})$ from vesicular stomatitis virus (Roche, Bressanelli et al. 2006; Roche, Rey et al. 2007) and one of the fusion proteins from herpes simplex virus, $\mathrm{gB}$, (Heldwein, Lou et al. 2006) has led to the identification of class III fusion proteins. The next section will discuss the similarities and differences in the three classes of fusion proteins by describing prototypic members of each.

\section{Three Classes of Viral Fusion Proteins}

Class I Viral Fusion Proteins. Class I viral fusion proteins all share common structural and functional characteristics in their fusion mechanisms. One key feature common to the class I viral fusion proteins is a refolding event that occurs during the fusion process. In the prefusion state, class I fusion proteins are present as trimeric spikes on the virion surface. Proteolytic cleavage is required for these proteins to mature to the prefusion form. Cleavage of the envelope protein can occur in the low $\mathrm{pH}$ environment of the endosome, or during maturation of the protein. Triggering of fusion leads to the rearrangement of a highly stable rod-like structure with a central $\alpha$-helical coiled-coil, which is termed the pre-hairpin intermediate. A key feature among this class of viral fusion proteins is the positioning of the fusion peptide, which is initially buried in the trimer interface. Initial triggering of fusion allows for formation of the pre-hairpin intermediate which exposes the fusion peptide and allows for insertion of the fusion peptide into the target membrane. While in this intermediate conformation the protein is in an extended form in which the C-terminal transmembrane domain and the fusion 
Table 1-1. Characteristics of class I and class II fusion proteins.

Class I Features

Conformational change from a metastable trimer to a stable trimer during fusion

Secondary structure is primarily $\alpha$-helical

Post fusion structure is a trimer of hairpins with a central $\alpha$-helical coiled-coil (6-helix bundle)

Proteolytic processing of fusion protein required to mature to the pre-fusion state

In the metastable pre-fusion state the fusion peptide is $\mathrm{N}$-terminal and buried in the trimer interface

\section{Class II Features}

Conformational change and oligomeric rearrangement from a metastable dimer to a stable trimer

Secondary structure is predominantly $\beta$-sheet

Post fusion structure is a trimer of hairpins primarily made up of $\beta$-sheets

Proteolytic processing of a companion protein required for maturation to the pre-fusion state

In the metastable pre-fusion state the fusion peptide is located at the fusion protein tip and is capped by dimer interaction 
peptide are at the opposite ends of the molecule. The next step in the conformational change is the formation of a hairpin structure in which the $\mathrm{C}$-terminal transmembrane domain and the fusion loops are brought into close proximity. Formation of the hairpin structure pulls the viral and host cell membranes together for the fusion event to occur. Some class I viral fusion proteins include: the S2 protein from SARS; the HA protein of the influenza A and B viruses; the F1 protein from PIV-5; and gp41 from HIV-1. The first viral fusion protein to be extensively studied was that of Influenza virus (HA) (Wiley, Wilson et al. 1981; Wilson, Skehel et al. 1981). From these studies began the understanding of a general pathway that enables membrane fusion. I will next discuss the means by which Influenza virus HA protein mediates membrane fusion to serve as an example of a typical class I protein.

Influenza Virus HA. Influenza virus belongs to the Orthomyxoviridae family and is a segmented, negative strand, enveloped, RNA virus. Embedded in the envelope are three types of surface protein, NA, HA, and M2. HA has both receptor binding and fusion activity, both of which are necessary for entry of influenza into host cells.

Initially HA0 protein is synthesized as uncleaved monomers that must fold correctly and trimerize for proper trafficking through the secretory pathway to the cell surface (Gething, McCammon et al. 1986). HA0 is a trimer with a large globular head domain that is made up primarily of two subunits, HA1 and a long $\alpha$-helical coiled-coil stalk region (Chen, Ariel et al. 1988). Host cell proteases cleave the precursor protein HA0 into two disulfide bonded subunits, HA1 and HA2. After cleavage, the overall structure of HA is nearly unchanged except the $\mathrm{N}$-terminal fusion peptide becomes buried in the trimer interface within the $\alpha$-helical stalk. HA1 binds the receptor and is present on the virion surface in a metastable state, while HA2 is the transmembrane subunit (also in a metastable state) that contains the fusion peptide and is required for membrane fusion.

HA1 binds sialic acid-containing receptors on the host cell surface (Wiley and Skehel 1987). The virion is internalized into the host cell through endocytosis as is observed in VSV infection (Maeda and Ohnishi 1980; Huang, Rott et al. 1981; White, Matlin et al. 1981). As the $\mathrm{pH}$ drops in the endosome to around 5 or 6 (Daniels, Downie et al. 1985), HA undergoes an irreversible conformational change from the prefusion metastable state to a low pH conformation (Bullough, Hughson et al. 1994) (Fig 1A). This irreversible conformational change contrasts with the reversible change observed in the VSV G fusion protein.

First, HA1 trimer contacts at the head domains are dissociated with the low $\mathrm{pH}$ induced conformational change. This initial conformational change releases the fusion peptide from its buried position and projects it toward the target membrane, where it irreversibly inserts (Bullough, Hughson et al. 1994). At this stage the protein is anchored in the target membrane by the fusion peptide and anchored in the virion membrane by the transmembrane domain, thereby forming the pre-hairpin intermediate. The next step in the conformational change is the movement of the long $\alpha$-helix of HA2 folding 

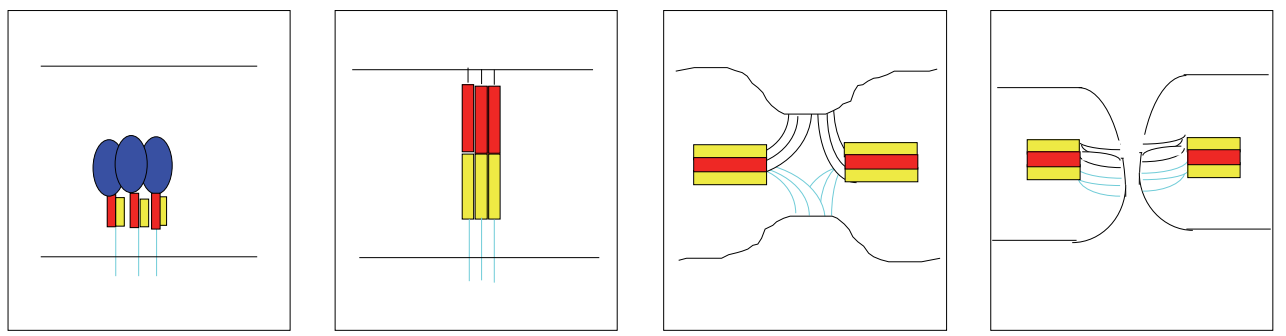

Virus Membrane

B

Cell Membrane
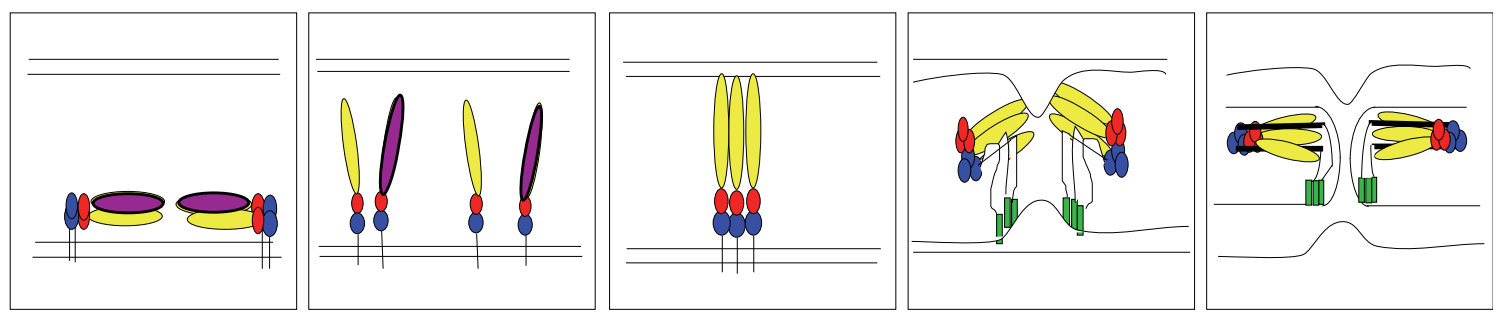

Virus Membrane

Figure 1-1. Class I and class II mediated fusion schematic. (A) A schematic representing HA mediated membrane fusion (class I). HA protein (prior to cleavage) is present as trimers on the virion surface. Large conformational change occurs after exposure to low $\mathrm{pH}$ exposing the fusion peptide leading to insertion into the target membrane. The fusion protein folds back on itself forming the six helix bundle and pulling the two membranes together for membrane merger (Skehel and Wiley 2000). (B) A Schematic representing class II mediated membrane fusion, as shown by SFV E. SFV E1 (yellow) and E2 (purple) are initially present on the virion surface as dimers. Exposure to low $\mathrm{pH}$ causes dissociation and exposure of the fusion loop. Low $\mathrm{pH}$ and presence of cholesterol in the target membrane triggers insertion of the fusion loop and alignment of the E1 subunits, favoring trimerization. E1 folds back on itself pulling the two membranes together leading to initial lipid mixing (hemifusion), which then progresses to full fusion. (Kielian and Rey 2006). 
downward, reversing the direction of the membrane proximal segment of HA2, in effect pulling the two opposing membranes together (Bullough, Hughson et al. 1994). The postfusion conformation of HA2 is a highly stable rod with the transmembrane domain and the $\mathrm{N}$-terminal fusion peptide at the same end of the molecule forming a trimer of hairpins (also referred to as a six-helix bundle)(Eckert and Kim 2001). Membrane fusion in class I viral fusion proteins is driven by the energy that is released during the conformational changes from the metastable, prefusion form to the stable post fusion form (Ruigrok, Wrigley et al. 1986; Carr, Chaudhry et al. 1997; Melikyan, Markosyan et al. 2000; Russell, Jardetzky et al. 2001). Structural analysis of other fusion proteins revealed unique features from what was seen in Influenza virus HA protein, which led to the grouping of a second class of fusion protein, that will now be discussed.

Class II Viral Fusion Proteins. Class II fusion proteins differ in several ways from their class I counterparts. Viral glycoproteins in the Alphavirus and Flavivirus families are initially present on the virion surface as dimers. Although the ectodomains of these proteins do not share much sequence homology, their secondary and tertiary structures are very similar (Lescar, Roussel et al. 2001). Secondary structures of class II fusion proteins are primarily made up of $\beta$-sheets (Kielian and Rey 2006; White, Delos et al. 2008). Classs II fusion proteins differ from class I fusion proteins in that they require a regulatory protein to fold properly that is later cleaved by the cellular protease, furin, late in the secretory pathway. This cleavage is a critical regulatory step for viral entry (Wengler and Wengler 1989; Salminen, Wahlberg et al. 1992; Stadler, Allison et al. 1997; Zhang, Wang et al. 2003). After cleavage of the regulatory protein, class II fusion proteins undergo an oligomeric rearrangement in which the dimers dissociate and reorganize into trimers, a process triggered by low $\mathrm{pH}$ in the endosome (Wahlberg, Bron et al. 1992; Allison, Schalich et al. 1995). When the dimers dissociate, the fusion peptide becomes exposed and inserts into the target membrane. A key difference between class I and class II fusion proteins is the location of their fusion peptide. Class II fusion proteins have an internal fusion peptide while the class I fusion proteins have a fusion peptide that is located N-terminally. The presence of cholesterol in the target membrane is needed for insertion of the fusion peptide into the target membrane in Alphaviruses (Kielian, Keranen et al. 1984; Nieva, Bron et al. 1994) and enhances membrane insertion in Flaviviruses (Corver, Ortiz et al. 2000; Stiasny, Koessl et al. 2003) as shown by liposome experiments. Insertion of the fusion peptide lines up the fusion proteins in a manner such that trimerization is favored. The protein then folds back on itself positioning the transmembrane domain and the fusion loops near one another and pulling the two membranes together. Semliki Forest virus E1 protein is a well characterized example of a class II fusion protein that will be described in further detail.

Semliki Forest Virus E1 Mediated Fusion. Semliki Forest virus (SFV) is a small, enveloped, positive strand RNA virus whose fusion is mediated by E1 glycoprotein embedded in the viral membrane. E1 is organized into three domains with the major secondary structure being $\beta$-sheets, a key feature of class II fusion proteins (Lescar, 
Roussel et al. 2001; Roussel, Lescar et al. 2006). Domain I (DI) begins at the N-terminus of E1 and has one end connected to two long extensions in Domain II (DII) with the other end is connected to domain III (DIII) by a linker region. One extension is the fusion loop while the other extension is the ij loop, which is closely associated with the fusion loop at the DII tip. Domain III connects to the stem region, which leads to the transmembrane domain, and contains an immunoglobin-like fold (Gibbons, Reilly et al. 2004).

An interesting feature of SFV E1 is that it actually lies tangential to the virus membrane in its native state (Fig 1-1B). E1 is present as a heterodimer in a complex with $\mathrm{E} 2$, the receptor binding subunit, at the virion surface. Initially, the fusion peptide is hidden by $\mathrm{E} 2$ when in the complex. As the $\mathrm{pH}$ drops in the endosome, a conformational change in the E1/E2 heterodimer occurs, causing dissociation of the complex, which in turn exposes the fusion peptide (Fig 1-1B). The next step in the process leading to fusion of the virus membrane with the endosomal membrane is the insertion of the fusion loop into the target membrane. Insertion of the fusion loop is dependent upon the presence of cholesterol in the target membrane (Kielian, Keranen et al. 1984; Nieva, Bron et al. 1994). Once the fusion loop interacts with the target membrane the E1 monomers are aligned and reorganized into trimers. Once the monomers have formed trimers they fold back on themselves forming a hairpin. Formation of the hairpin structure is dependent upon domain III and the stem region folding back on the fusion loop. The stem region has been shown to be important to E1 mediated virus-membrane fusion (Liao and Kielian 2006), which will be discussed at greater length later in this chapter. Vesicular stomatitis virus $G$ does not completely fit into either of these previously characterized classes of fusion proteins and therefore, a third class of fusion proteins will be discussed.

Class III Viral Fusion Proteins. Fusion glycoproteins from the Rhabdovirus and Herpesvirus families do not fit into either class I or class II fusion proteins. A key characteristic that separates class I and class II fusion proteins is the location of the fusion peptide. Class I fusion proteins have an N-terminal fusion peptide, whereas the fusion peptide in class II fusion proteins is internal. Class III fusion proteins appear to have qualities seen in both classes of viral fusion proteins. One commonality between these fusion glycoproteins and those from class I and II is the use of conformational changes to drive the formation of a hairpin oligomeric structure to pull the two opposing membranes together. Class III glycoproteins are initially present as trimers and remain trimers after the conformational change during virus-cell fusion, which is seen in class I fusion proteins. Like class II fusion proteins, these proteins have $\beta$-sheets as their major secondary structure, however, they also have $\alpha$-helices as seen in class I fusion proteins. Class III fusion proteins also have internal fusion loops like class II. It is not known if Rhabdoviruses and Herpesviruses fit into one class alone or if they vary widely enough from one another that they cannot be classified together. One possibility is that the less well characterized mechanisms for fusion in these proteins all essentially function in the same manner. However, viruses such as Herpesviruses and Poxviruses use a number of viral glycoproteins to fuse with target membranes. This complexity indicates that there may be much about the fusion processes that has yet to be determined. Vesicular 
stomatitis virus is the prototypic Rhabdovirus and serves as a good model to study fusion mechanisms of viruses in which less structural information is available.

Vesicular Stomatitis Virus. Vesicular stomatitis virus (VSV) is a prototypic member of the Vesiculovirus genus and Rhabdoviridae family. VSV is a small, enveloped virus with a single molecule of negative sense RNA as its genetic material. The virion has a bullet shaped morphology typical to Rhabdoviruses, and is approximately $180 \mathrm{~nm}$ long and 75 $\mathrm{nm}$ wide. VSV has been used as a prototypic virus to study entry, replication, and assembly due to its simple genetic organization, ability to be easily grown in cell culture, and broad host cell tropism. While VSV does not normally infect humans, the virus infects livestock and farm animals causing vesicular lesions on the hooves, teats, and gums. Vesicular stomatitis viruses are classified into two major serotypes: New Jersey and Indiana. These two serotypes share approximately 50\% glycoprotein amino acid sequence homology (Rose and Whitt 2001). Other serotypes of VSV include Chandipura, Cocal, Piry, and Isfahan. VSV's antisense, $11 \mathrm{~Kb}$ genome encodes five major proteins; the nucleocapsid $(\mathrm{N})$, phosphoprotein $(\mathrm{P})$, matrix $(\mathrm{M})$, glycoprotein $(\mathrm{G})$, and large polymerase (L). In addition to the 5 structural proteins, $\mathrm{C}$ and $\mathrm{C}^{\prime}$ are synthesized from an alternative reading frame in the P mRNA (Spiropoulou and Nichol 1993). Two other proteins (M2 and M3) are N-terminal truncation mutants (Jayakar and Whitt 2002).

The focus of this dissertation is the entry of VSV, which is initiated by the binding of the envelope protein, $\mathrm{G}$, to an unknown host cellular receptor. Identification of the receptor for VSV G has been challenging due to the broad cell tropism of the virus. Initial studies using proteolytic digestion of the cell surface did not inhibit VSV infection, indicating the receptor is not likely a protein. Furthermore, the receptor was shown to be soluble in chloroform-methanol and was sensitive to phospholipase $\mathrm{C}$, indicating the binding activity involves phospholipids (Schlegel, Willingham et al. 1982). Incubation of VSV with purified phosphatidyl serine resulted in an $80-90 \%$ decrease in VSV plaque formation (Schlegel, Willingham et al. 1982). The authors concluded the host cell receptor was likely phosphatidylserine (PS). Other reports suggested that VSV binding to cells is mediated by electrostatic interactions (Carneiro, Bianconi et al. 2002). The most recent findings, published in 2004, claim that the experiments indicating phosphatidyl serine is the receptor for VSV could not be reproduced. Experiments in this report indicated the level of PS on the cell surface had no affect on VSV infection or binding to cells. Furthermore, when cells were incubated with annexin V, which specifically binds PS on the cell surface, VSV binding and infection was still detected. Addition of PS to the cells enhanced VSV infection, but was not necessary, indicating PS is not the receptor but may be important to a step in the entry pathway post binding (Coil and Miller 2004).

Following cellular receptor binding, VSV is internalized into clathrin-coated endosomes (Matlin, Reggio et al. 1982). Fusion of the virus envelope with the endosomal membrane occurs as the $\mathrm{pH}$ drops to around 6.2 to 6.3 (the threshold $\mathrm{pH}$ for 
fusion of VSV G). Once fusion occurs, the nucleocapsid containing the VSV genome is released into the cytoplasm where replication occurs.

Approximately 1200 molecules of $\mathrm{G}$ are present on the virion surface, and these are organized into 400 trimeric spikes (Thomas, Newcomb et al. 1985). G is a typical type I transmembrane protein that is embedded into the viral envelope with a short cytoplasmic tail of 28 to 29 amino acids, a 20 residue transmembrane domain, and a large antigenic ectodomain of 446 amino acids (Rose, Welch et al. 1980; Rose, Doolittle et al. 1982). The VSV virion is made up of two components, the ribonucleoprotein (RNP) core, and the membrane envelope. The ribonucleoprotein core contains a single copy of the negative-sense RNA genome encapsidated in a tight complex with about 1,200 molecules of the nucleocapsid protein $(\mathrm{N})$. The L (large catalytic subunit) and $\mathrm{P}$ (phosphoprotein) proteins make up the RNA-dependent RNA polymerase which is also associated with the RNP. The L and P proteins are present in about 50 and 500 molecules, respectively in the virion (Thomas, Newcomb et al. 1985). The M protein must be removed for uncoating of the viral genome. This protein also plays a role in assembly of progeny virions as well as budding from the host cell membrane. Approximately 1800 molecules of matrix protein are inside the viral envelope between the membrane and the nucleocapsid core. Although this work focuses on the entry of VSV a brief discussion of VSV replication will follow to give a complete description of the viral life cycle.

Replication of $\boldsymbol{V S V}$. Viral replication of VSV occurs entirely in the host cell cytoplasm following entry. The viral genome is released into the cytoplasm and undergoes uncoating (Rigaut, Birk et al. 1991; Lyles and McKenzie 1998). Uncoating is a process by which the M protein dissociates from the RNPs causing decondensation of the RNP cores. Recent studies in our lab support a model in which the uncoating process is coupled to virion membrane fusion with the endosomal membrane. When the $\mathrm{pH}$ drops in the early endosome, VSV G undergoes a conformational change which mediates fusion. At this time, $\mathrm{G}$ also mediates the acidification of the virion interior which is suggested to affect the interaction between the membrane bound and the RNP bound M, leading to the release of the RNP into the host cell cytosol for replication (Mire 2008). The encapsidated RNA genome then is used as a template for the RNA-dependent RNA polymerase mediated transcription. Transcription is initiated at the 3 ' end of the genome and is sequential and polar as with other nonsegmented negative-sense RNA viruses. Each of the five genes is transcribed in the order in which is appears from the 3 ' end of the gene (Iverson and Rose 1981; Iverson and Rose 1982; Lyles and McKenzie 1998). These viral mRNAs then serve as templates for the synthesis of the viral proteins. The viral mRNAs are capped, methylated and polyadenylated by the RNA polymerase (Schubert, Keene et al. 1980; Hercyk, Horikami et al. 1988). Once enough N protein is made the leader is encapsidated. Replication of the viral genome then ensues, allowing for synthesis of the full-length positive sense replicative intermediate (RI). The RI is encapsidated and serves as a template for the synthesis of the genome. The newly made genomic RNA is encapsidated by the N protein to form the RNP. N protein is thought to associate with $\mathrm{G}$ protein in the plasma membrane. The $\mathrm{M}$ protein is recruited to the 
budding site leading to association with the nucleocapsid (Lyles and Swinteck 2008). The cores then bud through the host cell plasma membrane with the G proteins embedded within, forming new progeny virions. Further rounds of infection then ensue with the binding of the $\mathrm{G}$ protein to the next host cell, internalization, and fusion. The next few sections will focus more specifically on the G protein of VSV.

Vesicular Stomatitis Virus Glycoprotein. G protein is synthesized on the rER, is transported to the cell surface via the secretory pathway, and is localized to the host cell membrane. The glycoprotein is synthesized as a 511 amino acid precursor with a 16 amino acid signal peptide that is cleaved during transport into the ER. G has widely been used to study protein folding and protein transport through the secretory pathway, therefore much is known about its folding and maturation process (Doms, Keller et al. 1987; de Silva, Balch et al. 1990; de Silva, Braakman et al. 1993). While in the ER, the glycoprotein of VSV Indiana receives two N-linked oligosaccharides at positions 179 and 336. The $\mathrm{G}$ protein of the Indiana serotype is palmitoylated at a cysteine residue in the cytoplasmic tail, but this modification has been shown not to impact function of the protein (Whitt, Buonocore et al. 1991). As G is being translated, the ectodomain of G associates with ER chaperones, BiP (Machamer, Doms et al. 1990) and calnexin (Mathieu, Grigera et al. 1996). This association helps in proper folding and formation of disulfides in the ER. Once the G protein monomers are properly folded, they form noncovalently associated homotrimers. Formation of homotrimers is essential for the exocytic transport of G (Doms, Keller et al. 1987; Doms, Ruusala et al. 1988). Interestingly, VSV G trimers have a unique quality in that they are unstable and there is constant dissociation and reassociation of monomers that occurs both in the ER and on the cell surface (Zagouras, Ruusala et al. 1991; Zagouras and Rose 1993). Soluble forms of $\mathrm{G}$, lacking the transmembrane and $\mathrm{C}$-tails were constructed and were able to form trimers when expressed in cells, indicating the region responsible for trimerization lies within the ectodomain (Crise, Ruusala et al. 1989). Trimerization of VSV G has been proposed to be stabilized by the M protein (Lyles, McKenzie et al. 1992) as shown by incubating purified $\mathrm{M}$ protein or $\mathrm{M}$ protein associated with nucleocapsid protein with $\mathrm{G}$ and using resonance energy transfer to detect association of subunits. Since all fusion proteins in their active form have trimeric quaternary structure, it stands to reason that stabilization of VSV G trimers is critical to the productive entry of the virus. VSV entry, as mentioned above, is the focus of this work, so the next sections will address various aspects of membrane fusion and viral entry.

pH Dependent Conformational Changes. One limitation to the full understanding of the fusion process previously has been the fact that no structural information was available for G. VSV G adopts at least three different conformational states of which two of these structures have recently been published (Roche, Bressanelli et al. 2006; Roche, Rey et al. 2007) (Fig 1-2A and B). One unique feature of VSV G is the reversible nature of the $\mathrm{pH}$ dependent conformational changes. There is a $\mathrm{pH}$ dependent equilibrium between the pre- and post fusion conformations that is shifted toward the postfusion conformation when exposed to low pH (Roche and Gaudin 2002). In both class I and class II mediated 
Figure 1-2. Crystal structures of VSV G. (A) Crystal structure of VSV G in its prefuison state. $G$ sits on the virion surface like a tripod with the fusion loops shown in green (located in the fusion domain, yellow) extending toward the virion. Domain I, in red, is the lateral domain. Domain II (blue) on the interior is the trimerization domain. Orange represents the pleckstrin homology $(\mathrm{PH})$ domain, III. Reprinted with permission from Roche, S., F. A. Rey, et al. (2007). "Structure of the prefusion form of the vesicular stomatitis virus glycoprotein G." Science 315(5813): 843-848. (B) G in its post fusion form is represented using the same color scheme to identify each domain. All the domains undergo dramatic change in their orientation and position but retain their original folds except domain III which refolds. Reprinted with permission from Roche, S., S. Bressanelli. et al. (2006). "Crystal structure of the low-pH form of the vesicular stomatitis virus glycoprotein G." Science 313(5784): 187-191. 
A

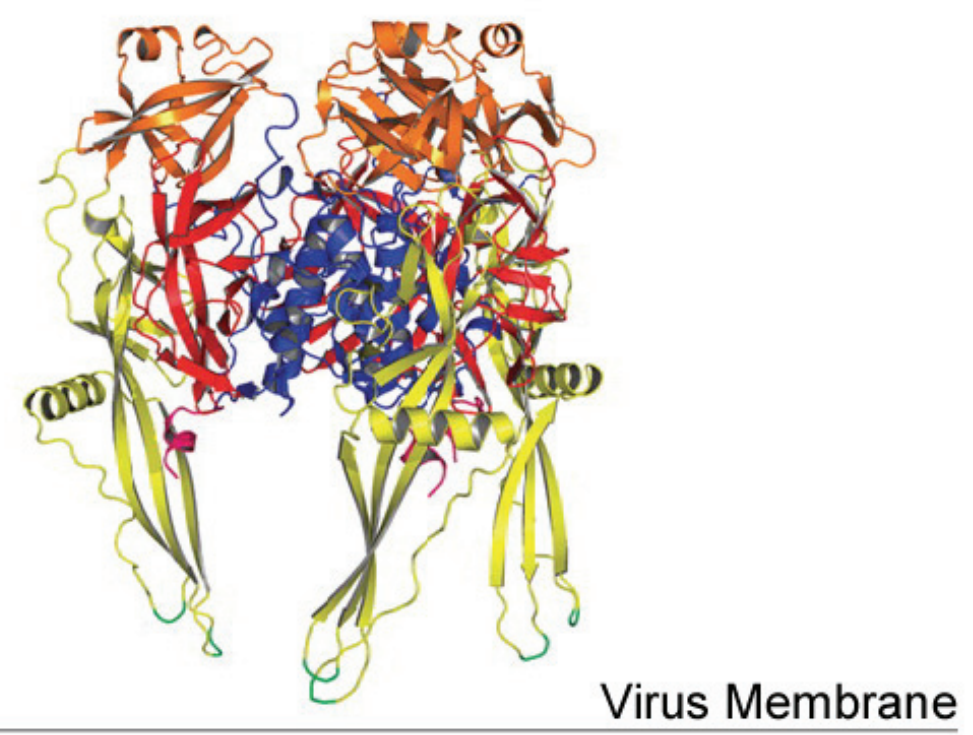

B Virus Membrane/Cell Membrane

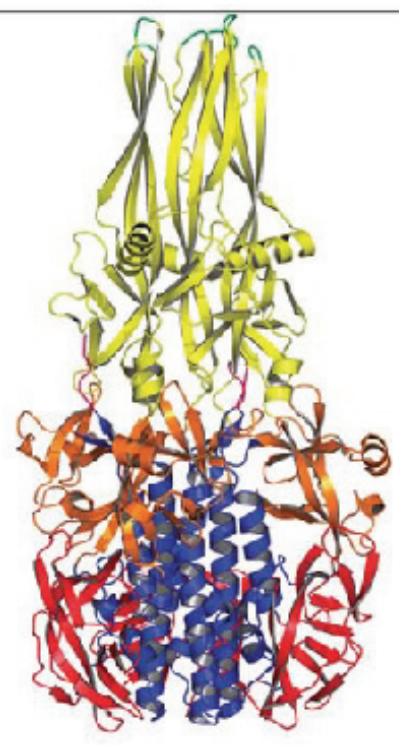


fusion, the glycoproteins are in a metastable state initially and upon the fusion trigger undergo irreversible conformational changes to a more stable form. The prefusion structure of VSV G is made up of four distinct domains (Roche, Rey et al. 2007). Domain I is referred to as the lateral domain, while domain II is the trimerization domain that likely functions to supply the interactions needed to form $\mathrm{G}$ trimers. Domain III is called the pleckstrin homology domain $(\mathrm{PH})$ and may likely serve for host cell binding due to the PH domain's capability to bind phosphoinositides (Harlan, Hajduk et al. 1994; Bottomley, Salim et al. 1998; Rebecchi and Scarlata 1998; Lemmon and Ferguson 2000). Domain IV is the fusion domain, containing the fusion loops that are required for membrane fusion and consequently, host cell entry.

Membrane proteins are difficult to crystallize due to their amphiphillic character and the fact that they must be kept soluble by detergents throughout the entire purification and crystallization process. Therefore, to avoid this dilemma, the $\mathrm{G}$ protein was cleaved with thermolysin generating a truncated $\mathrm{G}$ in which the membrane proximal region was not included. The focus of the work described in this dissertation is to better understand the role of the membrane proximal region of $\mathrm{G}$ protein in host cell entry. Since no structural data exists, theses studies employed a mutagenesis approach to examine the contribution of this region to the fusion process. In the prefusion conformation, $\mathrm{G}$ sits on the viral membrane in the shape of a tripod with the C-terminal segment extending out from the viral membrane (in a manner that is yet unknown). The fusion loops are kept apart and serve as the legs of the tripod.

Class I and class II fusion proteins are different in that their hydrophobic segments are buried at an oligomeric interface in the prefusion conformation while the fusion loops of $\mathrm{G}$ are exposed. Once exposed to low $\mathrm{pH}$ a dramatic structural rearrangement occurs. Within the lateral domain and the trimerization domain is a rigid block (RbI-II) that remains constant between pre- and postfusion conformations. In the transition between the prefusion conformation to the postfusion conformation, the fusion domain and the $\mathrm{C}$-terminal segment flip relative to the RBI-II. Both fusion loops and the transmembrane (TM) domain move $\sim 160 \AA$ from one end of the molecule to the other. Domains I, III, and IV retain their folded structure during this dramatic reorganization of the protein. Proposed intermediates in the structural transitions position the fusion loops in proximity to the target membrane in which they are able to insert. The final step in the conformational changes after the insertion of the fusion loops is the formation of the trimer of hairpins in which the two opposing membranes are brought into close proximity allowing for full fusion.

As mentioned previously, $\mathrm{G}$ is unique in that the conformational changes are reversible. The crystal structure of the low $\mathrm{pH}$ conformation was solved through $\mathrm{P} 408$, with a histidine at position 407 . Based on the crystal structures the authors suggested that H407 participates in a salt-bridge with D137, in the fusion domain, that likely stabilizes the post fusion structure (Roche, Bressanelli et al. 2006). Although the structures of G in the prefusion and low $\mathrm{pH}$ conformations have provided a wealth of information as to the fusion mechanism, many questions still remain. Intermediates in the conformational changes have yet to be identified and also the membrane-proximal region is not included 
in any structures, thereby leaving gaps in the understanding of the participation of this region. Studies of other membrane-proximal regions of fusion proteins have given insight as to an overall possible mechanism of action, but since VSV differs in the structural transitions from the better understood class I and class II fusion proteins further work must be done to understand the role of the membrane-proximal region. As mentioned, the crystal structure revealed a histidine residue that is likely important for stabilization of the post fusion structure. Histidine protonation has been suggested to be a key step in $\mathrm{pH}$ dependent viral fusion as will be discussed further.

Role of Histidine Protonation in pH Dependent Conformational Changes. Although VSV G differs in the structural transitions seen with class I and class II fusion proteins, one commonality is the requirement of a fusion trigger. Some viruses within each group of fusion proteins require exposure to low $\mathrm{pH}$ for host cell entry. Interestingly, low $\mathrm{pH}$ induced fusion generally occurs at a $\mathrm{pH}$ close to the $\mathrm{pKa}$ of histidine in water $(\mathrm{pKa}=6)$, strongly suggesting the protonation of one or more residues may drive the conformational changes. As mentioned above, the crystal structure reveals H407 likely participates in a salt bridge with D137 further supporting this hypothesis. Studies have indicated that protonation of histidines in other viral fusion proteins may drive the $\mathrm{pH}$ dependent conformational changes. Analysis of sequences from Influenza virus and Flavivirus envelope proteins, respectively, revealed a number of highly conserved histidine residues (Kampmann, Mueller et al. 2006). When histidines are buried within the protein, a lower $\mathrm{pH}$ is required for protonation, which could account for lower $\mathrm{pH}$ requirements for fusion proteins such as seen in dengue virus ( $\mathrm{pH}$ for fusion is 5) (Heinz and Kunz 2004). Most recently, Margaret Kielian's group identified a histidine residue (H3) in Semliki Forest virus that is required for the structural transitions that lead to fusion (Qin, Zheng et al. 2009). Five histidine residues were mutated to alanines with the one mutation at residue 3 resulting in reduced growth and a decrease in the $\mathrm{pH}$ required for membrane fusion. Dissociation of the heterodimer was not affected but the formation of E1 homotrimers required a decrease in $\mathrm{pH}$ from that of wild type. Speculation as to the role of histidines in the low $\mathrm{pH}$ induced conformational changes seen in VSV G arose well before the crystal structures were solved. In fact, chemical modification of histidines in $\mathrm{G}$ abolished cell-cell fusion. When the chemical treatment was reversed, VSV G mediated fusion was restored (Carneiro, Stauffer et al. 2003). Together these findings strongly suggest that the protonation of one or more histidine residues drives low $\mathrm{pH}$ induced conformational changes required for VSV G mediated membrane fusion. The next sections will specifically focus on membrane-proximal regions of viral fusion proteins and the possible contribution of this region in the $\mathrm{G}$ protein to membrane fusion.

\section{Membrane-Proximal Regions of Viral Fusion Proteins}

The membrane-proximal segments of various viral fusion proteins have highly hydrophobic characteristics and are often rich in tryptophan residues. In the final post fusion conformation, the membrane-proximal regions of viral fusion proteins are in close proximity with both membranes as well as in a position to possibly interact with the 
fusion domains (or fusion loops). Reports have suggested the membrane-proximal regions of HIV-1 gp41, (Salzwedel, West et al. 1999), Semliki Forest virus E1 (Liao and Kielian 2006), and VSV G (Jeetendra, Robison et al. 2002; Jeetendra, Ghosh et al. 2003), may have a mechanistic role in membrane fusion (virus entry).

HIV-1 gp41 Mediated Fusion. To understand the contribution of the membrane proximal region (MPER) of Human immunodeficiency virus (HIV-1), I will first provide a general overview of the fusion mechanism. HIV-1 is an enveloped virus in the family Retroviridae, genus Lentivirus, whose host cell entry mechanism has been widely studied. Protruding from the virion envelope are glycoprotein spikes termed env. HIV env is initially synthesized as a fusion inactive protein called gp160. gp160 is cleaved during transport to the cell surface while in the trans-Golgi complex into a non-covalently linked heterodimer made up of gp120 and gp41(Hallenberger, Bosch et al. 1992; Decroly, Vandenbranden et al. 1994). Gp120 is the receptor binding portion of the protein, while gp41 is the transmembrane segment containing the fusion peptide and is necessary for virus-cell fusion (Wyatt and Sodroski 1998). Gp41 is made up of three main domains, the ectodomain, membrane spanning domain, and the cytoplasmic tail. Within the ectodomain are the fusion peptide and two heptad repeats, one at the Nterminus and one at the $\mathrm{C}$-terminus, and the membrane-proximal external region (MPER). The MPER is a tryptophan rich region located N-terminally to the transmembrane domain (Salzwedel, West et al. 1999).

HIV-1 binds to a target cell via gp120 by utilizing a CD4 receptor (Maddon, Dalgleish et al. 1986) and a chemokine co-receptor (Lapham, Ouyang et al. 1996; Trkola, Dragic et al. 1996; Wu, Myszka et al. 1996; Berger 1998). Unlike Influenza HA, Semliki forest virus E, and VSV G, HIV env mediated fusion until recently has been believed to be $\mathrm{pH}$ independent (Stein, Gowda et al. 1987; Maddon, McDougal et al. 1988; McClure, Marsh et al. 1988). Recent evidence supports another model of entry in which HIV-1 enters via receptor mediated endocytosis and fuses within the endosome with the help of the cellular protein, dynamin (Miyauchi, Kim et al. 2009). This report indicated that only lipid mixing occurred at the plasma membrane whereas productive entry occurred via the endocytic pathway. Furthermore, due to the low levels of HIV-1 env on the virion surface (Zhu, Liu et al. 2006) it stands to reason the virus may need the additional help of cellular proteins to overcome the energy barrier leading to the membrane merger event. However, this model still indicates the need for the receptor/co-receptor binding. This initial receptor and co-receptor binding leads to a dramatic conformational change that exposes the V3 loop of gp120 (Choe, Farzan et al. 1996; Wu, Myszka et al. 1996). The initial conformational changes allow the glycoptrotein to interact with the chemokine coreceptor. Final conformational changes are triggered by binding to the co-receptor leading to virus-cell fusion (reviewed in Berger, Murphy et al. 1999; Doms and Trono 2000). These final conformational changes involve heptad repeats within the fusion protein reorganizing to form a six-helix bundle (hairpin structure). The conformational changes result in the hairpin formation that is seen in viral fusion proteins in their post fusion conformation. Like the other proteins described thus far, the TM domain and the 
fusion peptide lie at the same end of the molecule pulling the two membranes together (Chan, Fass et al. 1997; Weissenhorn, Dessen et al. 1997).

HIV-1 gp41 MPER. The membrane proximal external region (MPER) of gp41 has been shown to play a critical role in efficient incorporation into the viral envelope, as well as infectivity of HIV-1 (Salzwedel, West et al. 1999). The MPER has been predicted though computer algorithms to form $\alpha$-helices and also overlaps at the C-terminal sequence of a peptide, DP-178, that has been shown to potentially inhibit fusion and virus entry by binding to a portion of the N-terminal heptad repeats (Wild, Dubay et al. 1994). An epitope for a neutralizing antibody, 2F5, also lies within this region of the fusion protein. Five tryptophan residues are found within this short hydrophobic sequence that are conserved among all sequenced strains of HIV-1, and make up more than $25 \%$ of this region. Site-directed mutagenesis was used to determine the importance of these residues for maturation and virus entry. When seventeen residues in this region were deleted, cellcell fusion was abolished, while maturation of the protein, transport, and binding of CD4 were not affected. Substitution of all five tryptophans with alanines also resulted in the same phenotype. Single mutations were made to the tryptophan residues resulting in inefficient incorporation and decreased infectivity (Salzwedel, West et al. 1999).

The indole ring in tryptophan residues has been shown to have a strong tendency to insert into the membrane-water interface where it disrupts the organization of the phospholipids (Reithmeier 1995). Interestingly, this region can be replaced by a foreign, tryptophan rich sequence without significant fusion loss. These results indicate tryptophan residues are key factors in the fusion process. The work described here, from Eric Hunter's lab, supports the hypothesis that the membrane proximal region of HIV-1 gp41 utilizes the conserved tryptophans to interact with the target membrane at some stage during fusion to allow for fusion pore formation and transfer of viral genetic information.

Paramyxovirus F Stem. The stem region of Paramyxovirus fusion proteins have been shown to participate in the fusion process by a similar mechanism as was just described for HIV-1 gp41. Paramyxoviruses are enveloped, negative-stranded, RNA viruses. Paramyxovirus entry involves two surface proteins, an attachment protein $(\mathrm{HN}, \mathrm{H}$, or $\mathrm{G})$ and a fusion protein (F). Viral entry for these viruses occurs at the host cell plasma membrane when the attachment protein binds the receptor, activating the $\mathrm{F}$ protein for membrane fusion (Russell, Jardetzky et al. 2001; Takimoto, Taylor et al. 2002; Corey, Mirza et al. 2003; Gravel and Morrison 2003; Porotto, Murrell et al. 2005). F protein is initially synthesized as a precursor protein $\mathrm{F}_{0}$ and is cleaved into a small amino terminal subunit, $F_{2}$, and a carboxy-terminal subunit that is larger, $F_{1}$. F protein has two heptad repeat regions (termed HRA and HRB) that are both located in the ectodomain of $F_{1}$. HRA is located N-terminally (adjacent to the fusion peptide) while HRB is located adjacent to the transmembrane domain. Studies using peptides directed toward either HRA or HRB revealed an inhibition in membrane fusion activity of $F$ protein and replication of virus. The finding that the HRB region (stem region) of the $F_{1}$ protein is 
important to the formation of the hairpin structure (Russell, Jardetzky et al. 2001) is of particular interest, since the work presented here will be focused on the contribution of the membrane-proximal region of VSV G.

Semliki Forest Virus E1 Stem. Another glycoprotein that has been shown to have a membrane-proximal region that plays a key role in fusion is that of the SFV E1 protein. As mentioned previously, SFV E is grouped into the class II fusion proteins. SFV E is cleaved, forming E1, E2, and E3, with E1 containing the fusion peptide. E1 upon exposure to low $\mathrm{pH}$ reorganizes to form trimers as the fusion domain is inserted into the target membrane. The trimers undergo further conformational changes leading to the formation of the final hairpin structure. As with other viral glycoproteins, little is known about the structure or function of the stem region due to difficulties in crystallizing this region of a membrane protein. However, work has been done using site directed antibodies to this region providing some insight as to the role the memrane-proximal region might play may play (Liao and Kielian 2006). Polyclonal antibodies were made to either the N-or C-terminal halves of the E1 stem and used to identify intermediate conformational changes by blocking regions that may interact during the conformational changes. Data has shown that, unlike HIV-1 gp41 MPER, the stem region in E1 is thought to play a role in the conformational changes leading to the formation of the final trimer of hairpins (Liao and Kielian 2006). A critical step in the formation of hairpins and fusion process is packing of the outer layer of the protein onto the cental core. It was found that the stem was hidden in the neutral $\mathrm{pH}$ conformation and became exposed with the initial $\mathrm{pH}$ induced conformational changes. The stem then appeared to pack onto the trimer core to further the hairpin formation and at this point was once again inaccessible to antibody binding. These data suggested that the membrane-proximal region is important in mediating the fusion process, however is not absolutely necessary (Liao and Kielian 2006; Liao and Kielian 2006). The roles of the membrane-proximal regions of these fusion proteins provide clues as to the possible contribution of the region in VSV G, the focus of this work.

VSV G Stem. Since no structural information on the membrane-proximal stem region of $\mathrm{G}$ exists due to the need for thermolysin cleavage, the role this region plays in fusion has been challenging to understand. The carboxy terminus of $\mathrm{G}$ has been show to have a high degree of sequence homology between vesiculoviruses (Masters, Bhella et al. 1989; Gaudin, Raux et al. 1996; Jeetendra, Ghosh et al. 2003). Among the highly conserved residues in the stem region are completely conserved tryptophans. Substitution analysis of these tryptophan residues revealed that, unlike HIV-1 gp41, they are not necessary for fusion or budding from the host cell (Jeetendra, Ghosh et al. 2003). However, the membrane-proximal region of $\mathrm{G}$ has been shown to enhance the efficiency of VSV budding. Previous studies have shown that VSV can bud in the absence of G, however producing about 50-fold less particles (Schnell, Johnson et al. 1997). Truncation of G so that only the C-terminal and transmembrane domains were present indicated further requirements for efficient budding, suggesting a role within the ectodomain of $\mathrm{G}$ (Robison and Whitt 2000). Another truncation mutant (that will be discussed further in 
the context of fusion), containing the $\mathrm{C}$-tail, TM domain, and 42 membrane proximal amino acids was able to drive near wild type levels of viral budding (Robison and Whitt 2000). Further mutational analysis was done by making large insertions or deletions within the stem region to identify the impact on membrane fusion or virus infectivity. Deletion of the 13 membrane-proximal residues reduced cell-cell fusion and decreased virus infectivity by approximately 100 -fold (Jeetendra, Ghosh et al. 2003). Insertions and deletions in the membrane-proximal region showed a decrease in fusion activity as well as virus infectivity indicating this region plays a role in membrane fusion (Jeetendra, Ghosh et al. 2003).

Initial evidence indicating a possible role for the membrane-proximal region of VSV G was the development of a truncation mutant, as mentioned above, of G containing the $\mathrm{C}$-tail, transmembrane domain, and 42 residues leading up to the transmembrane domain (Robison and Whitt 2000). This mutant was constructed based on a temperature sensitive mutant, ts045. ts045 produces VSV particles lacking the G protein ("bald") when grown at the restricted temperature, $39.5^{\circ} \mathrm{C}$ (Knipe, Baltimore et al. 1977; Zilberstein, Snider et al. 1980). At this temperature $\mathrm{G}$ is misfolded and is retained in the endoplasmic reticulum and therefore no $G$ protein can be detected on the surface. These results were used for a long time to show that $\mathrm{G}$ protein was not necessary for the assembly and budding of the virus. It was later shown that the "bald" virus particles produced by ts 045 actually had a short portion of the $\mathrm{G}$ protein containing a part of the membrane proximal ectodomain, the transmembrane domain, and the cytoplasmic tail (Metsikko and Simons 1986). Robison and Whitt then constructed GS to determine if this short region of the ectodomain influenced assembly and budding of VSV. They showed that GS is expressed, forms trimers, is incorporated into the viral envelope with high efficiency and can promote wild type levels of budding (Robison and Whitt 2000). Therefore, this short region of the ectodomain was shown to contain signals for efficient budding. This mutant has also been studied in the context of viral fusion to further understand the role of the membrane-proximal region. This mutant has been found to potentiate the fusion activity of other heterologous viral glycoproteins that do not normally fuse on their own (Robison and Whitt 2000; Jeetendra, Robison et al. 2002). GS not only potentiates the fusion activity of glycoproteins that fuse at low $\mathrm{pH}$, but also those that fuse at neutral $\mathrm{pH}$. This finding indicates that GS participates in a step in the fusion process that is common to both pathways. Furthermore, GS has the ability to induce an active hemifusion state, an indication that GS can interact with and perturb membranes (Jeetendra, Robison et al. 2002).

\section{Thesis Statement}

Recent determination of VSV G crystal structures in the prefusion and low $\mathrm{pH}$ forms has provided a wealth of information on the fusion mechanism of VSV G. Not only has it helped in identifying possible structural transitions that mediate the fusion process, but it has identified another way to achieve cell-virus membrane fusion.

Previously, viral fusion proteins were grouped into two classes based on their oligomeric structure, their predominant secondary structure, the location of the fusion peptide and 
the presence of a companion protein. Fusion proteins in each of these groups have similar structural rearrangements leading to virus-cell membrane fusion. Structural determination of VSV G and HSV gB has led to the classification of a third group of viral fusion proteins that may induce membrane fusion through an alternative pathway to achieve the fusion active conformation. One caveat to the recent developments in understanding VSV G mediated fusion is the lack of structural information for the membrane proximal region adjacent to the transmembrane domain. One key feature seen in all fusion proteins thus far examined is the formation of a trimer of hairpins that functions to pull the two opposing membranes together leading to the membrane merger and fusion. Members of class I fusion proteins, such as HIV-1 gp41 and Influenza HA proteins require the membrane proximal region either for the formation of the hairpin or for the membrane merger event. Evidence has also shown the stem region in class II fusion proteins, such as Semliki Forest virus E1, plays a role in fusion. Previous mutational analysis has indicated the requirement for the highly conserved membrane proximal region in VSV G mediated fusion. Studies have shown that large insertions and deletions affect membrane fusion and virus infectivity, while mutation of the conserved tryptophan residues does not appear to have a marked effect. The work presented here is aimed to determine if individual residues in this highly conserved region play a direct role in the fusion process and to better understand the contribution of the membrane proximal region in VSV G mediated membrane fusion. We hypothesize that the highly conserved residues in the membrane-proximal region of VSV G protein are critical to membrane fusion through participation in low $\mathrm{pH}$ induced conformational changes and stability of theses structures. In Chapter 3 , I will examine the importance of the highly conserved residues in the stem region of $\mathrm{G}$ in fusion by using site-directed mutagenesis. In Chapter 4, I will examine second-site mutations that restored fusion activity in the context of the virus to determine the significance of these mutations in surface expression and viral fusion. The results from Chapters 3 and 4 will give insight as to residues that may directly participate in the fusion process to better formulate a model for VSV G mediated fusion and perhaps contribute further to the understanding of how the membrane-proximal regions of other viral fusion proteins participate in the fusion process. 


\section{Chapter 2: Materials and Methods}

\section{Mutagenesis}

Plasmids and Oligonucleotide-Directed Mutagenesis. The mutated G protein constructs were generated using overlapping PCR with pVSV-9.1(+) (Lawson, Stillman et al. 1995) as the template. The sequences of the primers used in generating the mutated $\mathrm{G}$ proteins are listed in Table 2-1. The PCR products were generated using conditions as follows; $95^{\circ} \mathrm{C}$ denaturation for 2 minutes, thirty cycles of amplification with 45 seconds at $95^{\circ} \mathrm{C}$, 45 seconds annealing at $50^{\circ} \mathrm{C}$, then $72^{\circ} \mathrm{C}$ for 1 minute, followed by one cycle of incubation at $72^{\circ} \mathrm{C}$ for 7 minutes. The PCR products were purified on a $6 \%$ polyacrylamide gel and electroeluted. The fragments were digested using KpnI and NheI restriction enzymes. The fragments encoding mutated $\mathrm{G}$ protein were subcloned into the pCAGGS-G $\mathrm{G}_{\text {Ind }}$ expression vector previously digested with the same enzymes. Colonies were selected and DNA was extracted using an alkaline lysis mini-prep protocol. The DNA was sequenced in both directions using pC-5'MCS (TACAGCTCCTGGGCAACGTG) and pC-3'MCS (TAGCCAGAAGTCAGATGCTC). Sequencing was performed by the Molecular Resource Center at the University of Tennessee Health Science Center. The mutated G fragment from the pCAGGS expression vector was then subcloned into the full length VSV genome, pVSV-9.1 (+) (Lawson et al 1995), using KpnI and NheI.

For the F440/F441 mutants that acquired additional mutations, BHK-21 cells were infected at an $\mathrm{MOI}=1$ for 1 hour while rocking at $31^{\circ} \mathrm{C}$. The inoculum was removed and replaced with fresh Dulbecco's Modified Eagles Medium (DMEM) containing 5\% Fetal Bovine Serum (FBS). 6 hours post infection, RNA extraction was performed on the cells. $1 \mathrm{~mL}$ of Trizol was added to the cells while rocking at room temperature for 5 mins to lyse the cells and the lysates were transferred to $1.5 \mathrm{ml}$ eppendorf tubes. $0.2 \mathrm{ml}$ of chloroform was added, tubes were shaken for 15 seconds and incubated at room temperature for 3 minutes. The samples were centrifuged at 10,000 g for 15 minutes, the aqueous phase was collected and transferred to a new tube. RNA was precipitated by adding $0.5 \mathrm{ml}$ of isopropanol and the samples were incubated at room temperature for 10 minutes. The samples were pelleted by centrifugation at $10,000 \mathrm{~g}$ for 10 mins and the supernatant removed. The pellet was rinsed with $75 \%$ ethanol and vortexed. The pellet was air dried and resuspended in $25 \mu 1$ of nuclease free water. Reverse transcription (RT) was performed on the $2 \mu \mathrm{g}$ of RNA extracted from the infected cells using a One-step RT-PCR kit from Quiagen according to manufacturer's instructions. Primers that were used for the RT and PCR amplification were MW36 (coding) and 3464 (non-coding) (Table 2-1). cDNA was digested with NheI and KpnI restriction enzymes and subcloned into a pCAGGS-G $\mathrm{G}_{\mathrm{IND}}$ expression vector digested with the same enzymes. Plasmids were sequenced to identify any additional mutations in the G gene containing the originally cloned in substitutions or deletions. 
Table 2-1. Sequences of primers used in overlapping PCR mutagenesis.

\begin{tabular}{|c|c|c|}
\hline Mutation & Sense Primer & Antisense Primer \\
\hline$\Delta \mathrm{H} 423 / \mathrm{P} 424 / \mathrm{H} 425$ & $\begin{array}{l}\text { 5'GCTCAGGTGTTCGAAA } \\
\text { TTCAAGACGCTGCTTCG3' }\end{array}$ & $\begin{array}{l}\text { 5'GTCTTGAATTTCGA } \\
\text { ACACCTGAGCCTTTG 3' }\end{array}$ \\
\hline $\mathrm{H} 423 \mathrm{~A} / \mathrm{P} 424 \mathrm{~A} / \mathrm{H} 425 \mathrm{~A}$ & $\begin{array}{l}\text { 5'AGGTGTTCGAAGCTGCTG } \\
\text { CAATTCAAGACGCTGCTT 3' }\end{array}$ & $\begin{array}{l}\text { 5'GTCTTGAATTACAGC } \\
\text { AGCTTCGAACACCTG } \\
\text { AGCCTTTG 3' }\end{array}$ \\
\hline$\Delta \mathrm{H} 425$ & $\begin{array}{l}\text { 5'GTGTTCGAACCTCACATT } \\
\text { CAAGACGC 3' }\end{array}$ & $\begin{array}{l}\text { 5'GAATGTGAGGTTCGA } \\
\text { ACACCTGAGC 3' }\end{array}$ \\
\hline $\mathrm{H} 425 \mathrm{~A}$ & $\begin{array}{l}\text { 5'AGGTGTTCGAAGCTCCT } \\
\text { CACATTC 3' }\end{array}$ & $\begin{array}{l}\text { 5'GTCTTGAATGTGAGG } \\
\text { AGCTTCGAA 3' }\end{array}$ \\
\hline D435A/D436A/E437A & $\begin{array}{l}\text { 5'CTTCTTGCTGCTGC } \\
\text { TAGTTTATTTTTTGG } 3 \text { ' }\end{array}$ & $\begin{array}{l}\text { 5'ATAAACTAGCAGCA } \\
\text { GCAGGAAGTTGC 3' }\end{array}$ \\
\hline $\mathrm{F} 440 \mathrm{~A} / \mathrm{F} 441 \mathrm{~A}$ & $\begin{array}{l}\text { 5'GAGAGTTTAGCTGCTG } \\
\text { GTGATACTGGGC 3' }\end{array}$ & $\begin{array}{l}\text { 5'TATCACCAGCAGCTA } \\
\text { AACTCTCAT 3' }\end{array}$ \\
\hline T444A/G445A & $\begin{array}{l}\text { 5'GGTGATGCTGCTCTA } \\
\text { TCCAAAAATCC 3' }\end{array}$ & $\begin{array}{l}\text { 5'TTGGATAGAGCAG } \\
\text { CATCACCAAAAAATA } \\
\text { AACTCTC 3' }\end{array}$ \\
\hline $\mathrm{N} 449 \mathrm{~A} / \mathrm{P} 450 \mathrm{~A}$ & $\begin{array}{l}\text { 5'CTATCCAAAGCGGCGA } \\
\text { TCGAGCTTGTAGAAGG 3' }\end{array}$ & $\begin{array}{l}\text { 5'CTACAAGCTCGATCG } \\
\text { CCGCTTTGGATAGCCCA } \\
\text { GTAT 3' }\end{array}$ \\
\hline $\begin{array}{l}\text { MW36 } \\
\text { (Outside Primer) }\end{array}$ & $\begin{array}{l}\text { 5'GTGGATCTCAGCTATCT } \\
\text { TGCTCC 3' }\end{array}$ & \\
\hline $\begin{array}{l}3464 \\
\text { (Outside Primer) }\end{array}$ & & $\begin{array}{l}\text { 5'CAAACATGAAGAA } \\
\text { TCTGGCTAGCA 3' }\end{array}$ \\
\hline
\end{tabular}


Surface Expression. Surface expression of the various G proteins was initially measured using indirect immunofluorescence assays. Approximately $7.5 \times 10^{5}$ baby hamster kidney cells (BHK-21) were transfected with a DNA:liposome suspension containing $2 \mu \mathrm{g}$ of plasmid encoding the respective $\mathrm{G}$ mutants and $8 \mu \mathrm{l}$ of lipofectamine (GIBCOBRL), according to the manufacturer's instructions. Three hours post transfection, the media was replaced with DMEM containing 10\% FBS and the cells were incubated for 24 hours at $37^{\circ} \mathrm{C}$.

Following transfection and expression as described above, the cells were fixed with 3\% paraformaldehyde and processed for indirect immunofluorescence microscopy. The cells were probed with a G specific monoclonal antibody, Mab I1 (Lefrancois and Lyles 1982), followed by a secondary anti-mouse antibody conjugated to FITC (Jackson ImmunoResearch Laboratories, Inc.). The cells were transfected as previously described using $2 \mu \mathrm{g}$ of plasmid DNA and $8 \mu 1$ of Lipofectamine reagent (GIBCO) according to manufacturer instructions. The transfection media was removed and replaced DMEM containing $10 \% \mathrm{FBS}$ and the cells were incubated at $37^{\circ} \mathrm{C}$ for approximately 24 hours. The cells were removed from the plates using PBS containing $50 \mathrm{mM}$ EDTA and pelleted by centrifugation at $1250 \mathrm{xg}$ for $5 \mathrm{~min}$. The cells were fixed in suspension for 10 minutes in $3 \%$ paraformaldehyde at room temperature. Two washes were done using PBS containing $10 \mathrm{mM}$ glycine $+0.05 \%$ sodium azide to quench the fixative, then the suspension was incubated in PBS-glycine $+0.5 \%$ bovine serum albumin (BSA) (Sigmaaldrich) for 30 minutes at room temperature. The cells were then probed with a monoclonal antibody directed toward G, I1, followed by a secondary goat anit-mouse antibody conjugated to FITC. To quantify cell surface expression, flow cytometric analysis was employed. The cells were analyzed by flow cytometry using an LSRII Special Option Flow Cytometer (BD). BHK-21 cells transfected with empty vector (pCAGGS-MCS) were used as a negative control and cells expressing wild type $\mathrm{G}$ were used as the positive control.

Surface expression was also examined in virally infected cells. BHK-21 cells were plated out to $\sim 90 \%$ confluency and infected with the appropriate virus at an $\mathrm{MOI}=1$ for one hour while rocking at $31^{\circ} \mathrm{C}$. The inoculum was then replaced with DMEM supplemented with $5 \% \mathrm{FBS}$ and the cells transferred to a $37^{\circ} \mathrm{C}$ incubator with $\sim 7 \% \mathrm{CO}_{2}$. Six hours post infection cells were removed from the dish as described above, fixed and stained with I1 followed by FITC secondary antibody for flow cytometric analysis.

\section{Initial Characterization of Mutants}

Cell-Cell Fusion Assays. BHK-21 cells were transiently transfected as described above and approximately $24 \mathrm{hrs}$ post transfection the cells were treated with fusion media [(10 $\mathrm{mM} \mathrm{Na}_{2} \mathrm{HPO}_{4}, 10 \mathrm{mM} \mathrm{N}$-2-hydroxyethylpiperazine-N'-2-ethanesulfonic acid (HEPES), 10mM 2-(N-morpholino) ethanesulfonic acid (MES) titrated to the indicated $\mathrm{pH}$ (e.g. 5.2, 5.5, 6.0, 7.0)] by rinsing one time with fusion media at the appropriate $\mathrm{pH}$, then incubating for $1 \mathrm{~min}$ at room temperature. The fusion media was then replaced with 
DMEM containing $5 \% \mathrm{FBS}$ and incubated at $37^{\circ} \mathrm{C}$ for 30 minutes. The cells were not fixed in order to allow for better visualization of polykaryon formation and then photographed using phase contrast optics with a 10X objective on a Zeiss Axiophot camera and Axiophot software. Fusion was then quantitated by counting the cells not fused in three separate fields of view, and averaging them. Percent of cells fused was then determined by subtracting the average number of unfused cells from the average number of cells in the plates treated with buffer at neutral $\mathrm{pH}$ (unfused). The number of mutant unfused cells was then divided by the number of fused cells and multiplied by 100 .

Alternately, BHK-21 cells were infected at an $\mathrm{MOI}=1$ for 1 hour while rocking at $31^{\circ} \mathrm{C}$. The inoculum was removed and replaced with DMEM containing 5\% FBS and incubated at $37^{\circ} \mathrm{C}$ for 6 hours. At 6 hours post infection, the cells were treated with fusion medium as described above then fixed with $3 \%$ paraformaldehyde. Fusion was then measured as described.

Metabolic Labeling, Transport Kinetics, and Trypsin-Sensitivity Assays. The assays were done as previously described (Fredericksen and Whitt 1995; Fredericksen and Whitt 1995) with a few modifications. BHK-21 cells were plated out into $35 \mathrm{~mm}$ plates at $\sim 80 \%$ confluency and transfected with $2 \mu \mathrm{g}$ of the appropriate plasmid as described previously. Approximately 12 hours post transfection, the cells were rinsed once in methionine free DMEM (met-free) and then incubated in 2mls met-free DMEM for 15 minutes at $37^{\circ} \mathrm{C}$. The media was replaced with $2 \mathrm{mls}$ of met-free DMEM containing $50 \mu \mathrm{Ci}$ of $\left[{ }^{35} \mathrm{~S}\right]$ methionine (protein labeling mix, Perkin-Elmer) for various amounts of time. The cells were then either lysed immediately with $1 \mathrm{ml}$ of detergent lysis buffer (10mM Tris, (pH 7.4), 66mM EDTA, 1\% TX-100, 0.4\% deoxycholic acid, $0.02 \%$ sodium azide) or chased with DMEM + 5\% FBS medium containing $2 \mathrm{mM}$ excess nonradioactive methionine and then lysed at the desired times. The cell lysates were centrifuged at $14,000 \mathrm{rpm}$ for $1 \mathrm{~min}$ on a table-top microcentrifuge to remove the nuclei and cell debris. Anti-G tail rabbit polyclonal antibody (\#3226) was then used as the primary antibody for immunoprecipitation as previously described (Whitt, Buonocore et al. 1991) except that the post-nuclear supernatants were made to $0.3 \%$ sodium dodecyl sulfate (SDS) and the primary antibody incubations were performed at $37^{\circ} \mathrm{C}$ for 1 hour. For transport kinetic studies, one half of the cell lysates were digested with Endo $\mathrm{H}(\mathrm{New}$ England Biolabs) according to the manufacturer's instructions. Samples were then subject to analysis on a $10 \%$ SDS-PAGE gel.

The trypsin-sensitivity assay was performed by labeling BHK-21 cells expressing G protein with ${ }^{35} \mathrm{~S}-\mathrm{methionine}$ (as described above) and then chasing for 1 hour with DMEM containing 5\% FBS and excess unlabeled methionine. The cells were then lysed in 1x MNT buffer (20 mM MES, $150 \mathrm{mM} \mathrm{NaCl}, 30 \mathrm{mM}$ Tris, $\mathrm{pH} 7.5$ ) contatining 1\% $\mathrm{TX}-100$ at the indicated $\mathrm{pH}(7.4,6.1,5.2)$. After removing the nuclei and cell debris by centrifugation, the post-nuclear supernatants were incubated with or without TPCKtrypsin for $30 \mathrm{~min}$ at $37^{\circ} \mathrm{C}$. Digestion was halted by adding 100 trypsin inhibitor units of aprotonin. G proteins were then immunoprecipitated by incubating with a polyclonal $\alpha-$ 
VSV antibody followed by Pansorbin. A 10\% SDS-PAGE gel was used to resolve the immunoprecipitated $\mathrm{G}$ proteins and fluorography was used for visualization.

\section{Characterization of rVSV Encoding Mutant G Proteins}

Recovery of Virus Containing Mutated G Proteins. Infectious viruses encoding G proteins with mutations in the membrane-proximal region were recovered from plasmids as described previously (Takada, Robison et al. 1997), with a few modifications (Fig 21). Approximately $3 \times 10^{6}$ baby hamster kidney cells (BHK-21) were infected with a recombinant vaccinia virus encoding the T7 RNA polymerase (vTF7-3) (Earl, PL) at an MOI of 5 for 1 hour at $31^{\circ} \mathrm{C}$. The inoculum was removed and the cells were transfected with a DNA-liposome suspension composed of $5 \mu \mathrm{g}$ of the appropriate pVSV-G mutant plasmid and $5 \mu \mathrm{g}, 3 \mu \mathrm{g}, 5 \mu \mathrm{g}$, and $1 \mu \mathrm{g}$ respectively, of plasmids containing $\mathrm{G}, \mathrm{N}, \mathrm{P}, \mathrm{L}$ genes from VSV IND with $76 \mu 1$ of TransfectAce (Rose, Buonocore et al. 1991; Whitt, Buonocore et al. 1991). After $4 \mathrm{hrs,} \mathrm{the} \mathrm{transfection} \mathrm{mix} \mathrm{was} \mathrm{removed} \mathrm{and} \mathrm{replaced} \mathrm{with}$ DMEM containing $10 \%$ FBS. The cells were incubated at $37^{\circ} \mathrm{C}$ for approximately 48 hrs. $48 \mathrm{hrs}$ post transfection, the supernatants were harvested and filtered through a $0.2 \mu$ filter (Millipore, Millex-GS) to remove any residual vaccinia virus. The filtrate was then applied to BHK-21 cells in a $35 \mathrm{~mm}$ dish that had been transfected with $2 \mu \mathrm{g}$ of pCAGGS$\mathrm{G}_{\mathrm{IND}}$ plasmid $24 \mathrm{hrs}$ earlier. $24-48 \mathrm{hrs}$ later, recovery of the virus was assessed by examining the cells for cytopathic effects that are typically seen in a VSV infection. All recombinant viruses were recovered using G-complementation (P1). 200 $\mu 1$ of the recovery supernatant was used to infect BHK-21 cells without G-complementation to produce rVSV expressing the mutated $\mathrm{G}$ protein on the surface $(\mathrm{P} 2)$. The viruses were plaque purified (P3), then passaged on BHK-21 cells to make virus stocks (P4).

Plaque Assay. BHK-21 cells (approximately 5 x $10^{5}$ cells) were plated into each well of a 6 well plate and infected with 10 -fold serial dilutions of the virus at $31^{\circ} \mathrm{C}$ while rocking for 1 hour. The inoculum was removed and the cells were overlayed with DMEM $+0.9 \%$ agar $+5 \%$ FBS and incubated at $37^{\circ} \mathrm{C}$ for $24-48$ hours. Plaques were counted and averaged between at least two dilutions. Virus titers were expressed as plaque forming units $(\mathrm{PFU}) / \mathrm{ml}$. To determine plaque sizes, the overlay medium that was added consisted of DMEM $+5 \% \mathrm{FBS}+1.8 \%$ methylcellulose. Approximately $24-48$ hours post infection the overlay was removed and the cells were washed twice with PBS-glycine. The cells were fixed using 3\% paraformaldehyde and stained using $\alpha-\mathrm{G}$ I1 monoclonal antibody followed by a secondary antibody conjugated to either FITC or rhodamine. After staining the cells, the plaques were imaged using a Zeiss Axiophot epifluorescent microscope and Axiophot software. The plaques were measured for their diameter horizontally and vertically. The diameters for 10 plaques were averaged and the area calculated. 
Figure 2-1. Schematic representing recovery scheme for $\mathrm{rVSV}$ encoding mutated G proteins. BHK-21 cells are infected with vvT7 virus that encodes for T7 RNA

polymerase at an $\mathrm{MOI}=5$ for one hour. The inoculum is removed and the cells are transfected with plasmids encoding for $\mathrm{N}, \mathrm{P}, \mathrm{L}$ and $\mathrm{G}$ at a 3:5:1:5 ratio for $4 \mathrm{hrs}$. The media is replaced with fresh DMEM containing 10\% FBS and the cells are incubated at $37^{\circ} \mathrm{C}$. Approximately $48 \mathrm{hrs}$ post transfection the supernatants are filtered through a 0.22 $\mu$ filter onto BHK-21 cells transiently transfected with pCAGGS-G $\mathrm{I}_{\mathrm{IND}}$. 24-48 hrs later the cells were observed for cytopathic effects typically seen in VSV infection. Supernatants were passaged 3-4 times in the process of obtaining a working stock. 
pVSVFL(+)-2

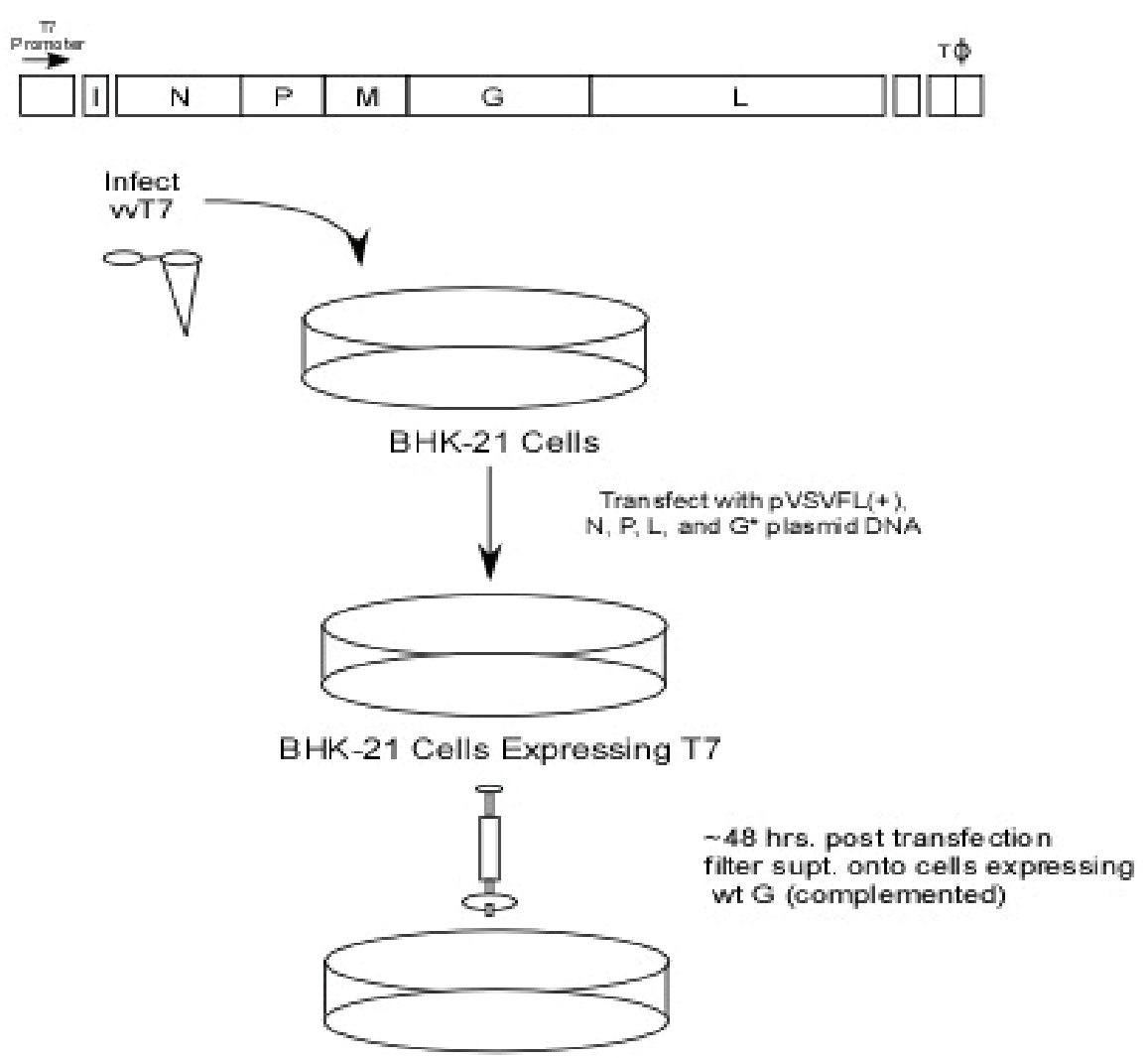

BHK-21 Cells Expressing wt G

$\downarrow$

Look for VSV specific cytopathic effects

or VSV protein expression

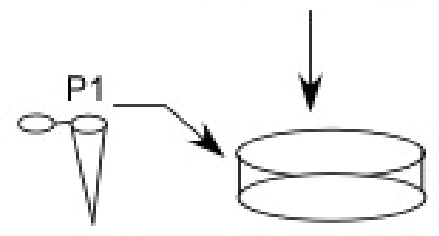

Passage vius on fresh BHK-21 cells

to produce non-complemented virus ( $\mathrm{P} 2$ )

$\downarrow$

Amplified 1X (P3) then

grew up working stock (P4) 
One-Step Growth Curve. BHK-21 cells were grown to confluency in $35 \mathrm{~mm}$ plates and infected with either wt or mutant viruses at an MOI $=10$ for $1 \mathrm{hr}$ at $31^{\circ} \mathrm{C}$. The inoculum was removed and the cells were washed three times with serum free DMEM (SFDMEM) to remove residual inoculum. The last wash was replaced with $2 \mathrm{mls}$ of DMEM $+10 \% \mathrm{FBS}$ and the cultures were incubated at $37^{\circ} \mathrm{C}$. Every 2 hours for 16 hours an aliquot of supernatant was removed and the amount of infectious virus was determined by plaque assay as previously described.

Detection of GS. To measure the amount of cleaved G protein (GS) present in virions, confluent monolayers of BHK-21 cells were infected at an $\mathrm{MOI}=1$. At approximately 16 hours post infection, the supernatant was collected, clarified of cells and cell debris by centrifugation at 2500 RPM for 5 minutes and the virus particles were then pelleted by ultra-centrifugation at $100,000 \times \mathrm{g}$ for $35 \mathrm{~min}$ through a $20 \%$ sucrose cushion. The viral pellets were resuspended in $100 \mu 1$ of reducing sample buffer and $5 \mu 1$ was loaded on a $10 \%$ SDS-PAGE gel to resolve the proteins. One gel was stained with commassie blue, while a duplicate gel was used for western blot analysis. Samples were transferred to PVDF membrane (Millipore), the membrane was blocked in 5\% bovine serum albumin (BSA) for $30 \mathrm{~min}$ at room temperature, and then polyclonal rabbit $\alpha$-G-tail antibody was used as the primary antibody at a 1:500 dilution in blocking buffer and incubated at room temperature for 30 minutes. The blot was then incubated with anti-rabbit antibody conjugated to Horseradish Peroxidase (HRP) at a 1:20,000 dilution for 30 minutes. Proteins were then detected by treating the blot in HRP detection substrate (Millipore).

Selection of Plaque Isolates. To identify virus variants within the recovery supernatants (Fig 2-1), a standard plaque assay was performed as described. Ten plaques of various sizes were selected and removed from the plate using a Pasteur pipette and resuspended in 500 $\mu$ l of DMEM containing 5\% FBS for 4-5 hours. The supernatant containing the plaque isolate was then was used to infect a $35 \mathrm{~mm}$ plate of BHK-21 cells at an MOI $=10$. Approximately 6 hrs post infection the media was removed, RNA was extracted, reverse transcribed, PCR amplified using MW36 (forward) and 3464 (reverse) primers (Table 2-1), and the resultant cDNA was used for sequencing (as described previously). 


\section{Chapter 3: Mutational Analysis of the Membrane-Proximal Region of VSV G}

\section{Introduction}

Vesicular stomatitis virus is an enveloped, negative-sense, nonsegmented, RNA virus belonging to the Rhabdovirus family and the Mononegavirales order. Like other enveloped viruses, entry into the host cells is dependent upon a fusion event between the virus and cell membranes that is mediated by the outer surface glycoprotein, G. G protein attaches to an unknown receptor on the host cell surface (Coil and Miller 2004) and is internalized via receptor mediated endocytosis (Matlin, Reggio et al. 1982). Fusion of the viral envelope and the host cell endocytic membrane is triggered by the decrease in $\mathrm{pH}$ within the endocytic environment. When the $\mathrm{pH}$ reaches between 6.2 and 6.3 , initial conformational changes in $\mathrm{G}$ are triggered leading to exposure of the fusion loops and insertion in to the target membrane. Further conformational changes then occur forming a hairpin structure that pulls the two opposing membranes together. Formation of the hairpin (six-helix bundle) structure allows for the initial mixing of the outer leaflets of the opposing membranes, which is referred to as hemifusion (Chernomordik, Melikyan et al. 1987; Lentz, Malinin et al. 2000). Once the lipids from the outer leaflets have mixed forming the hemifusion intermediate, a stalk is formed in which the outer leaflets have collapsed while the inner leaflets remain intact (Jahn and Sudhof 1999; Kuzmin, Zimmerberg et al. 2001). Finally a fusion pore forms at the fusion site in which the viral nucleocapsid can possibly pass through or the pore may expand further to allow for release into the host cell cytoplasm. Fusion pores have been observed through patch-clamp experiments with cells expressing influenza HA (Melikyan, Niles et al. 1993; Melikyan, Niles et al. 1993; Zimmerberg, Blumenthal et al. 1994; Blumenthal, Sarkar et al. 1996). Regardless of the type of fusion protein or the lack of sequence or structural homology, they all undergo a series of conformational changes that expose a hydrophobic membrane interacting region (fusion peptide or fusion loop) and pull the two membranes together.

The structural rearrangements that VSV G undergoes when exposed to low $\mathrm{pH}$ are different than what is seen with the well characterized class I fusion proteins, such as influenza HA, and are also different from the changes that are observed in members of class II fusion proteins. A key feature that is different in $\mathrm{G}$ mediated fusion from the fusion proteins grouped in either class I or class II is the reversible nature of the low $\mathrm{pH}$ triggered conformational changes observed for VSV G. There is a $\mathrm{pH}$ dependent equilibrium between the pre- and postfusion conformations that is shifted toward the postfusion form when exposed to low $\mathrm{pH}$ (Roche and Gaudin 2002). Prior to determination of the 3-dimensional crystal structures of the two forms of VSV G (Roche, Bressanelli et al. 2006; Roche, Rey et al. 2007), extensive mutational analysis of G was employed to identify regions of the protein that participate in membrane fusion. A putative fusion peptide was identified by mutational analysis and photolabeling experiments to residues 118-136 in the VSV G ectodomain. This region was believed to insert into target membranes when exposed to a low $\mathrm{pH}$ environment (Whitt, Chong, et al. 1989; Li, Drone et al. 1993; Zhang and Ghosh 1994; Durrer, Gaudin et al. 1995; 
Fredericksen and Whitt 1995). Deletions and insertions of residues between 395 and 418 also affected the ability of $\mathrm{G}$ to induce membrane fusion (Shokralla, Chernish et al. 1999). Furthermore, when double mutants were constructed containing changes to residues in both of these regions, fusion was affected in an additive manner, indicating a possible interaction between these residues (Shokralla, Chernish et al. 1999). These data were confirmed with the solution of the crystal structures of $\mathrm{G}$ in the neutral $\mathrm{pH}$ (or prefusion) and low $\mathrm{pH}$ (or postfusion) conformations (Roche, Bressanelli et al. 2006; Roche, Rey et al. 2007). Interestingly, the structures revealed a unique feature in that there were two loops extending toward the viral membrane in the prefusion conformation and both of these likely insert into the target membrane upon low $\mathrm{pH}$ induced conformational changes. These two loops were proposed to make up a bipartite fusion peptide, similar to what has been suggested for the Viral hemorrhagic septicemiavirus (Gaudin, de Kinkelin et al. 1999).

To understand the role of the membrane-proximal stem region (MPR) of G we employed a mutational analysis coupled with cell-cell fusion and virus infectivity assays. Since no structural data exists for the MPR, we chose to mutate charged residues, histidines that can form salt bridges with the charged residues (Carneiro, Stauffer et al. 2003; Roche, Rey et al. 2007), or highly conserved residues. We initially characterized the mutated $G$ proteins based on surface expression and cell-cell fusion capacity. Those mutant $\mathrm{G}$ proteins with cell-cell fusion phenotypes different from that of wild type were examined for their ability to undergo $\mathrm{pH}$ dependent conformational changes. We also recovered recombinant virus encoding mutated $G$ proteins to examine the effects of the mutations on the infectivity of the virus.

\section{Results}

Mutagenesis of the Membrane-Proximal Region of $G$. To investigate the role of the membrane-proximal region of VSV G we employed a mutational analysis, focusing on highly conserved residues as well as residues that are conserved for their chemical properties. Available sequences from VSV-Indiana San Juan strain, (Rose and Gallione 1981), VSV New Jersey (Gallione and Rose 1983), Chandipura virus (Masters, Bhella et al. 1989), Cocal virus (Bhella, Nichol et al. 1998), Isfahan virus (Marriott 2005), Piry virus (Brun, Bao et al. 1995), and spring viremia of carp virus (SVCV) (LecocqXhonneux, Thiry et al. 1994) were aligned, revealing several completely conserved amino acids as shown in yellow (Fig 3-1A). Several residues in this region are completely conserved, while others are functionally conserved based on their chemical properties as depicted with turquoise color. Many residues in this region were also conserved for their chemical properties and are represented with a green background. Some interesting features within this region are the conserved HPH motif (H423, P424, and H425) as well as the conserved acidic residues D435, D436, and E437. Residues 440 and 441 are conserved among the closely related vesiculoviruses in the alignment, with phenylalanines at both positions. In the New Jersey serotype $\mathrm{G}$ these two positions a 
A.

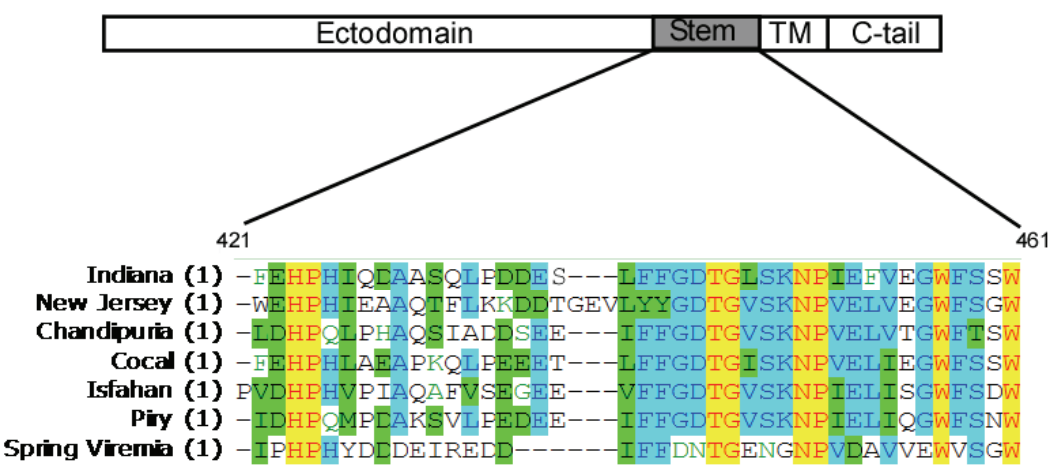

B.

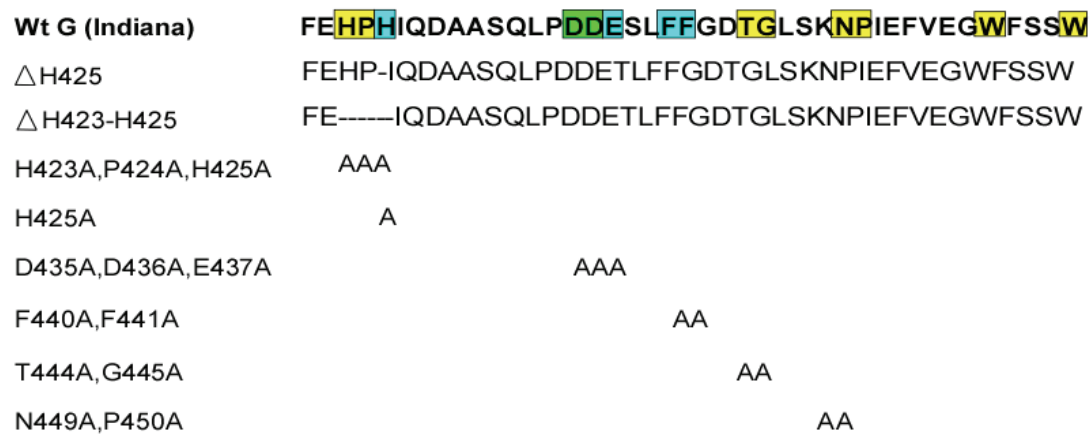

Figure 3-1. Sequence alignment of closely related vesiculoviruses and mutations made. (A) Sequences from various strains of vesiculoviruses were aligned using Vector NTI Software (Alignx), to identify residues in this region of the protein that are completely or highly conserved. The strains of vesiculovirus shown are from VSV Indiana (Rose and Gallione 1981), VSV New Jersey (Gallione and Rose 1983), Chandipuria virus (Masters, Bhella et al. 1989), Cocal virus (Masters, Bhella et al. 1989; Bach, Bringmann et al. 1990; Bhella, Nichol et al. 1998), Isafan virus (Marriott 2005), Piry virus (Brun, Bao et al. 1995), and spring viremia of carp virus (SVCV) (LecocqXhonneux, Thiry et al. 1994). Residues with a yellow background represent conservation among all of the vesiculoviruses aligned. Residues with a turquoise background are almost completely conserved with only one exception and residues with a green background are those with similar biophysical properties. (B) Mutations that were made to the $\mathrm{G}$ protein from the Indiana serotype (San Juan strain) are shown. 
tyrosines, which strongly resemble phenylananine in that they both are bulky, strongly hydrophobic, and contain a conjugated ring system. T445 and G446 were completely conserved as were N449 and P450, suggesting a possible role for these residues in the function of the protein. Two tryptophan residues are completely conserved in this sequence alignment. Studies with HIV-1 env revealed a key role for conserved tryptophans in both env mediated membrane fusion and virus budding (Salzwedel, West et al. 1999). Theses two conserved tryptophans in VSV G residues were previously mutated to determine their importance for entry and budding, but surprisingly, these experiments revealed no critical role in either process (Jeetendra, Ghosh et al. 2003).

To examine the contribution of the conserved residues in the membrane proximal region to the fusion activity of $\mathrm{G}$ protein, I made substitutions and deletions (Fig 3-1B). The HPH motif was deleted $(\Delta \mathrm{H} 423-\mathrm{H} 425)$ as well as replaced with alanines (H423A/P424A/H425A). H425, individually, was also deleted or replaced with an alanine. D435-E437 was mutated to alanines as were F440/F441, T445/G446, and N449/P450. These mutants were initially characterized for surface expression, fusion capacity, and the ability to undergo low $\mathrm{pH}$ induced conformational changes.

Surface Expression of VSV G Mutants. To determine if the mutations affected the transport from the ER to the Golgi or cell surface expression of the mutant G proteins, Endo $\mathrm{H}$ resistant assays and flow cytometry were performed on cells expressing each of the mutants. BHK-21 cells were transfected with plasmids expressing either wild type or mutant $\mathrm{G}$ proteins and the cells were processed for indirect immunofluorescence microscopy using a G specific mAb (I1) (Lefrancois and Lyles 1982) as an initial screen for surface expression. The initial screen indicated that all the mutated $\mathrm{G}$ proteins were expressed on the cell surface, but the G proteins with mutations made to the HPH motif appeared to be expressed at lower levels than that of wild type $G$ protein (data not shown). Flow cytometry was then used to quantify the levels of surface expression and the surface expression was described as relative florescence intensity based on the percent of cells expressing $\mathrm{G}$ and the mean fluorescence intensity of those cells (Fig 3-2). Deletion of H423- H425 or substitution of all three residues to alanines resulted in a dramatic decrease in surface expression of the $\mathrm{G}$ protein to $\sim 20 \%$ that of wild type levels. However, the single mutation of $\mathrm{H} 425$ to an alanine resulted in a protein that was expressed at levels $\sim 70 \%$ that of wild type. Substitution of D435-E437 with alanines resulted in near wild type levels of expression, while F440A/F441A showed a reduction in surface expression to $35 \%$ that of wild type levels. When T445-G446 and N449P450 were mutated to alanines the levels of surface expression was also similar to wild type (Fig 3-2). Flow cytometric data from those mutants with a reduced level of surface expression ( $\triangle \mathrm{HPH}, \mathrm{H} 423 \mathrm{~A} / \mathrm{P} 424 \mathrm{~A} / \mathrm{A} 425 \mathrm{~A}, \Delta \mathrm{H} 425$, and $\mathrm{F} 440 \mathrm{~A} / \mathrm{F} 441 \mathrm{~A})$ revealed that approximately $50 \%$ of the cells were expressing $\mathrm{G}$ as determined by the percent parent cells expressing. However, the mean fluorescence intensity was greatly reduced as compared to wild type, explaining the relative fluorescence intensity amounts described above (Table 3-1). These results indicate that the cells transfected with plasmids encoding the G proteins with mutations to the HPH or FF motifs were expressing the 


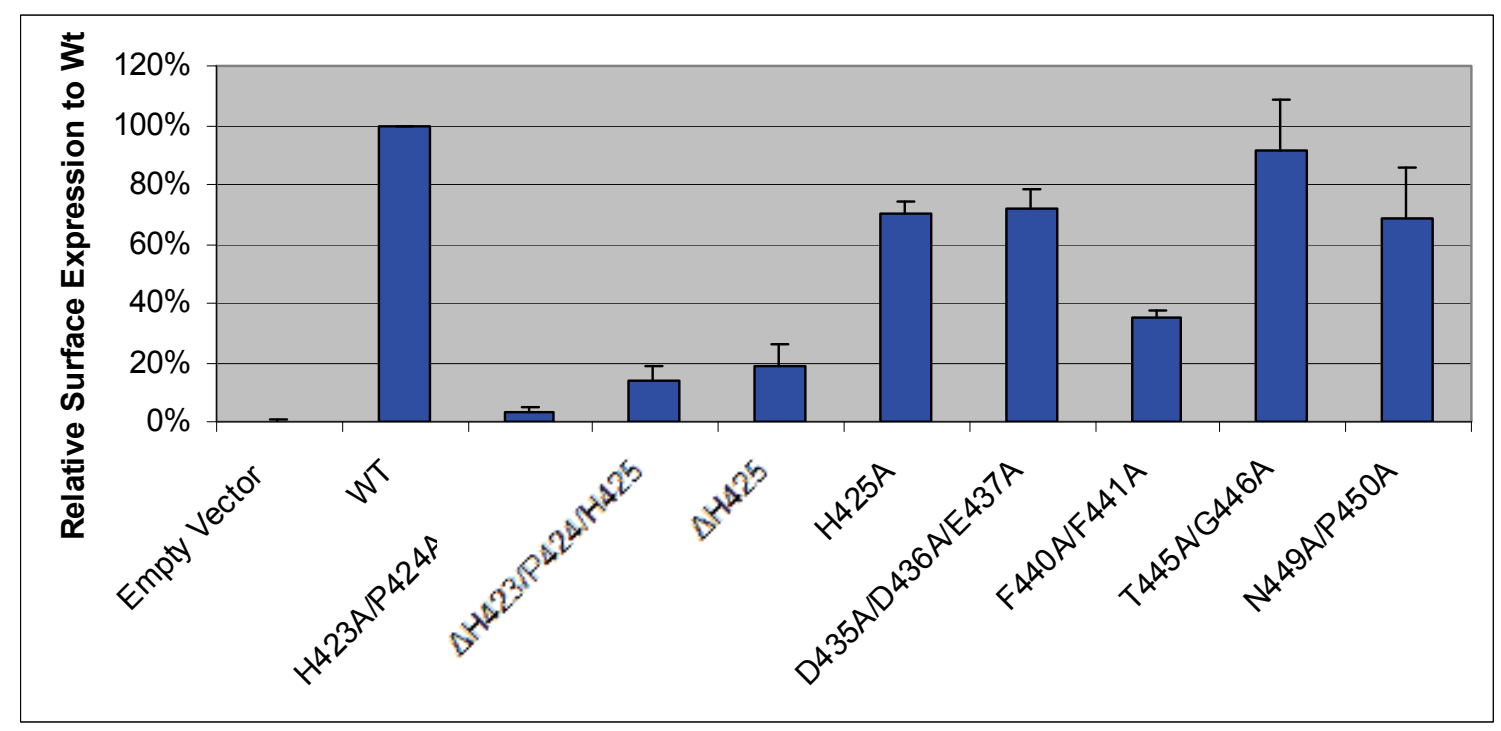

Figure 3-2. Cell surface expression of glycoprotein mutants. BHK-21 cells were transiently transfected with $2 \mu \mathrm{g}$ of plasmid encoding the indicated $\mathrm{G}$ protein. Approximately $24 \mathrm{hr}$ later, cells were prepared for flow cytometry using a monoclonal antibody directed to G (I1) and a secondary antibody conjugated to FITC. Expression levels represent relative surface expression. Relative surface expression $=(\%$ positive cells in mutant population $\mathrm{x}$ mean fluorescence intensity) / (\% WT positive cells $\mathrm{x}$ WT mean fluorescence intensity). Values are expressed as a percentage of WT surface expression, which was set at $100 \%$. Averages of three separate experiments were calculated with standard deviations shown. 
Table 3-1. Percent parent expressing cells and mean fluorescence intensity values.

\begin{tabular}{lcr}
\hline \multicolumn{1}{c}{ Protein } & Percent Parent & $\begin{array}{c}\text { Mean Fluorescence } \\
\text { Intensity }\end{array}$ \\
\hline $\mathrm{MCS}$ & & \\
$\mathrm{Wt} \mathrm{G}$ & $0.5 \%$ & 1036 \\
$\mathrm{H} 423 \mathrm{~A} / \mathrm{P} 424 \mathrm{~A} / \mathrm{H} 425 \mathrm{~A}$ & $87.7 \%$ & 10950 \\
$\Delta \mathrm{H} 423 / \mathrm{P} 424 / \mathrm{H} 425$ & $38.2 \%$ & 2722 \\
$\Delta \mathrm{H} 425$ & $45.4 \%$ & 3296 \\
$\mathrm{H} 425 \mathrm{~A}$ & $51.4 \%$ & 4957 \\
$\mathrm{D} 435 \mathrm{~A} / \mathrm{D} 436 \mathrm{~A} / \mathrm{E} 437 \mathrm{~A}$ & $73.7 \%$ & 9646 \\
$\mathrm{~F} 440 \mathrm{~A} / \mathrm{F} 441 \mathrm{~A}$ & $77.7 \%$ & 9657 \\
$\mathrm{~T} 445 \mathrm{~A} / \mathrm{G} 446 \mathrm{~A}$ & $57.5 \%$ & 5617 \\
$\mathrm{~N} 449 \mathrm{~A} / \mathrm{P} 450 \mathrm{~A}$ & $88.4 \%$ & 10320 \\
& $77.1 \%$ & 10849 \\
\hline
\end{tabular}


protein but at significantly lower levels than what is observed for wild type. Since these proteins appear to be expressed at lower levels, the next step in characterization is to determine whether these mutants are able to be transported from the ER to the Golgi and if so, the rate at which this occurs.

To examine the transport kinetics of the mutant $\mathrm{G}$ proteins that showed greatly reduced cell surface expression as compared with wild type G, Endoglycosylase H (Endo $\mathrm{H}$ ) analysis was used (Fig 3-3). While in the ER, G (or other membrane bound or secreted proteins) acquire high mannose oligosaccharides. At this stage in the secretory pathway, the proteins are sensitive to Endo $\mathrm{H}$ digestion. The protein then moves from the ER to the medial Golgi where the high mannose oligosaccharides are cleaved by Golgi mannosidase II, resulting in complex oligosaccharides that are resistant Endo $\mathrm{H}$ digestion. Acquisition of Endo $\mathrm{H}$ resistance, therefore can be used to compare rates at which the mutated proteins migrate from the ER to the Golgi, or if they do at all. The $\Delta \mathrm{H} 423 / \mathrm{P} 424 / \mathrm{H} 425$ and H423A/P424A/H425A mutants acquired EndoH resistant sugars more slowly than wild type and after 60 minutes were still not entirely resistant to digestion. H423A/P424A/H425A does not have a band in the treated or untreated lane at the 15 minute time point likely due to an inefficient transfection (the treated and untreated samples for each time point came from one plate of transfected cells). Since complete Endo $\mathrm{H}$ resistance was not observed even after 60 minutes, the lack of protein in the 15 minute samples does not impact the interpretation of the data. The transport kinetics of $\Delta \mathrm{H} 425$ and F440A/F441A were more similar to that of wild type in that by 30 minutes these proteins were completely resistant to Endo $\mathrm{H}$ digestion, but perhaps slightly reduced in rate based on the amount of resistance at 15 minutes. From this experiment it appears that, surprisingly, $\Delta \mathrm{H} 425$ and $\mathrm{F} 440 \mathrm{~A} / \mathrm{F} 441 \mathrm{~A}$ are moving from the ER to the medial Golgi at a similar rate as compared to wild type. This finding is particularly surprising for the $\Delta \mathrm{H} 425$ mutant that is reduced in surface expression by $\sim 80 \%$ from that of wild type. The next step in the characterization of the mutated $G$ proteins is to examine the fusion capacity through the use of a syncytium formation assay.

Cell-Cell Fusion Activity of Mutants. The functionality of these mutated G proteins was examined based on the premise that fusion proteins can be transiently expressed in cells and mediate cell-cell fusion. Syncytium formation can then be observed as a means by which to quantify the fusion capacity of a protein. Likewise, cells can be infected with virus and treated with fusion media to observe syncytium formation. BHK-21 cells expressing either wild type $\mathrm{G}$ protein or the mutants individually were treated with fusion media buffered to $\mathrm{pH} 6.0$ or 7.0 as an initial screen for fusion capacity. A separate plate of cells transfected in parallel was used for flow cytometry to quantify the level of cell surface expression for the experiment. Cell-cell fusion was not observed for several of the mutants. The $\Delta \mathrm{H} 423 / \mathrm{P} 424 / \mathrm{H} 425, \Delta \mathrm{H} 425, \mathrm{H} 423 \mathrm{~A} / \mathrm{P} 424 \mathrm{~A} / \mathrm{H} 425 \mathrm{~A}, \mathrm{~F} 440 \mathrm{~A} / \mathrm{F} 441 \mathrm{~A}$, and D435A/D436A/E427A mutants all showed no cell-cell fusion based on a lack of syncytium formation in the plates treated at $\mathrm{pH} 6.0$ (data not shown). All of these 


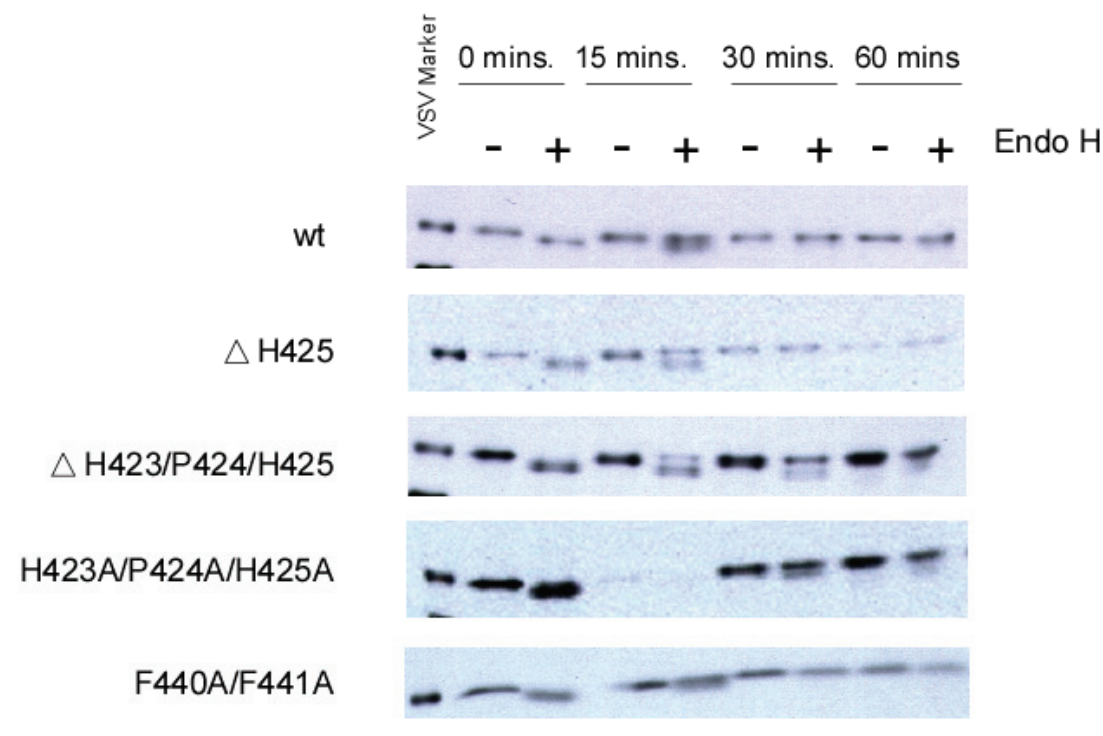

Figure 3-3. Transport kinetics of mutants with reduced surface expression. BHK-21 cells were transfected as described in figure 3-2. Approximately $12 \mathrm{hr}$ later, the cells were metabolically labeled with ${ }^{35}$ S-methionine, chased with medium containing excess non-radioactive labeled methionine for the times indicated, and immunoprecipitated using a polyclonal $\alpha$-VSV antibody (TN-1). The precipitated proteins were then digested with Endo $\mathrm{H}$ and analyzed on a $10 \%$ SDS-PAGE gel. 
mutants, with the exception of D435A/D436A/E437A, were expressed at lower levels than wild type on the cell surface as assessed by flow cytometry (data not shown).

Based on the reduced cell surface expression, two possible conclusions could be drawn. It has previously been suggested for rabies virus that approximately 13 to 19 trimers are needed at the fusion site to cause membrane coalescence (Roche and Gaudin 2002), and therefore, a decreased amount of protein on the cell surface could prevent fusion from occurring. Alternatively, the mutations, while important to proper folding and surface expression, may also affect a critical step in the fusion process. To examine these possibilities, BHK-21 cells were transfected using varying amounts of plasmid expressing wild type $\mathrm{G}$ and mutant $\mathrm{G}$ proteins such that the surface expression levels of wild type was less than or equal to that of the mutants. The cells were treated with fusion media buffered to $\mathrm{pH} 5.2,5.5,6.0$, or 7.0 to also examine the possibility that the mutations may have resulted in a decrease in the threshold $\mathrm{pH}$ required for fusion.

Interestingly, the $\Delta \mathrm{H} 423 / \mathrm{P} 424 / \mathrm{H} 425$ mutant when expressed on the cell surface at a level greater than that of wild type, showed no cell-cell fusion activity at any of the pHs examined (Fig 3-4). These data indicated that $\Delta \mathrm{H} 423 / \mathrm{P} 424 / \mathrm{H} 425$ is a fusion defective mutant. Analysis of the $\Delta \mathrm{H} 425, \mathrm{D} 435 \mathrm{~A} / \mathrm{D} 436 \mathrm{~A} / \mathrm{E} 437 \mathrm{~A}$, and F440A/F441A mutants, (when expressed on the cell surface at levels greater than that of wild-type) revealed minimal fusion at $\mathrm{pH} 6.0$ as compared with wild type $\mathrm{G}$ protein (Fig 3-5A). These results indicate that the $\Delta \mathrm{H} 425, \mathrm{D} 435 \mathrm{~A} / \mathrm{D} 436 \mathrm{~A} / \mathrm{D} 437 \mathrm{~A}$, and F440A/F441A mutants have a reduced $\mathrm{pH}$ threshold for fusion. H423A/P424A/H425A was expressed at a lower level than wild-type in all experiments so conclusions on the fusion capacity could not be drawn. To quantify cell-cell fusion in these experiments, cells that had not fused in three separate fields of view were counted, averaged, and subtracted by the number of cells unfused in the plates that had been treated with neutral $\mathrm{pH}$ buffer. These data further confirmed a reduced threshold for cell-cell fusion activity that was initially observed for the $\Delta \mathrm{H} 425, \mathrm{D} 435 \mathrm{~A} / \mathrm{D} 436 \mathrm{~A} / \mathrm{E} 437 \mathrm{~A}$, and F440A/F441A mutants. Likewise, the $\Delta \mathrm{H} 423 / \mathrm{P} 424 / \mathrm{H} 425$ mutant was completely fusion defective at each $\mathrm{pH}$ examined.

Analysis of pH Dependent Conformational Changes. Since several mutants showed defects or a reduction in fusion activity, I wanted to determine if these mutants could undergo $\mathrm{pH}$ dependent conformational changes. It has been shown that VSV G in the prefusion form is sensitive to trypsin digestion and as the $\mathrm{pH}$ decreases the protein becomes more resistant to digestion (Fredericksen and Whitt 1996). Acquisition of trypsin resistance is believed to be a result of the large scale conformational changes that occur in $\mathrm{G}$ when exposed to a $\mathrm{pH}$ below 6.3. Therefore, this assay is used as a tool to identify if the mutations made to the $G$ protein interfere with the ability to undergo the $\mathrm{pH}$ triggered conformational changes. To determine if the mutations made in the membrane-proximal region of $\mathrm{G}$ affected $\mathrm{pH}$ dependent conformational changes, cells expressing either wild type or a mutant $\mathrm{G}$ protein were lysed in a detergent solution buffered to $\mathrm{pH} 5.2,6.1$, or 7.4 and treated with TPCK-trypsin for 30 minutes at $37^{\circ} \mathrm{C}$. The reaction was stopped by the addition of aprotonin and lysates were immunoprecipitated using a polyclonal $\alpha$-VSV antibody and then analyzed on a $10 \%$ 


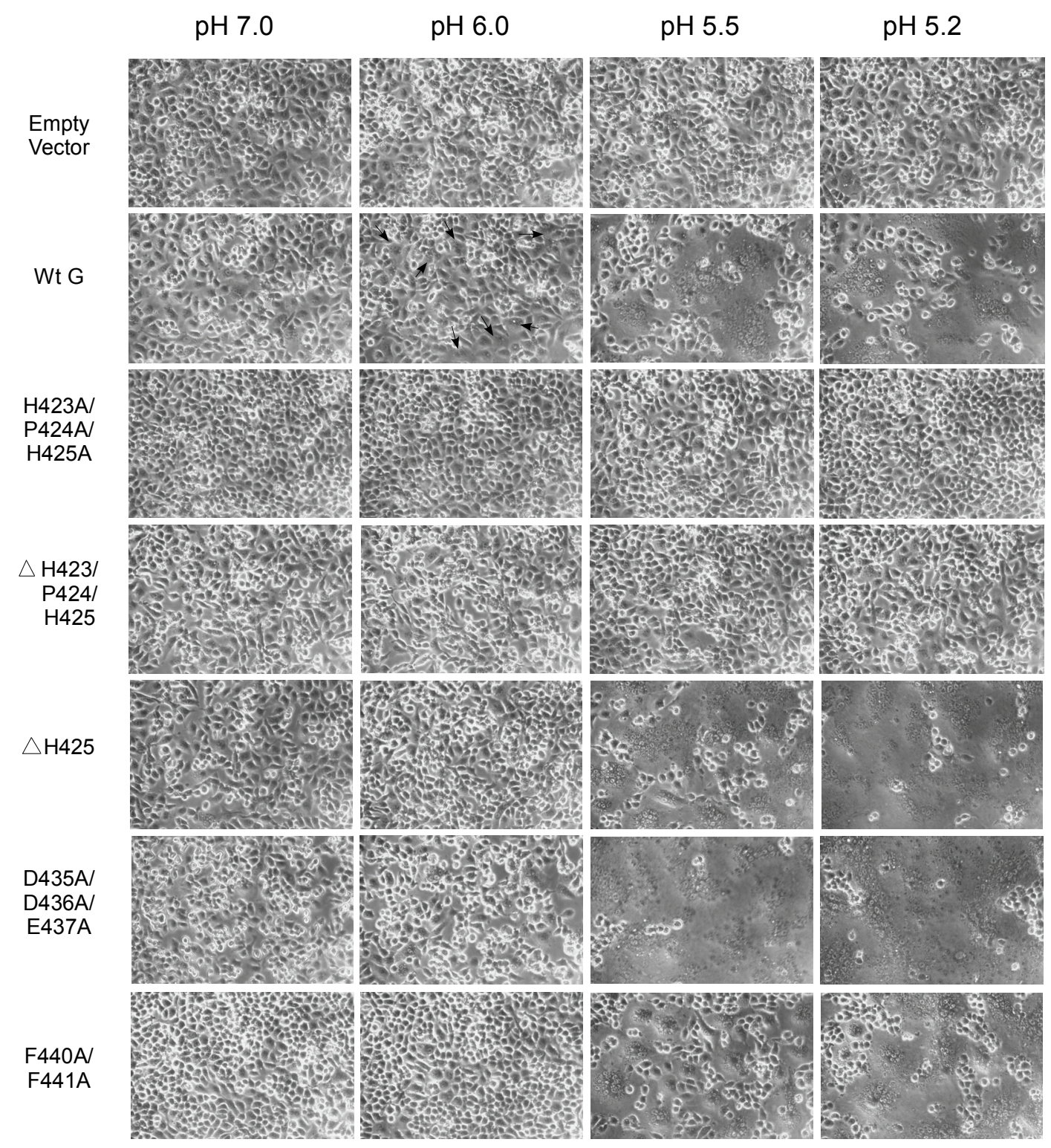

Figure 3-4. Cell-cell fusion in transiently transfected cells. BHK-21 cells were transiently transfected with varying amounts of plasmid encoding the mutant proteins to set the expression levels greater than or equal to wild type. Approximately 20 hours post transfection, the cells were treated in media buffered to $\mathrm{pH} 7.0,6.0,5.5$, or 5.2 and images were collected using a Zeiss Axiophot camera and Axiophot software. Arrows indicate syncytium formation. 
Figure 3-5. Quantitation of cell-cell fusion. (A) Quantitation of the experiment described in figure 3-4 was done by counting the number of unfused cells in three separate fields of view per condition and averaging the results. The number of unfused cells was then subtracted from the total average number of cells in wells treated at neutral $\mathrm{pH}$ to obtain the number of cells fused. Percentage of fused cells was then determined by dividing the number of fused cells in the low $\mathrm{pH}$ wells by the number of cells in the wells treated with fusion media buffered to $\mathrm{pH}$ 7.0. (B) Cells from a separate well were transfected at the same time as those used for the fusion assay and used for flow cytometry to measure surface expression. 
A

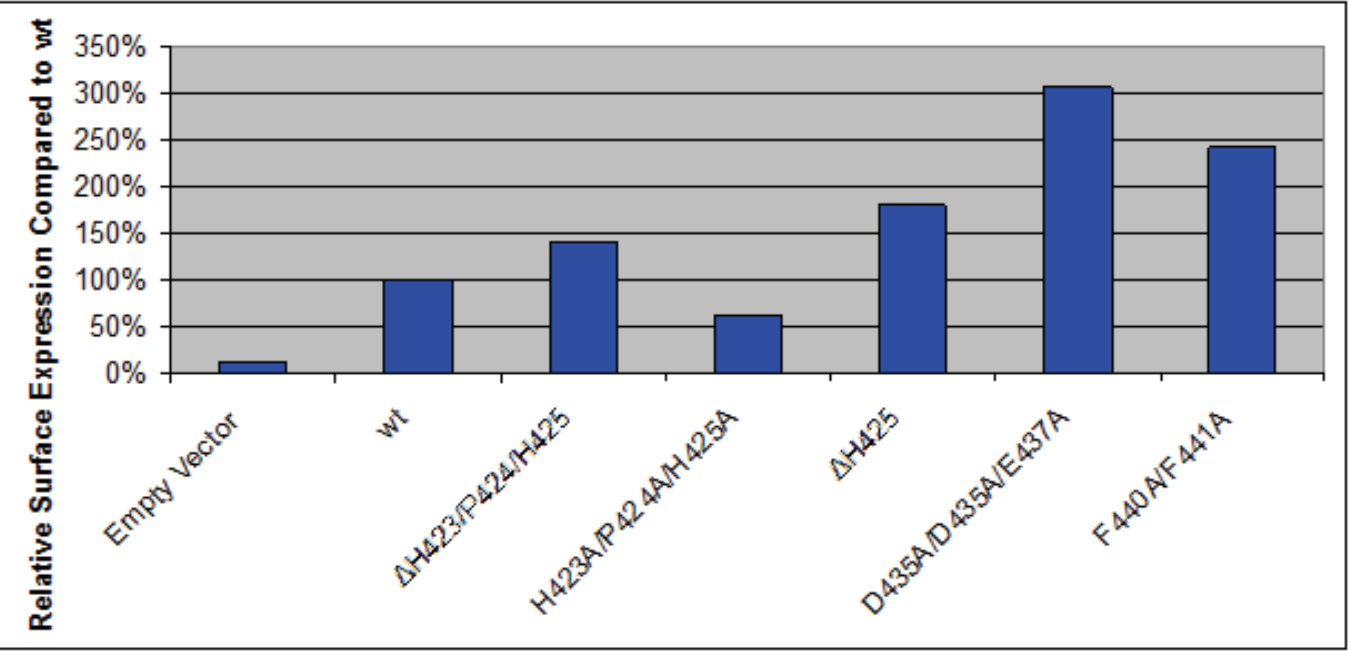

B

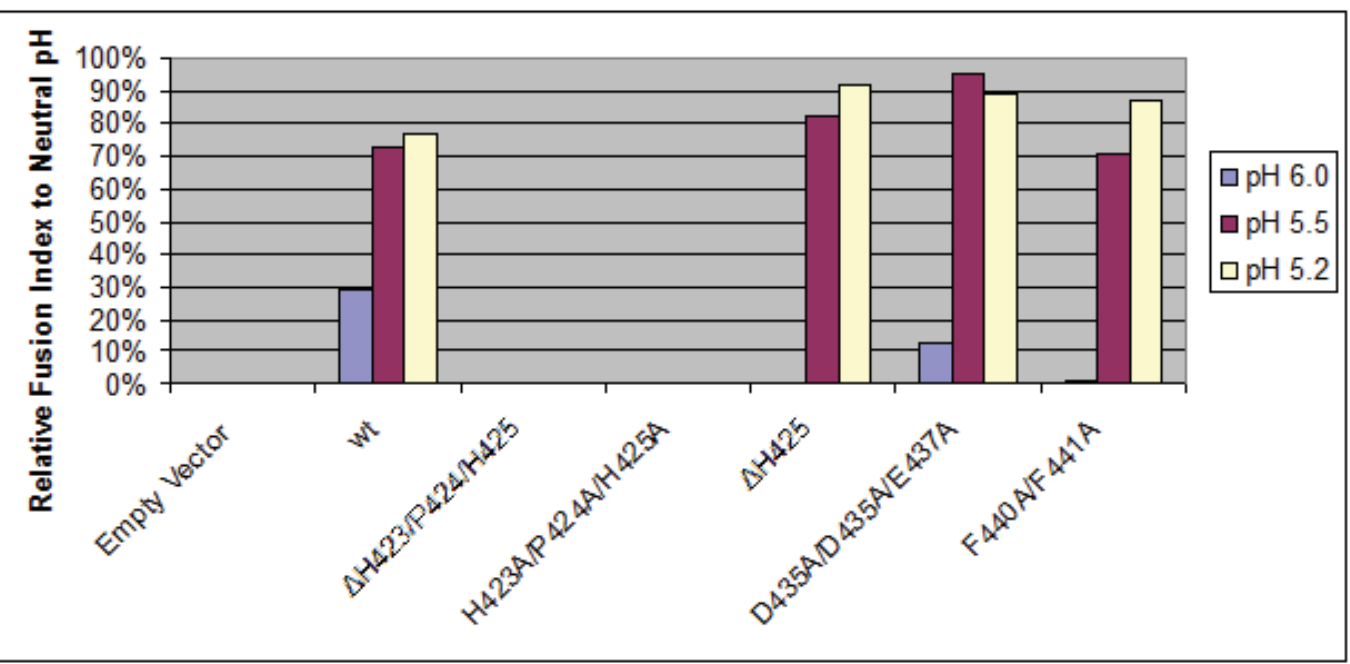


SDS PAGE gel. All of the mutants examined became sensitive to trypsin digestion at similar $\mathrm{pH}$ values as wild type indicating that the mutations do not interfere with the ability of the glycoprotein to undergo acid induced conformational changes required for fusion (Fig 3-6). The next step in characterizing the effects of the mutations on the $G$ proteins is examination of virus infectivity.

Recovery of Recombinant Mutant VSV. Reverse genetics was employed to recover recombinant VSV encoding the mutant G proteins to assess the impact that these mutations have on the ability of the virus to grow and spread. All viruses were recovered using $\mathrm{G}$ complementation to compensate for any potential fusion defects and to help in the successful recovery of recombinant virus. H423A/P424A/H425A was the only virus that was unable to be recovered after multiple attempts, despite complementation with wild type G. This mutant was expressed at significantly lower levels than wild type and therefore could not be examined in terms of fusion. In contrast, all the other mutants were recovered on the first or second attempt. $\Delta \mathrm{H} 423 / \mathrm{P} 424 / \mathrm{H} 425$ was completely fusion defective in the initial fusion assays using transient transfections and was able to be recovered using $\mathrm{G}$ complementation, and as expected, produced viral particles that were not infectious (data not shown). Recovery of recombinant VSV encoding $\Delta \mathrm{H} 423 / \mathrm{P} 424 / \mathrm{H} 425$ was detected by staining the cells with $\alpha-\mathrm{N}$ monoclonal antibody (10G4) as well as observation of VSV induced cytopathic effects. After recovery of wild type $\mathrm{G}$ complemented recombinant virus encoding $\Delta \mathrm{H} 423 / \mathrm{P} 424 / \mathrm{H} 425$, the recovery supernantant was used to infect cells to produce virus expressing the mutated $\mathrm{G}$ protein on the virion surface. Subsequent infection of fresh cells with the $\Delta \mathrm{H} 423 / \mathrm{P} 424 / \mathrm{H} 425$ resulted in no cytopathic effects, indicating the virus was not infectious. The recovered recombinant viruses containing the mutated $\mathrm{G}$ proteins were then characterized based on their growth kinetics, surface expression, and fusion capacity.

One-Step Growth Curve. To determine the growth kinetics of the viruses encoding the mutated $\mathrm{G}$ proteins, a one-step growth curve was performed. The cells were infected with mutant and wild type virus (that had been titered in duplicate) at an MOI of $0.1 \mathrm{pfu}$ and rinsed three times after the infection, before replacing the inoculum with fresh media to help ensure the initial infection was the same for all viruses. Interestingly, titers for rVSV-H425A, rVSV-D435A/D436A/E437A and rVSV-T444A/G445A initially were lower than that of Wt, but by 4 hrs post infection reached wild type levels (Fig 3-7A). Surprisingly, D435A/D436A/E43A, which appeared to have a decrease in the $\mathrm{pH}$ threshold for fusion (Fig 3-3, Fig 3-4), was able to grow to near wild type titers suggesting efficient fusion activity (entry). Likewise, rVSV-H425A, T444A/G445A, and N449A/P450A all grew to wild type titers, as expected based on the cell-cell fusion and surface expression phenotypes observed (Fig 3-2 and 3-5).

The recombinant viruses all reached wild type titers by 4 hours post infection and maintained near wild type levels through 16 hours (Fig 3-7A). At 16 hours post infection the supernatants were harvested, virus was pelleted by centrifugation through a $20 \%$ sucrose cushion and an aliquot was analyzed for protein content by SDS-PAGE. As was 


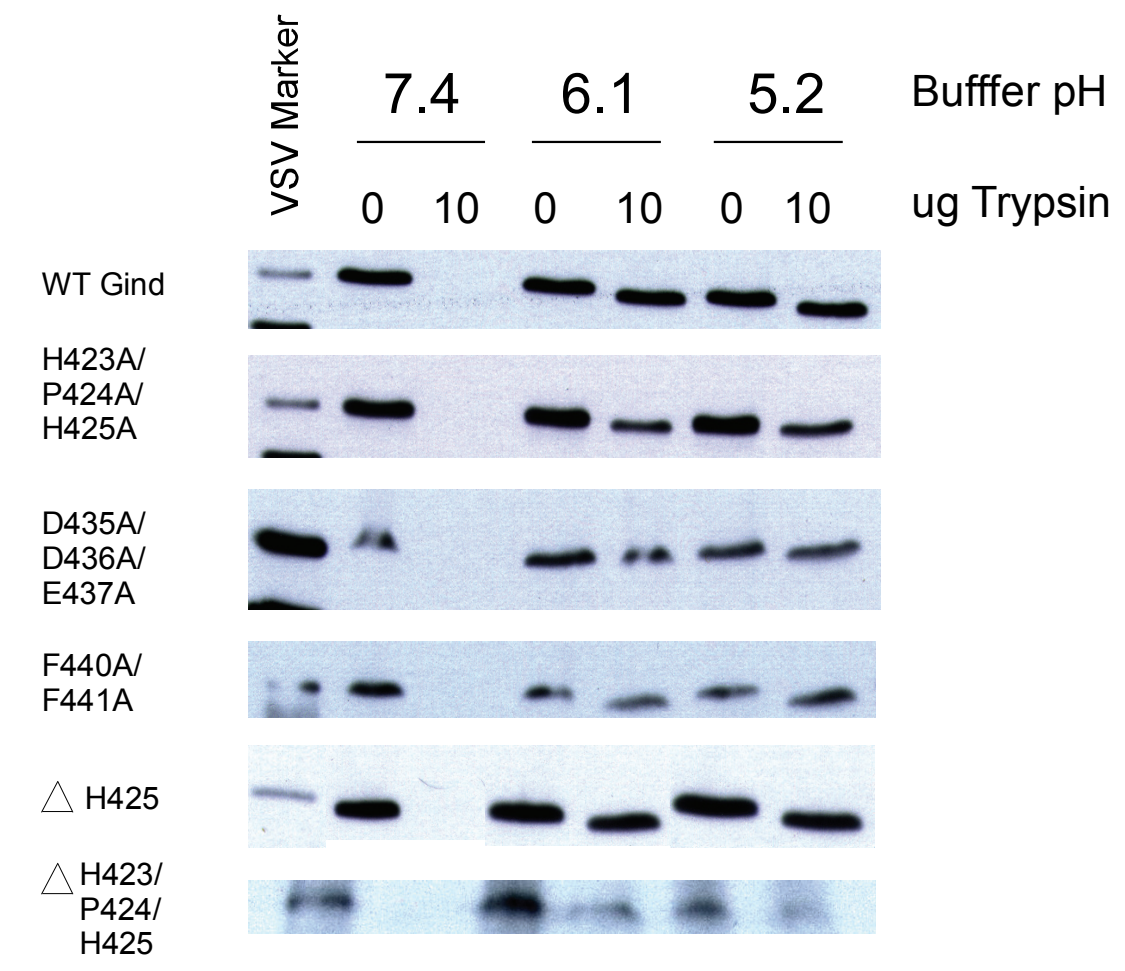

Figure 3-6. pH dependent protease sensitivity. BHK-21 cells were transfected with the appropriate plasmid DNA, metabolically labeled with ${ }^{35} \mathrm{~S}$-methionine, lysed with detergent (TX-100) buffered to the indicated $\mathrm{pH}(7.4,6.1$, or 5.2), treated or not treated with trypsin-TPCK, and then immunoprecipitated using a polyclonal $\alpha$-VSV antibody and analyzed by SDS-PAGE 
Figure 3-7. One-step growth curve measuring virus infectivity. (A) BHK-21 cells were infected at an MOI $=10$ for 1 hour. The cells were washed two times to remove any unbound virus and the supernatants were collected over 16 hours and used in a standard plaque assay to determine the titer at various times post infection. (B) The titers at 16 hours from three individual experiments were averaged and expressed PFU/ml. (C) Virus purified from the supernatant of the infections in (B) were analyzed by SDS-PAGE and the gel was stained with Coomassie to visualize viral proteins released from cells after 16 hours. 


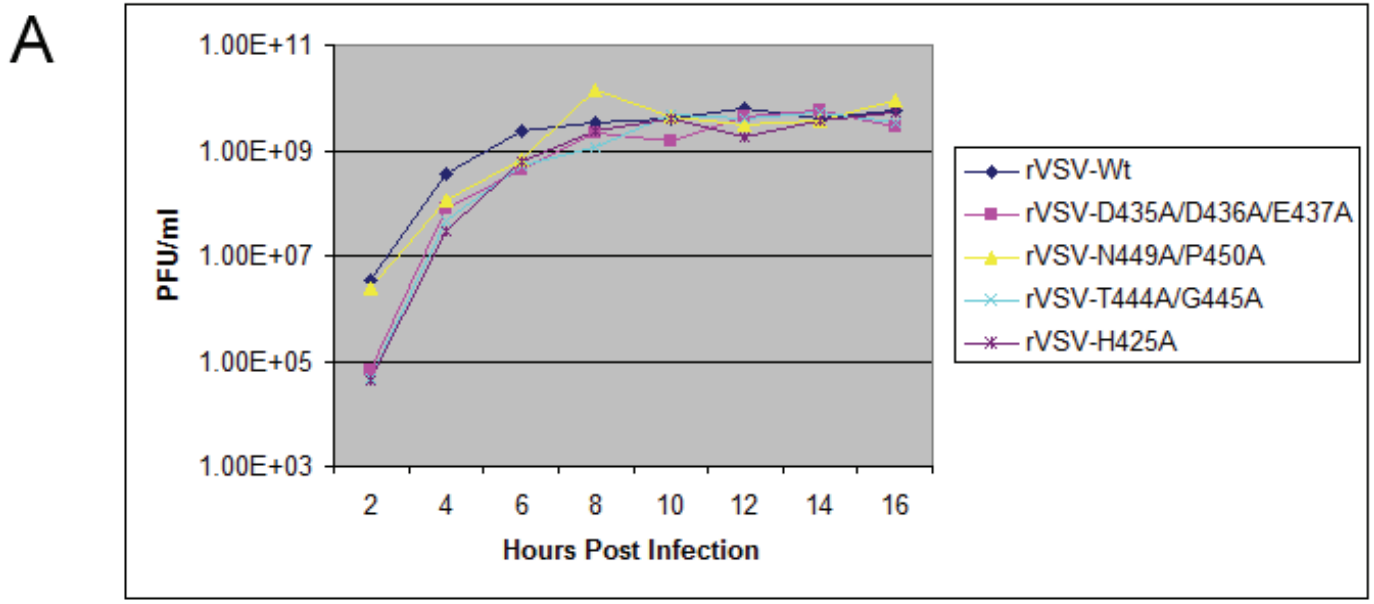

B
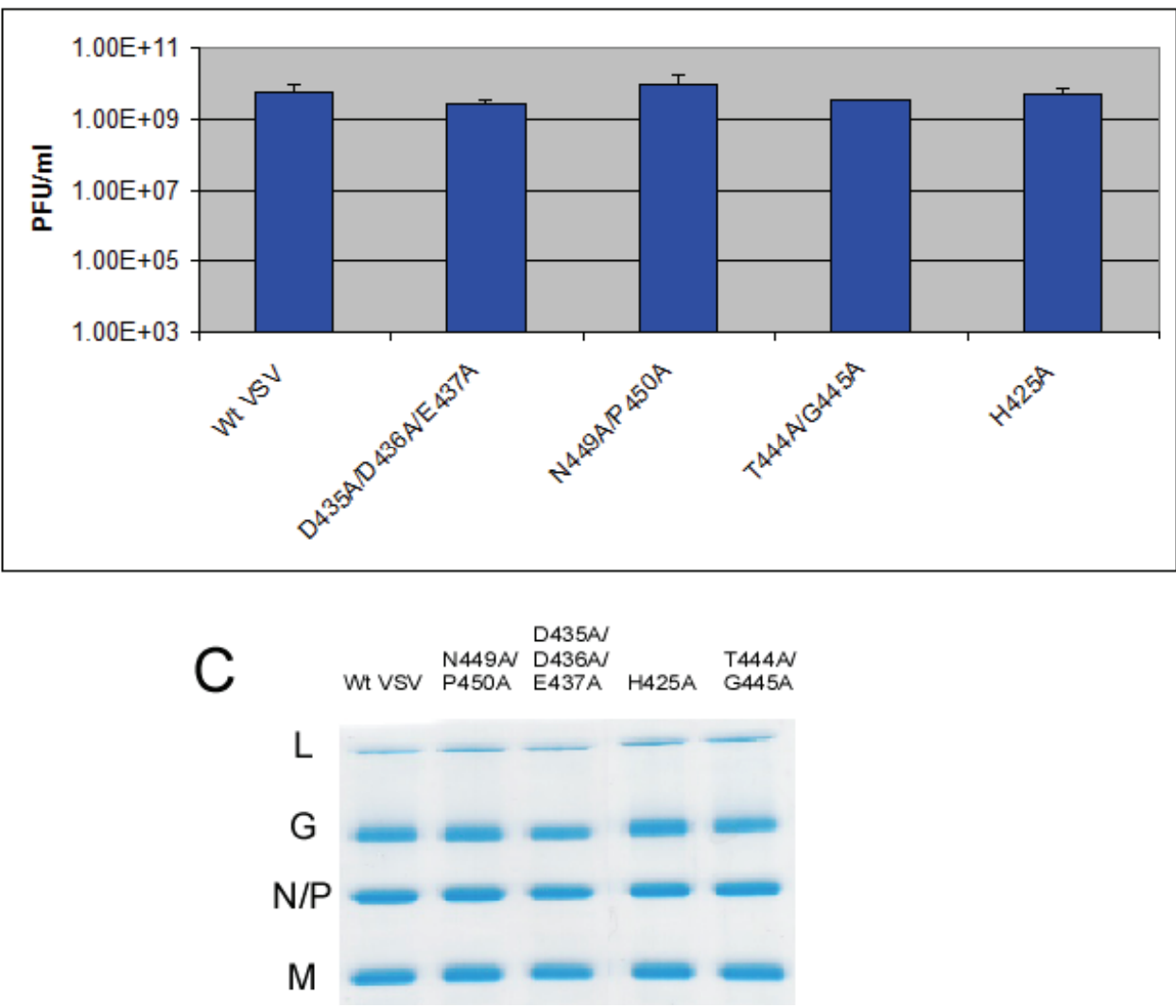
expected based on the one-step growth curve, similar amounts of virus were released compared to wild type and the amount of $\mathrm{G}$ protein incorporated appeared to be similar to wild type virus (Fig 3-7B and 3-7C).

To further assess the replication capacity of viruses encoding the mutated $G$ proteins, plaque sizes from a standard plaque assay were examined by staining with the monoclonal antibody, I1, which is directed to G. All of the plaque sizes were comparable to those of wild type VSV, with only the T44A/G445A mutant being slightly reduced (Fig 3-8). These data confirm what was seen in the one-step growth curve, indicating that the mutations did not affect the growth or spread of the virus at late time points post infection. Since the recombinant VSV encoding the G protein with the T444A/G445A mutation reached wild type titers the reduced plaque does not likely indicate a growth defect. Interestingly, the plaque assay further confirmed the results seen in the standard growth curve indicating the D435A/D436A/E437A mutant grew and spread like wild type. These results were surprising based on the decrease in $\mathrm{pH}$ required to trigger cellcell fusion in transiently transfected cells.

Surface Expression and Fusion in Virally Infected Cells. A previous report showed that some viruses encoding $G$ proteins with minimal fusion capacity in transient transfection assays can still be infectious in the context of virus infection (Cross, Wharton et al. 2001; Jeetendra, Ghosh et al. 2003). These results were explained by suggesting that a small fusion pore is able to form, allowing for transfer of the nucleocapsid into the cell but not large enough for polykaryon formation. To examine this possibility, cells were infected with the rVSV mutants, and cell surface expression was measured by flow cytometry at 6 hours post infection using a monoclonal G antibody (Fig 3-9). Surface expression of the mutated $\mathrm{G}$ proteins was similar to that of wild type. Also, a fusion assay was conducted at the same time point post infection (6 hours) in which the cells were treated with fusion media buffered to $\mathrm{pH}$ 6.1, or 5.8. As expected the H425A mutant and the N449A/P450A mutant showed wild type or greater fusion levels (Fig 310). Unexpectedly, the D435A/D436A/E437A mutant also fused like wild type in the viral cell-cell fusion assay.

Presence of Cleaved G on the Recombinant VSV Virion. Since the phenotypes of the D435A/D436A/E437A mutant in experiments involving transiently transfected cells did not correlate with those observed in the context of virus infected cells, I wanted to examine the amount of cleaved $G$ on the virion surface. VSV has been shown to have a population of $\mathrm{G}$ on its virion surface that has been cleaved, leaving the membrane proximal domain, transmembrane domain, and cytoplasmic tail (GS). Experiments have indicated that this truncated $\mathrm{G}$ protein can potentiate the activity of fusion proteins that either are defective or do not fuse on their own (Robison and Whitt 2000; Jeetendra, Robison et al. 2002). Based on these findings, I hypothesized that the difference observed in the transient plasmid-expressed cell-cell fusion assays and the virus infectivity/virus infected cell-cell fusion assay may be due to an enhanced cleavage of D435A/D436A/E437A and the higher level of GS may help to overcome the defects in 
Figure 3-8. Plaques of wt and mutant VSV. (A) Standard plaque assay was performed followed by staining the cells with a $G$ specific monoclonal antibody, I1. Plaques labeled rVSV-wt represent the wild type plaques observed in the same experiment as the panels to the right of the control (B) Relative plaque sizes were determined by photographing plaques using a Zeiss axiophot camera and Axiovision software, enlarging the photographs and measuring the diameter horizontally and vertically. The diameters were averaged and used to calculate the relative area of the plaques. The data represent the average measurements from three separate plaques expressed as a percentage of wild type. 

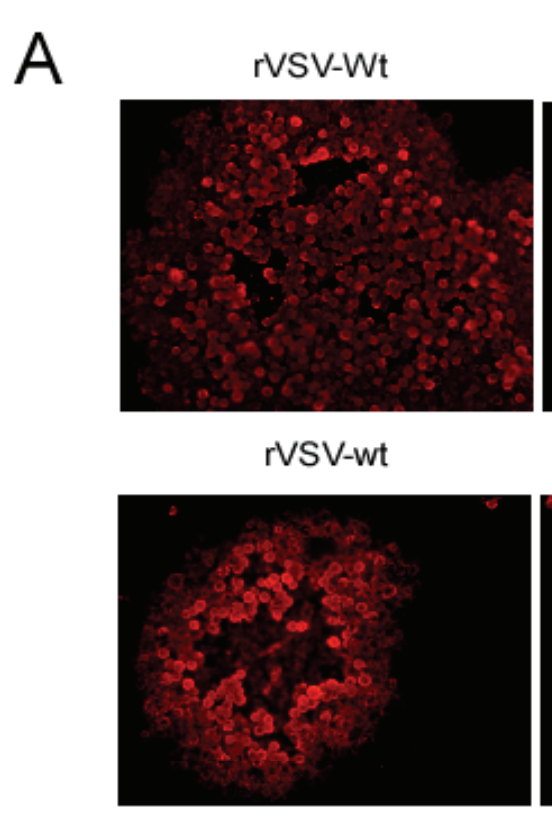

rVSV-

D435A/D436A/E437A

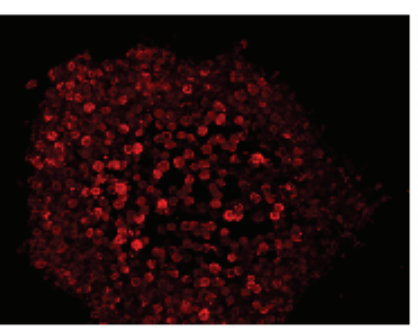

rVSV-H425A

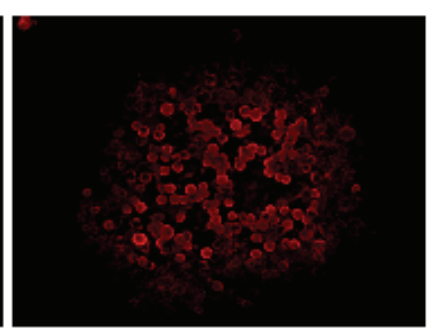

rVSV-T444AVG445A

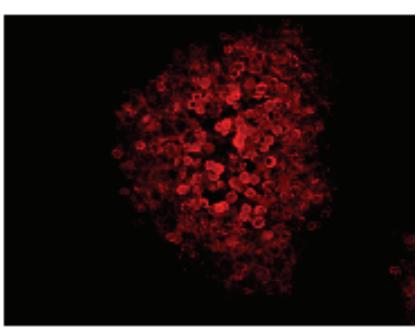

B

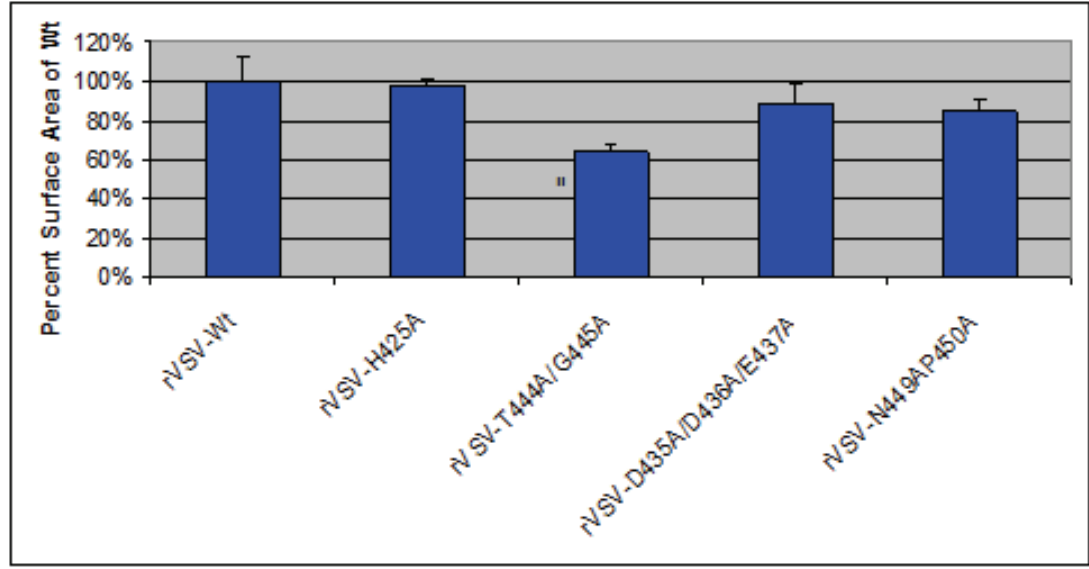




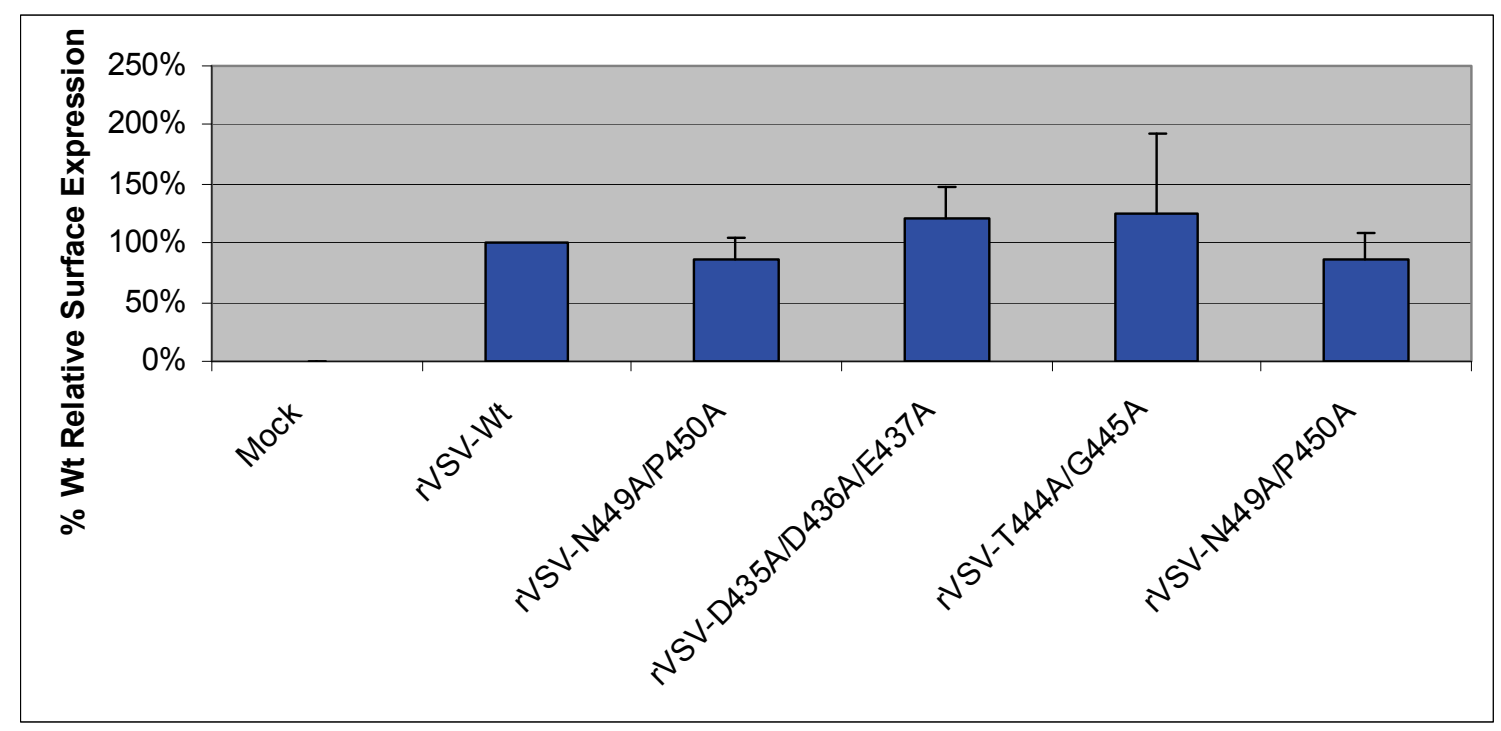

Figure 3-9. Surface expression in virally infected cells. BHK-21 cells were infected at an $\mathrm{MOI}=10$ at $31^{\circ} \mathrm{C}$. After $1 \mathrm{hr}$ the media was replaced with fresh DMEM containing 5\% FBS and the cells were transferred to $37^{\circ} \mathrm{C}$. $6 \mathrm{hrs}$ post infection the cells were fixed and processed for flow cytometry using a $\mathrm{G}$ monoclonal antibody, I1 followed by a secondary antibody conjugated to FITC. Relative surface expression was calculated as described in Fig 3-2. 


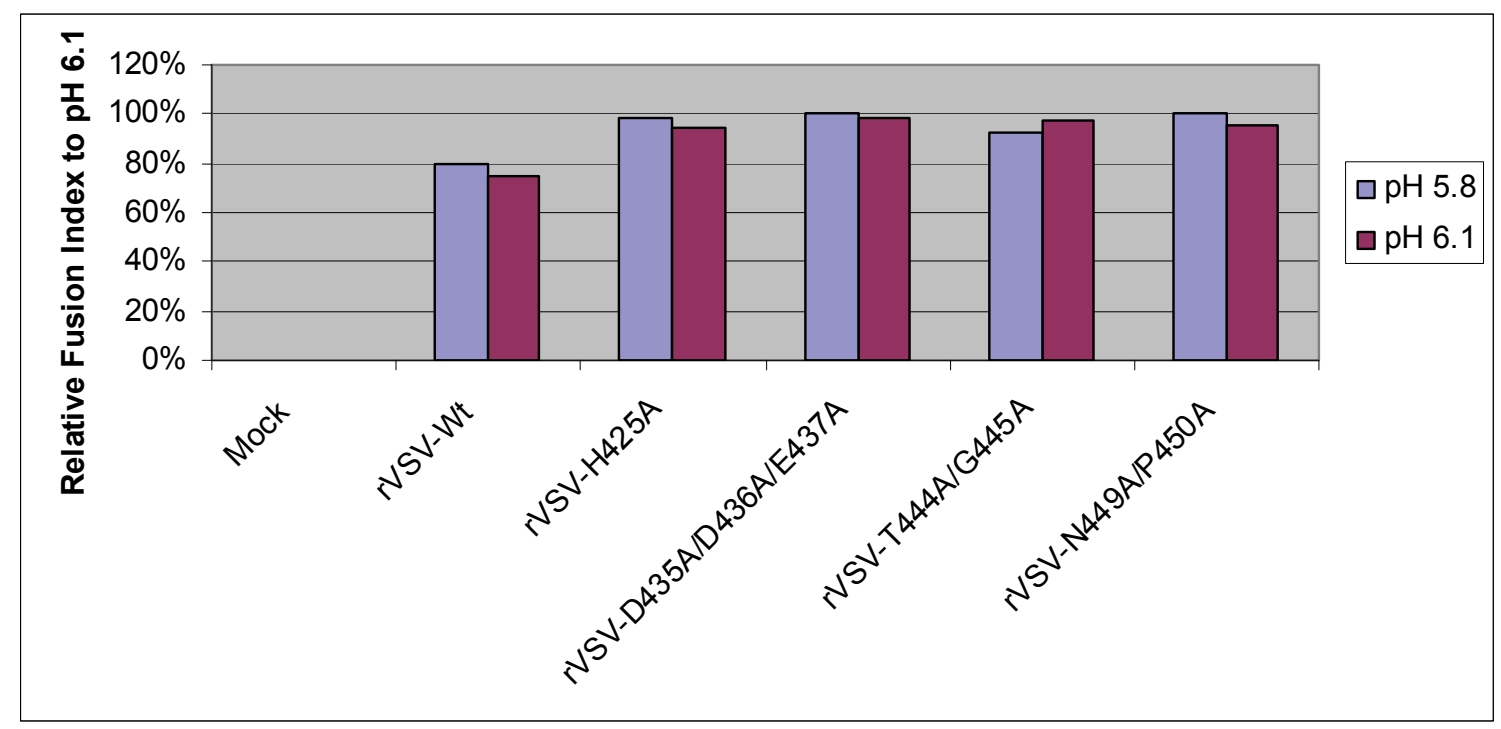

Figure 3-10. Cell-cell fusion in virally infected cells. BHK-21 cells were infected with the indicated virus as described in figure 3-9. At 6 hours post infection, the cells were treated with fusion media buffered to $\mathrm{pH} 7.0,6.1$, or 5.8 for 1 minute at room temperature. The fusion buffer was replaced with DMEM plus 5\% FBS and the cells were incubated at $37^{\circ} \mathrm{C}$ for 30 minutes. Cell-cell fusion was quantitated by counting cells in three separate fields of view and subtracting from the total cell number. Relative fusion index was then calculated by dividing the number of fused cells from the number of unfused cells at $\mathrm{pH}$ 7.0. 
fusion activity. To examine this possibility, purified virus was immunoblotted using an antibody that binds to the cytoplasmic tail (C-tail) of G. As shown in figure 3-11 there was more GS detected in the cells infected with the recombinant VSV encoding the G protein containing the D435A/D436A/E437A mutation. The rest of the viruses containing mutated $\mathrm{G}$ proteins appeared to have similar amounts of GS as was seen with wild type (data not shown).

\section{Discussion}

Determination of crystal structures from VSV G (Roche, Bressanelli et al. 2006; Roche, Rey et al. 2007) and herpes simplex virus gB (Heldwein, Lou et al. 2006) led to classification of a new group of fusion proteins, the class III proteins, as previously mentioned. More recently, the structures of the baculovirus gp64 (Kadlec, Loureiro et al. 2008), and the Epstein-Barr virus gB (Backovic, Longnecker et al. 2009) fusion proteins were solved, revealing structural homology to the herpes gB and VSV G fusion proteins, further supporting the need for a third classification. VSV G is the only class III fusion protein in which both pre- and postfusion structures have been solved. Availability of the structures provides a wealth of information in regard to the structural transitions that take place when the protein is exposed to low $\mathrm{pH}$ in the endosome during viral entry. However, $\mathrm{G}$ protein was cleaved upstream of the membrane-proximal region for successful crystallization, therefore, no structural information exists for this region. Likewise, crystal structures of other fusion proteins have had the same limitation, resulting in the absence of structural data to help understand the contribution of these regions to the fusion event.

We chose to employ a mutational analysis approach in an effort to determine if individual residues within the membrane proximal region of VSV G are needed for membrane fusion. Previous mutational analyses of $\mathrm{G}$ in which large deletions or insertions were made suggested a role for this region in the membrane fusion process (Jeetendra, Ghosh et al. 2003). The large insertions and deletions indicated the size of this region may be important to $\mathrm{G}$ mediated membrane fusion, however did not determine if individual residues may be critical. Sequence alignment of a number of closely related Vesiculoviruses revealed a high level of conservation of the residues in this region (Robison and Whitt 2000) (Fig 3-1). The crystal structure in the post fusion conformation extends to the H407. H407 correlates with the histidine at position 423 that is described in this chapter. The numbering differs between the crystal structure and the work presented here is because the crystal structure numbering represents the G protein with the signal sequence cleaved (16 residues) and the numbering of residues in this chapter includes the signal sequence. H407 (H423) is shown to participate in a salt bridge with an aspartate in the post fusion conformation (D137 in crystal structure). Based on the crystal structures, the authors conclude that the $\mathrm{pH}$ dependent conformational changes are driven by the protonation of specific histidine residues. The direct role of histidines in

$\mathrm{pH}$ dependent conformational changes required for fusion was earlier hypothesized based on chemical modification of various histidine residues in $\mathrm{G}$ protein, resulting in 


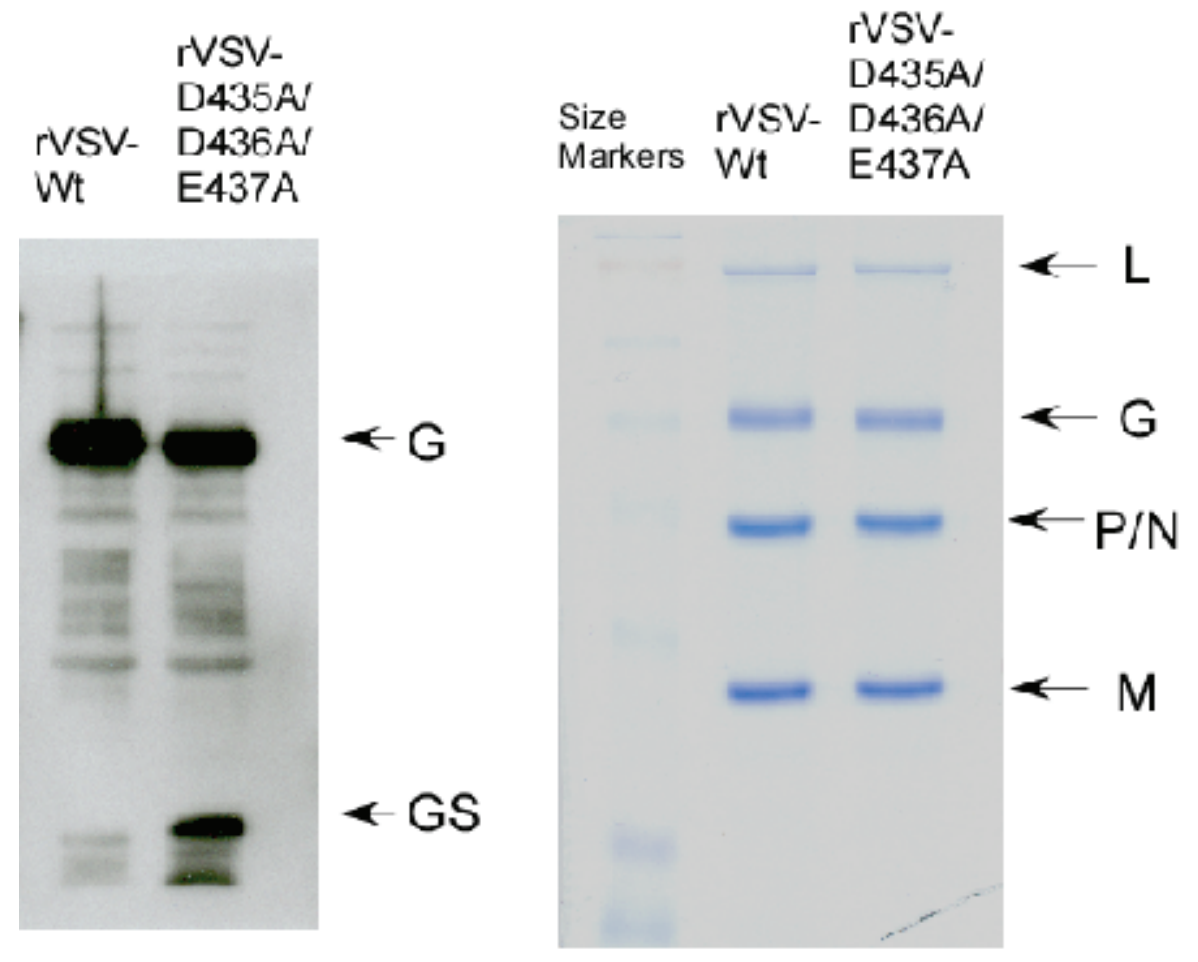

Figure 3-11. Presence of cleaved $G$ protein on the virion. BHK-21 cells were infected with either wild type VSV or rVSV-D435A/D436A/E437A at an MOI=10 for 16 hours then supernatants were analyzed by SDS-PAGE and either treated with Coomassie to visualize amount of virus or immunoblotted using a polyclonal $\mathrm{G}$ antibody specific to the C-tail. 
abolished fusion activity of VSV G (Carneiro, Stauffer et al. 2003). Furthermore, when the chemical modification was reversed, cell-cell fusion capacity was restored. As mentioned previously, VSV G is unique in that the conformational changes that occur when exposed to acidic $\mathrm{pH}$ are completely reversible (Roche and Gaudin 2002). Another interesting feature of this fusion protein is the constant association and dissociation of $\mathrm{G}$ trimers (Lyles, Varela et al. 1990; Zagouras, Ruusala et al. 1991; Zagouras and Rose 1993). Due to these characteristics, G may require specific interactions to stabilize the states needed for the fusion event. The structural data for $\mathrm{G}$ suggests that in the prefusion conformation, the fusion domain and the membrane proximal region interact to stabilize the structure. Exposure to low $\mathrm{pH}$ interrupts these interactions, releasing the fusion peptide and propelling it toward the target membrane. The final conformational changes involve the formation of salt bridges between acidic residues and protonated histidines to help lock $\mathrm{G}$ in the postfusion structure that pulls the two membranes together to allow for membrane fusion (Roche, Bressanelli et al. 2006; Roche, Rey et al. 2007).

The first step in characterization of these mutant $\mathrm{G}$ proteins was to assess their expression levels. H425A, D435A/D436A/E437A, T445A/G446A, and N449A/P450A were all expressed on the cell surface at levels similar to that of wild type. Both the TG motif and the NP motif are completely conserved among the Vesiculoviruses aligned (Fig 3-1), however, it appears these residues are not conserved for their role in proper folding of the protein. $\Delta \mathrm{HPH}, \mathrm{H} 423 \mathrm{~A} / \mathrm{P} 424 \mathrm{~A} / \mathrm{H} 425 \mathrm{~A}, \Delta \mathrm{H} 425, \mathrm{~F} 440 \mathrm{~A} / \mathrm{F} 441 \mathrm{~A}$ were all expressed at levels greatly reduced from that of wild type. These findings suggest that the HPH and FF motifs have critical roles in the proper folding of $G$ for localization to the cell membrane. To examine further the folding of these proteins and the movement through the secretory pathway, an Endo $\mathrm{H}$ analysis was employed. Wild type $\mathrm{G}$ is typically transported to the trans-Golgi apparatus with a half time of 18-20 minutes (Doms, Keller et al. 1987; Balch 1989; Machamer, Doms et al. 1990). The results from the endo H analysis revealed the $\Delta \mathrm{H} 423 / \mathrm{P} 424 / \mathrm{H} 425$ mutant was slower in transport kinetics as compared to wild type $\mathrm{G}$, as was expected based on the reduced expression levels. Interestingly, the $\Delta \mathrm{H} 425$ and $\mathrm{F} 440 \mathrm{~A} / \mathrm{F} 441 \mathrm{~A}$ mutants appeared to acquire resistance to Endo $\mathrm{H}$ digestion at around the same time point as wild type $\mathrm{G}(\sim 30$ minutes $)$ and by 60 minutes were completely resistant to Endo $\mathrm{H}$ digestion, indicating the protein should be expressed on the cell surface at levels similar to wild type G. Expression levels for the $\Delta \mathrm{H} 425$ mutant were observed to be reduced by $\sim 80 \%$ as compared to wild type $\mathrm{G}$ protein, however, the lower level of surface expression did not appear to be due to inefficient transport to the cell surface. Surface expression levels were determined by flow cytometry, using a G specific monoclonal antibody (I1) for detection while in the Endo $\mathrm{H}$ assay, $\mathrm{G}$ was immunoprecipitated using a polyclonal anti-VSV antibody. One possible explanation for the disconnect in surface expression levels and the kinetics of transport observed for these mutant $\mathrm{G}$ proteins is that the I1 antibody epitope becomes partially hidden with a slight misfold in the protein. Less efficient binding of the I1 antibody would cause the data to indicate the expression levels were reduced. However, the Endo $\mathrm{H}$ resistance would not be affected because this experiment uses a polyclonal anti-VSV antibody. To address this possibility, surface expression should also be examined in a biotinylation assay. The kinetics of transport are reduced as compared to wild type for the HPH deletion mutant and H423A/P424A/H425A mutant, while the 
$\Delta \mathrm{H} 425$ and F440A/F441 mutants acquire resistance to Endo $\mathrm{H}$ digestion by 30 minutes as is seen with wild type. Both the $\Delta \mathrm{H} 423 / \mathrm{P} 424 / \mathrm{H} 425$ and $\mathrm{H} 423 \mathrm{~A} / \mathrm{P} 424 \mathrm{~A} / \mathrm{H} 425 \mathrm{~A}$ mutants are more reduced in surface expression than is seen in the $\Delta \mathrm{H} 425$ and $\mathrm{F} 440 \mathrm{~A} / \mathrm{F} 441 \mathrm{~A}$ mutants. Perhaps, these mutants are able to stabilize the prefusion form slightly better than those with the HPH motif deleted or mutated. The $\mathrm{pH}$ in the secretory pathway plays a pivotal role in the efficient posttranslational modifications and processing of proteins (Carnell and Moore 1994). As the proteins progress along this pathway the $\mathrm{pH}$ decreases. In the endoplasmic reticulum the $\mathrm{pH}$ is neutral ( 7.2) (Kim, Johannes et al. 1998; Wu, Grabe et al. 2001). The cis-Golgi has a pH of around 6.7 (Kim, Lingwood et al. 1996) and the $\mathrm{pH}$ decreases to around 6.0 in the trans-Golgi (Seksek, Biwersi et al. 1996; Demaurex, Furuya et al. 1998). Perhaps, if the mutations made to the MPR of the $\mathrm{G}$ protein affected $\mathrm{pH}$ dependent conformational changes the transport to the cell surface was also affected because the proteins could be in a different conformation than the wild type $\mathrm{G}$ proteins as they progress through the increasingly acidic environment within the secretory pathway.

The next step in characterizing the role of the membrane proximal residues in $\mathrm{G}$ was to assess the affects the mutations had on the protein function. Cells transiently expressing either the wild type or mutated proteins were treated with fusion media. The fusion media was buffered to $\mathrm{pH} 7.0,6.0,5.5$, or 5.2. At $\mathrm{pH} 7.0$ the majority of wild type $\mathrm{G}$ protein should be in prefusion conformation and therefore minimal fusion should be observed. When the cells expressing the $\mathrm{G}$ proteins are treated with fusion media at $\mathrm{pH}$ 6.0, extensive cell-cell fusion should be observed in wild type, since the threshold $\mathrm{pH}$ for fusion is around 6.2-6.3. If fusion is observed at this $\mathrm{pH}$ one would expect to see fusion with in the mildly acidic environment of the early endosomes as is observed in wild type $\mathrm{G}$ mediated membrane fusion. Treatment with media at $\mathrm{pH} 5.5$ as well as 5.2 represents the acidic environment found in the late endosomes. An initial screen to identify mutated $\mathrm{G}$ proteins with fusion defects revealed those with mutations to the HPH, FF, and DDE motif were fusion defective at $\mathrm{pH} 6.0$. Interestingly, $\Delta \mathrm{H} 423 / \mathrm{P} 424 / \mathrm{H} 425$ was completely fusion defective, even at $\mathrm{pH} 5.2$ while mutations to the DDE and FF motifs resulted in a reduced $\mathrm{pH}$ threshold for fusion. VSV G typically is believed to mediate fusion in the early endosomes where there is a mildly acidic environment that correlates with the threshold $\mathrm{pH}$ required for fusion which is 6.2-6.3. Since the experiment was not done with smaller increments ( $0.1 \mathrm{pH}$ units) it remains to be seen at exactly what $\mathrm{pH}$ fusion is occurring and therefore, it is not known at exactly what point in the endocytic pathway the RNP is released for these mutated G proteins. However, if fusion is not seen until the $\mathrm{pH}$ reaches 5.5 (Fig 3-4, 3-5) one would expect the viral RNP to be released in to the host cell cytosol from the late endosomes or lysosomes as opposed to the early endosomes.

We hypothesized that the mutated residues in $\mathrm{G}$ that caused a reduced capacity for fusion are likely involved in the structural transitions between the pre- and postfusion conformations. Therefore, we examined the ability of the $\mathrm{G}$ protein to acquire trypsin resistance when exposed to low $\mathrm{pH}$. The experiment revealed that all of the proteins that were defective in fusion or required a lower $\mathrm{pH}$ for fusion were able to undergo $\mathrm{pH}$ dependent conformational changes (as observed for wild type) making them resistant to trypsin digestion (Fig 3-6). From these results I concluded that the mutations affected a 
step in the fusion process after the proteins underwent the low $\mathrm{pH}$ triggered conformational changes. This step is possibly the stabilization of the postfusion conformation. Therefore, the mutated G proteins are able to undergo conformational changes required for fusion but may not maintain this structure long enough to pull the two membranes together for membrane merger and pore formation.

Experiments using recombinant virus expressing the mutated $\mathrm{G}$ proteins revealed an interesting disconnect in data. Mutation of the DDE motif resulted in a reduced $\mathrm{pH}$ threshold for fusion in cells transiently expressing the protein. Previous studies in our lab identified mutants with a reduced $\mathrm{pH}$ threshold for fusion that also showed a reduction in titer as well as plaque size (Fredericksen and Whitt 1998). Based on these previous findings we expected that those viruses expressing the mutated $G$ proteins with a decreased threshold $\mathrm{pH}$ for fusion would grow to lower titers and produce smaller plaques as compared to wild type G. Recombinant VSV encoding D435A/D436A/E437A was recovered and a one-step growth curve was performed. Surprisingly, the data from this experiment indicated the virus was able to grow and spread as well as wild type VSV. The growth curve also revealed another interesting feature. The titers for H425A, D435A/D436A/D437A, T444A/G445A were all over a $\log$ reduced from that of wild type at the two hour time point but by about 7 hours had reached wild type levels. These data indicate the cells were not initially producing as much virus but between the 2 and 7 hour time points, produced much more virus. The viruses with the reduced growth phenotype at two hours possibly are replicating and making more progeny virus, however the virus is unable to bud through the host cell plasma membrane to be released. After 2 hours this block is apparently relieved and the progeny virus that had accumulated in the cell could be released, explaining the steep increase from the 2 to 7 hour time points. Further experiments would need to be done to identify the exact step affected by the mutations.

The next step in characterizing the recombinant viruses expressing the mutated $\mathrm{G}$ proteins was to look at the plaque formation. Once again, we were surprised to see the DDE mutant formed near wild type size plaques. Interestingly the T444A/G445A mutant's plaque size was reduced from that of wild type. This mutant was expressed on the cell surface, had no fusion defect, and grew to wild type titers at 16 hours post infection. To further examine the fusion activity of the mutated $G$ proteins, surface expression and fusion capacity was measured in virally infected cells. Data from all of the viral infections correlated with what was observed in the experiments in which cells were transiently transfected with the exception of the D435A/D436A/E437A mutant. This mutant appeared to have a very different phenotype when transfected into cells versus when cells were infected with virus encoding the mutated $\mathrm{G}$ protein. I hypothesized that $\mathrm{G}$ protein was possibly being cleaved, producing more G-stem (truncated $\mathrm{G}$ protein containing $\mathrm{C}$-terminus, transmembrane domain, and a short ectodomain) on the virion surface.

Previous studies in our lab have shown that the truncated G protein, GS, can potentiate the membrane fusion of glycoproteins that do not normally mediate fusion on their own. Furthermore, use of a three color fusion assay showed that GS can induce 
lipid mixing when expressed alone, but cannot proceed to full fusion (Jeetendra, Robison et al. 2002). Since GS is present on the wild type VSV virion at low levels, we hypothesized that the mutation may have caused a reduction in cell-cell fusion that the virus was able to compensate for in the context of infection by producing more GS on the virion surface.

Based on the hypothesis that acidic residues may form interactions to stabilize $\mathrm{G}$ in the postfusion conformation, we expected to see a reduction or defect in fusion capacity of the D435A/D436A/E437A mutant. In the context of transient transfections, we saw a reduction in fusion, however when the recombinant virus was recovered it grew to wild type levels. GS was detected at seemingly higher levels in the rVSVD435A/D436A/E437A virus in comparison to that of wild type rVSV (Fig 3-11). Efforts to visualize GS levels in cells transfected with the mutant glycoprotein were unsuccessful (data not shown) so we can only suggest possible roles the added GS plays since we are uncertain if there is a population of GS present on the surface of cells transiently expressing D435A/D436A/E437A. The role of GS during VSV infection has yet to be understood. To our knowledge this is the first suggestion that GS has a direct role in efficient entry of the virus. 


\section{Chapter 4: Examination of Variants with Enhanced Growth Phenotypes}

\section{Introduction}

A hallmark feature of RNA viruses is the very high rate of mutations that arise during replication. These high mutation rates can be attributed to the error prone RNA dependent RNA polymerase that is used for replication (Steinhauer, De La Torre et al. 1989; Bilsel and Nichol 1990; Kearney, Donson et al. 1993). RNA viruses make up the largest group of pathogens affecting humans, animals, and plants. Many riboviruses cause severe disease in humans, some of these include; Influenza virus, HIV-1, and Ebola virus. High rates of mutation are believed to be an asset to the viruses as they are better able to adapt to changing environments and become more fit for infection.

Vesicular stomatits virus has been used as a model for evolutionary virology due to its broad tropism, simple genetic organization, and ability to be grown to high titers in cell culture. VSV enters the host cell through receptor mediated endocytosis that is dependent upon $\mathrm{G}$ protein binding to the host cell (Matlin, Reggio et al. 1982). Once the $\mathrm{pH}$ drops in the endosome, $\mathrm{G}$ protein undergoes a reversible conformational change allowing for the bipartite fusion loop to insert into the endosomal membrane (Roche, Bressanelli et al. 2006; Roche, Rey et al. 2007). Further conformational changes result in the two opposing membranes being pulled together causing the initial membrane merger event (hemifusion), stalk formation, and finally formation of a fusion pore in which the viral nucleocapsid can pass through and be released into the host cell cytoplasm. VSV replication occurs once the virus has been released into the host cell cytoplasm. Since VSV does not undergo homologous recombination during replication any base changes that arise during replication occur due to misincorporation of ribonucleoside triphosphates because of the error prone RNA dependent polymerase and the lack of proofreading (Drake 1999; Drake and Holland 1999).

Chapter 3 focused solely on identifying residues within the $\mathrm{G}$ protein membraneproximal region of VSV that are important for membrane fusion. Mutations made to $\mathrm{H} 425(\Delta \mathrm{H} 425)$ and F440/F441, within this region, resulted in recombinant viruses that rapidly acquired second site mutations or changes from the intended mutation. Studies in this chapter were aimed at characterizing the new mutants that arose from passaging the viruses. Two variants were observed in the recovery supernantants from the recombinant virus encoding $\Delta H 425$. The variants were; $\Delta H 425 / \mathrm{I} 426 \mathrm{~S} / \mathrm{S} 438 \mathrm{I}$ and $\Delta \mathrm{H} 425 / \mathrm{S} 438 \mathrm{I}$. The recovery supernatants from recombinant virus encoding F440A/F441A were observed to contain more variants, including; F440V/F441A, F440T/F440A, F440A/F441A/S438I, and F440A/F440A/CT9 (F440A/F440A/CT9 has a cytoplasmic tail that is truncated to only 9 residues). Experiments conducted, in chapter 3 , using transient transfections resulted in a decreased level of surface expression and a reduced $\mathrm{pH}$ threshold for fusion for the $\Delta \mathrm{H} 425$ and F440A/F441A mutants (fusion was observed at $\mathrm{pH} 5.5$ but not 6.0). Therefore the work presented in this chapter characterizes the variants that arose during passage to identify further residues that may play a role in the efficient entry and spread of VSV. 


\section{Results}

Identification of Rapidly Acquired Mutations. In chapter 3, G proteins with $\Delta \mathrm{H} 423$ or F440A/F441A mutations revealed interesting fusion phenotypes in that a reduction in the $\mathrm{pH}$ threshold for fusion was observed. Reverse genetics with G-complementation was used to recover recombinant VSV encoding G proteins containing these mutations. Since the cell-cell fusion assays indicated these viruses may have a reduced capacity to enter cells due the shift in the $\mathrm{pH}$ threshold required for membrane fusion activity, the recombinant viruses were generated using $\mathrm{G}$ complementation to help ensure a successful recovery. Passage on cells not expressing wild type G protein then should produce VSV with only the desired mutant $\mathrm{G}$ protein embedded in the envelope. In chapter 3, when the plasmids encoding the mutated $\mathrm{G}$ proteins were transfected into cells and treated with fusion media buffered to various $\mathrm{pH}$ values, fusion was not observed at $\mathrm{pH} 6.0$ but was seen at $\mathrm{pH} 5.5$ and $\mathrm{pH}$ 5.2. As expected, fusion activity was observed in cells expressing wild type $\mathrm{G}$ at $\mathrm{pH}$ 6.0. Since fusion was observed in the transiently transfected cells we expected to recover virus that was infectious, but that perhaps would grow to lower titers than wild type G. Prior studies have shown mutations in $\mathrm{G}$ that caused a reduction in the $\mathrm{pH}$ required to induce membrane fusion resulted in virus that grew to lower titers than wild type VSV (Fredericksen and Whitt 1998). Once the viruses were recovered, they were passaged on BHK-21 cells without G complementation (using $100 \mu 1$, or $5 \%$ of the recovery supernatant) to produce virus with the mutated $\mathrm{G}$ on the virion surface (P1). Supernatant from this infection was then titered using a standard plaque assay and then a single plaque was selected and resuspended in $500 \mu 1$ of DMEM $+5 \%$ FBS to obtain a plaque isolate $(\mathrm{P} 2)$. Supernatant from the plaque isolate $(\mathrm{P} 2)$ was amplified by another passage on BHK-21 cells (using $200 \mu \mathrm{l}$ ) to generate the P3 stock. Finally after a total of 3 passages on cells without $\mathrm{G}$ complementation a working stock of the virus was generated by infecting at an MOI $=0.1(\mathrm{P} 4)$. The $\mathrm{P} 4$ stock of recombinant VSV encoding $\mathrm{G}$ with the $\Delta \mathrm{H} 425$ mutation grew to a very low titer $\left(\sim 6 \times 10^{6} \mathrm{PFU} / \mathrm{ml}\right)$. When growing up additional stocks of the virus I used the P3 working stock to generate a new working stock (and each successive passage after, for additional stocks), producing later passages of the virus. Later stocks of the virus (P5 and P6) grew to significantly higher titers $(\sim 2 \mathrm{x}$ $10^{7}$ and $2 \times 10^{9}$, respectively). These findings contrast with what was observed in the recombinant viruses encoding mutant $\mathrm{G}$ proteins that displayed efficient cell-cell fusion activity. For those mutants (T444A/G445A and N449A/P450A), the titers from the early stocks were near wild type level $\left(\sim 1 \times 10^{9} \mathrm{PFU} / \mathrm{ml}\right)$. The plaque sizes observed from the initial recovery supernatant (for both $\Delta \mathrm{H} 425$ and F440A/F441A) were also significantly smaller than those observed after the virus had been passaged several times (data not shown).

To ensure the P4 working stocks of the viruses contained $\mathrm{G}$ proteins with only the desired mutations, BHK-21 cells were infected at an MOI $=1$ for 6 hours using virus from the working stock (P4), RNA was extracted from the cells, reverse transcribed, and PCR amplified using a sense primer upstream of the KpnI site and a nonsense primer in the 3'UTR of G. The resulting cDNA was used to sequence the G gene and surprisingly, revealed additional mutations that were not originally present in the plasmids used for 
recovery. The $\mathrm{P} 4$ stock of $\Delta \mathrm{H} 425$ had acquired two additional mutations, I426S and S438I. Interestingly, virus stock recovered using plasmid encoding F440A/F441 A revealed a F440V/F441A mutation. The original plasmids used in recovery of the recombinant VSVs encoding the mutated G proteins were re-sequenced confirming that only the original constructed mutations were present.

Isolation of Plaques to Identify Additional Mutants. Based on the initial observations of additional mutations arising in the recombinant VSV encoding the mutated G proteins, I decided to isolate multiple plaques from the original rVSV- $\Delta \mathrm{H} 425$ and rVSVF440A/F441A recovery supernatants using a standard plaque assay. Approximately 24 hours post infection 10 plaques of various sizes were isolated by using a Pasteur pipette and being careful to only obtain one plaque at a time. Plaques of various sizes were chosen in an effort to select for possible variants that grew and spread at different rates. As described, the plaque isolate was re-suspended in 500 $\mu 1$ of DMEM containing 5\% FBS. BHK-21 cells were infected with supernatant from the plaque isolate re-suspension and RNA extracted from the cells. The viral RNA was reverse transcribed and PCR amplified using the coding primer, MW36, and the non-coding primer 3464 (Table 2-1) (Fig 4-1). The entire G gene was sequenced, showing that no additional mutations arose outside of the membrane-proximal region. Alignment of these sequences with those from wild type $\mathrm{G}_{\mathrm{IND}}$ revealed a mixed population of viruses from the original recovery supernatant (Fig 4-2). The recombinant VSV that was originally cloned to express a G protein containing only the $\Delta H 425$ mutation yielded virus with the intended mutation, but there was also virus expressing $\mathrm{G}$ containing an additional amino acid change at position 438 (serine to isoleucine). None of the plaque isolates observed in this particular experiment contained a $\mathrm{G}$ protein with the double site mutation at I426 and S438 $(\Delta \mathrm{H} 425 / \mathrm{I} 426 \mathrm{~S} / \mathrm{S} 438 \mathrm{I})$. This mutant $\mathrm{G}$ was only observed when the initial recovery supernatant had been passaged 4 times in the production of working viral stocks. Since this mutant was observed in the working stocks that had been passaged more times than the plaque isolates the additional I426S mutation likely arose in passaging multiple times and this mutant will be included in the studies.

When 10 plaque isolates were sequenced from the recovery supernatant of rVSVF440A/F441A, a larger number of variants were observed. The mutations that arose included; F440V/F441A, F440T/F441A, F440A/F441A/S438I, and F440A/F441A/CT9 (F440A/F441A/CT9 acquired a stop codon in the C-tail that resulted in a tail with only 9 residues). Interestingly none of the plaque isolates contained $\mathrm{G}$ proteins with the original intended mutation, F440A/F441A, that was present in the plasmid used for recovery of the virus.

Standard Plaque Assay. One means by which to assess the ability of a mutated virus to grow and spread efficiently is through the use of a standard plaque assay. Figure 4-3 shows representative plaques for each of the mutant viruses that are stained with the $G$ 
Figure 4-1. Selection of plaque isolates. Initial recovery supernatants from viruses encoding $\Delta \mathrm{H} 425$ and F440A/F441A were titered using a standard plaque assay. $24 \mathrm{hrs}$ post infection, plaques of various sizes were picked and resuspended in $0.5 \mathrm{ml}$ DMEM containing $5 \%$ FBS. Virus in $0.2 \mathrm{ml}$ of the eluted plaque isolate was used to infect $\sim 5 \mathrm{x}$ $10^{5}$ BHK cells and RNA was extracted from cells at 6 hours post infection, reverse transcribed, and PCR amplified. The resulting cDNA was then sequenced (University of Tennessee Health Science Center Molecular Resource Center). Alternately, an aliquot of the eluted plaque isolate was titered on BHK-21 cells and used to infect a $10 \mathrm{~cm}$ plate at an $\mathrm{MOI}=0.1$ to grow up a working stock. RNA was extracted from the cells used to grow up the working stock, reverse transcribed, and PCR amplified. 

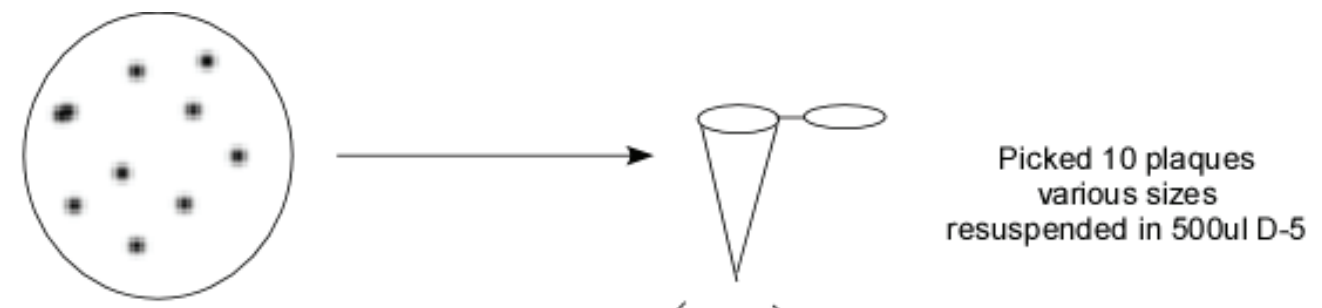

Standard plaque Assay (BHK-21 cells)
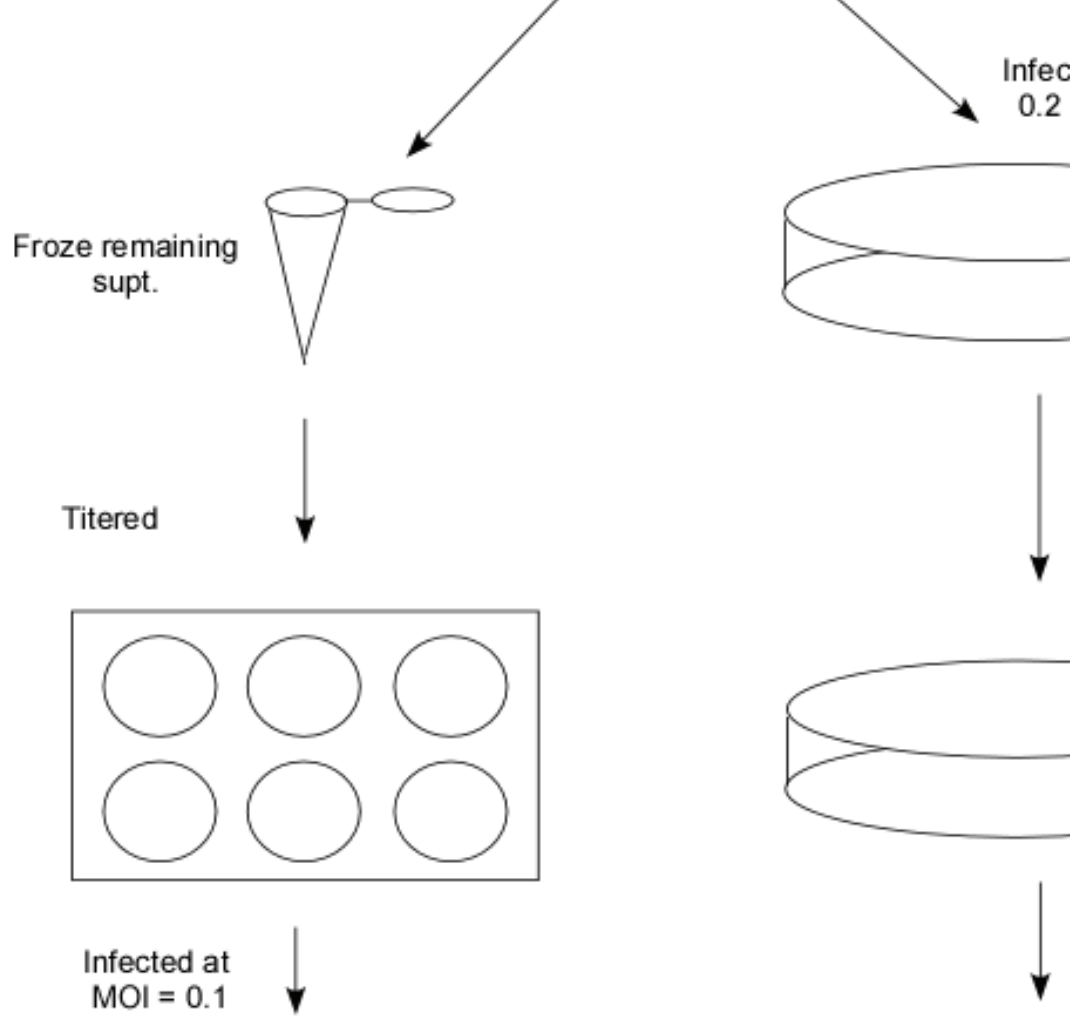

Infect BHK-21 cells

$0.2 \mathrm{ml}$ for $\sim 6 \mathrm{hrs}$
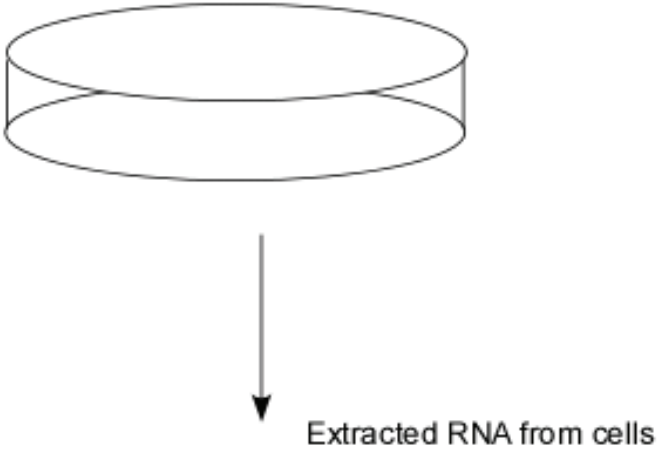

$\mathrm{MOI}=0.1 \quad \forall$
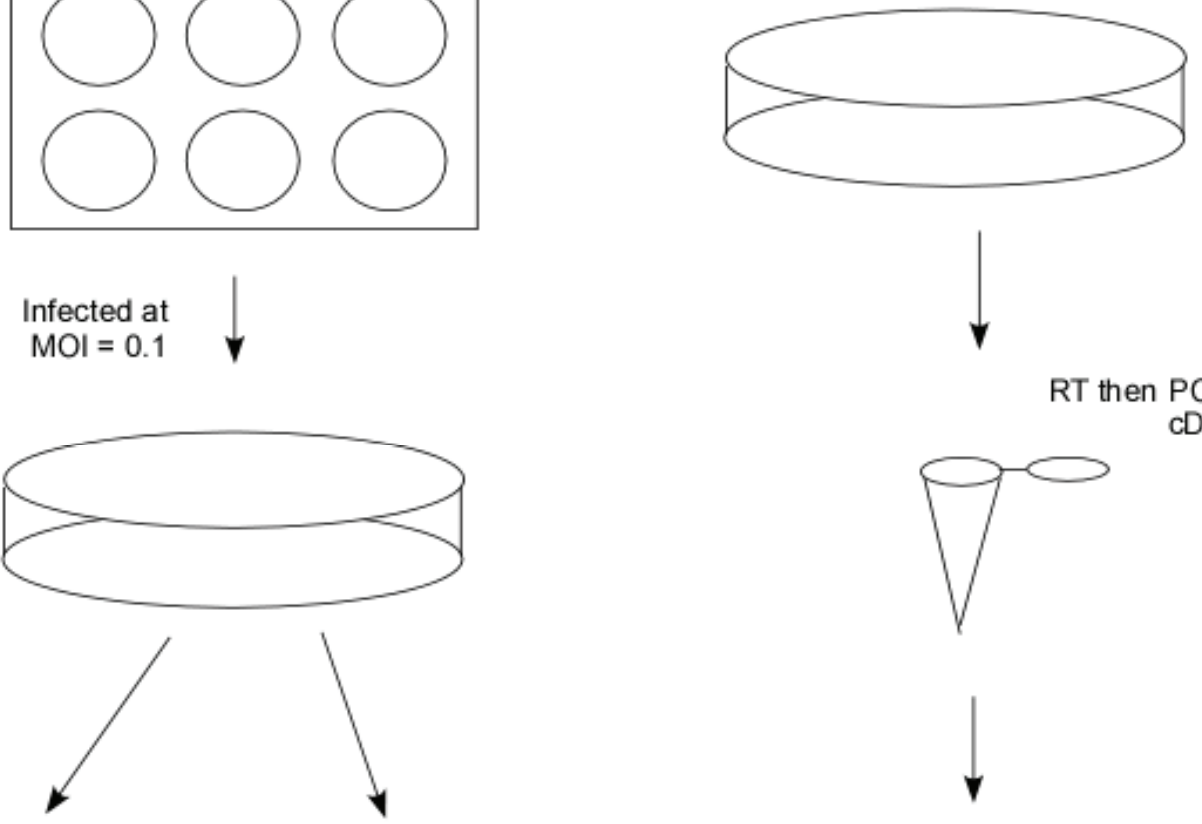

Titered working stock

extracted RNA

RT then

PCR Amplified

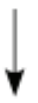

Sent cDNA

for sequencing 


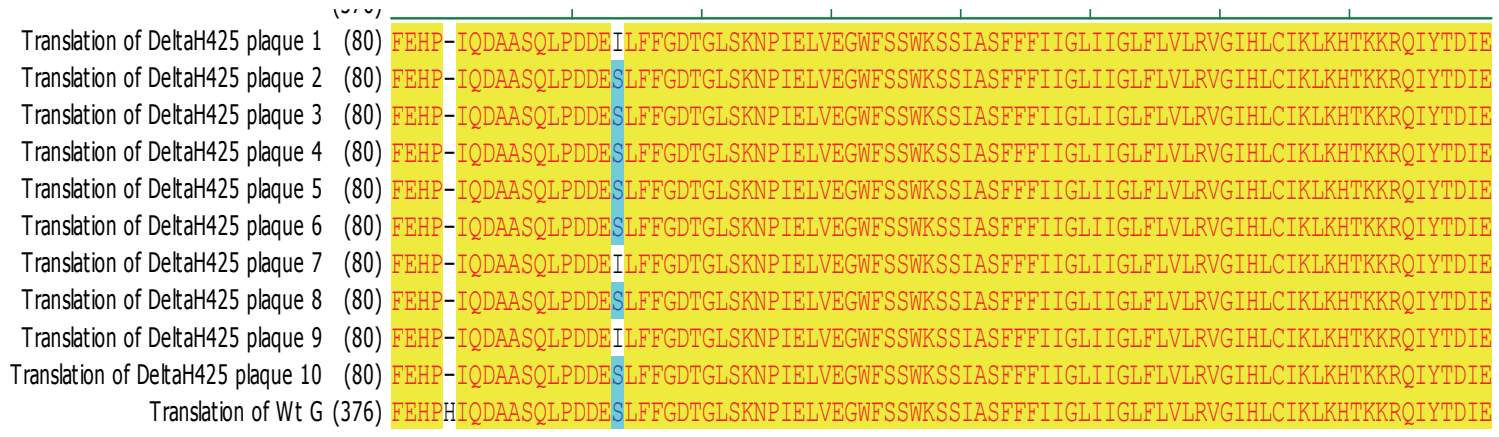

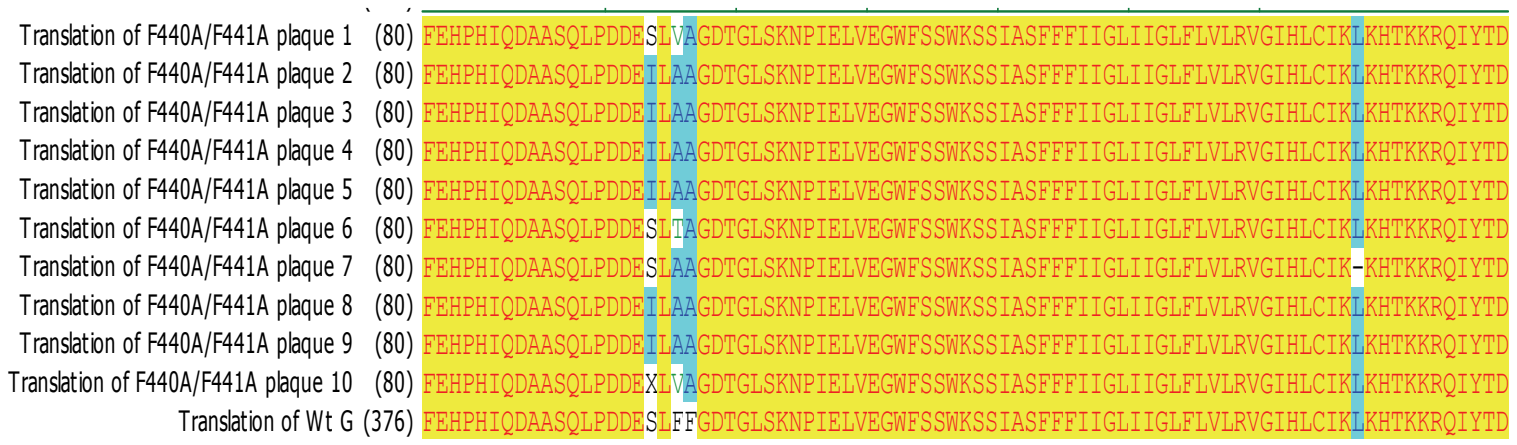

Figure 4-2. Sequence alignments of plaque isolates. Unpassaged supernatants from a recovery of rVSV encoding $\mathrm{G}$ containing $\Delta \mathrm{H} 425$ and F440A/F441A, respectively, were titered using a standard plaque assay. Approximately $24 \mathrm{hrs}$ post infection 10 plaques from each plaque assay were removed using a Pasteur pipette, resuspended in DMEM containing 5\% FBS and the eluted virus (plaque isolate) was used to infect BHK cells. RNA was extracted from the cells, reverse transcribed, the membrane-proximal region, transmembrane, and cytoplasmic tail were PCR amplified and the resulting cDNA was used for sequencing 


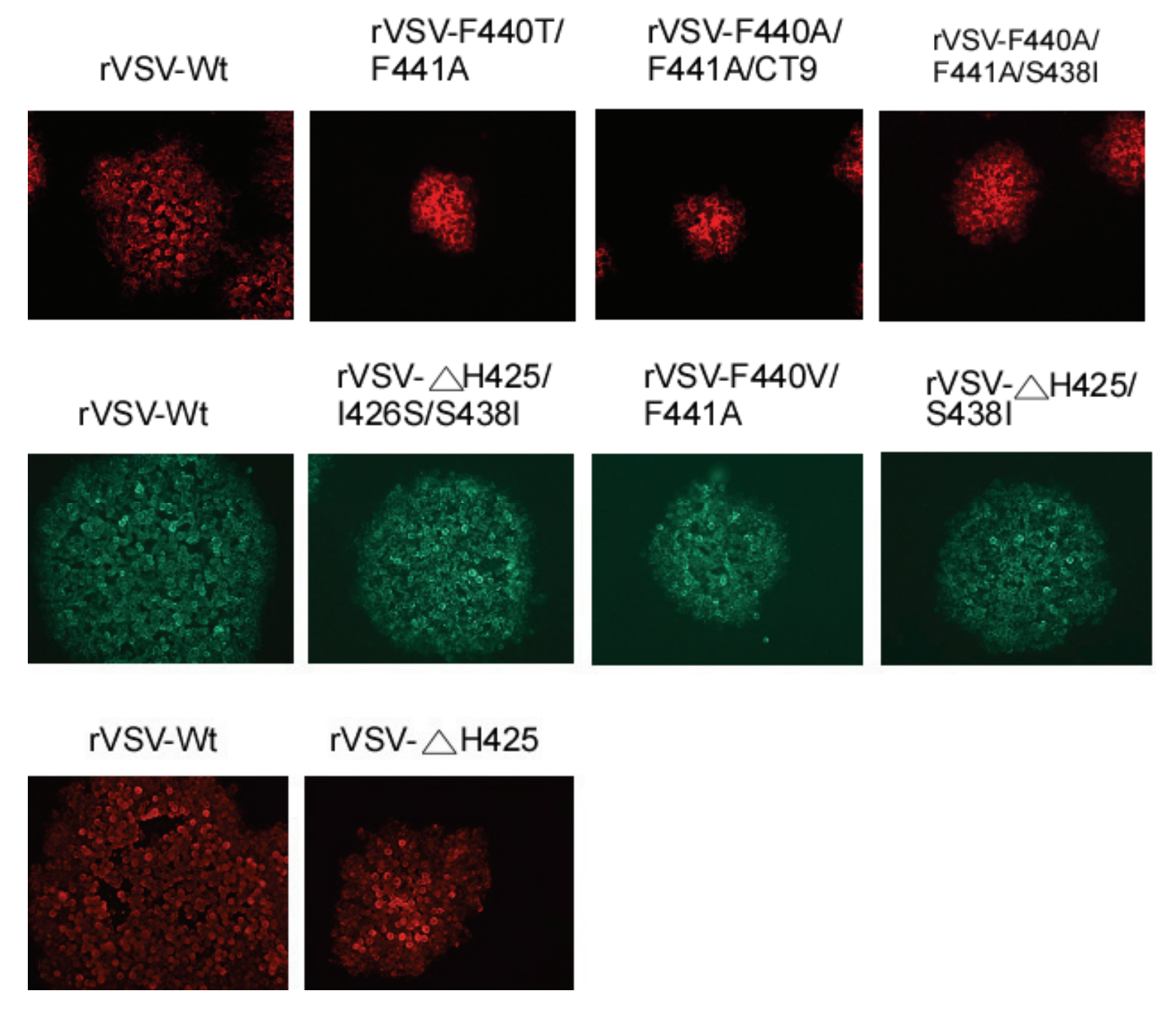

Figure 4-3. Plaque sizes. Representative plaques are shown from plaque assays in which the cells were infected with viruses containing $G$ mutations as indicated. Three separate experiments were done with wild type controls from each experiment shown. Approximately $36 \mathrm{hrs}$ post infection plaques were stained with I1 monoclonal antibody followed by a fluorescently conjugated secondary antibody. 
specific monoclonal antibody, I1, followed by a fluorescently conjugated secondary antibody. Three panels showing wild type VSV plaques are shown. Three separate experiments were done so the three wild type panels the positive control for each experiment. The sizes of the wild type plaques vary in part due to the confluency of the cells that are infected. If a plate is less confluent, a larger plaque would likely be observed whereas when the cells are highly confluent and touching one another the plaques generally appear smaller. Similar amounts of cells were used each of the plates for an experiment (but may vary between experiments). The plaque sizes of the F440T/F441A, F440A/F441A/CT9, F440V/F441A, and $\Delta$ H425 mutant virus infections were greatly reduced in size from the wild type control. Interestingly, F440A/F441A/ S438I, $\Delta \mathrm{H} 425 / \mathrm{I} 426 \mathrm{~S} / \mathrm{S} 438 \mathrm{I}$, and $\Delta \mathrm{H} 425 / \mathrm{S} 438 \mathrm{I}$ plaques were all near the same size as wild type plaques. Since the mutations arose upon passaging the virus very few times we could not be sure that during these experiments further mutations were not arising. Therefore, the rest of the characterization of these mutants will be done using cells transiently expressing the protein instead of virus infection.

Surface Expression in Transiently Transfected Cells. The first step in identification of possible advantages variants may have gained, enabling outgrowth of the mutant parent virus, was to examine the surface expression of these mutant $\mathrm{G}$ proteins using transient transfection assays. First, the mutant $\mathrm{G}$ proteins were sub-cloned into $\mathrm{pCAAGS}-\mathrm{G}_{\mathrm{IND}}$ expression vectors. This was done by extracting viral RNA from infected cells, reverse transcription, and then the region containing the mutations was amplified using MW36 and 3464 (as previously described). The amplicon was digested with KpnI and NheI restriction enzymes and subcloned into a pCAGGS-G IND $_{\text {plasmid digested with the same }}$ enzymes. The plasmids were sequenced to ensure no unexpected mutations arose during PCR amplification.

Since the original constructed mutations resulted in a reduced level of surface expression (Fig 3-2), I wanted to determine if the additional mutations arose to compensate for the reduced cell surface expression. All of the mutants were expressed as well or better than wild type $\mathrm{G}_{\mathrm{IND}}$ with the exception of the F440A/F441A/CT9 mutant, which was expressed less than $20 \%$ that of wild type (Fig 4-4). This result was not surprising since previous studies with a mutant $\mathrm{G}$ protein containing only 9 residues in the C-tail showed cell surface expression levels approximately $38 \%$ that of wild type $\mathrm{G}$ (Whitt et al 1989). These results indicated that the additional mutations that arose, with the exception of F440A/F441A/CT9, enhanced surface expression of the mutated G proteins.

Cell-Cell Fusion in Transiently Transfected Cells. The next step in potentially understanding the means by which the mutations acquired during passaging of the virus overcame growth defects was to examine cell-cell fusion capacity. A syncytium formation assay was used to compare the cell-cell fusion activity of the mutants with that of wild type G. Since the cell-cell fusion assays in BHK-21 cells transiently expressing G proteins containing F440A/F441A and $\Delta \mathrm{H} 425$ mutations indicated the threshold $\mathrm{pH}$ for 


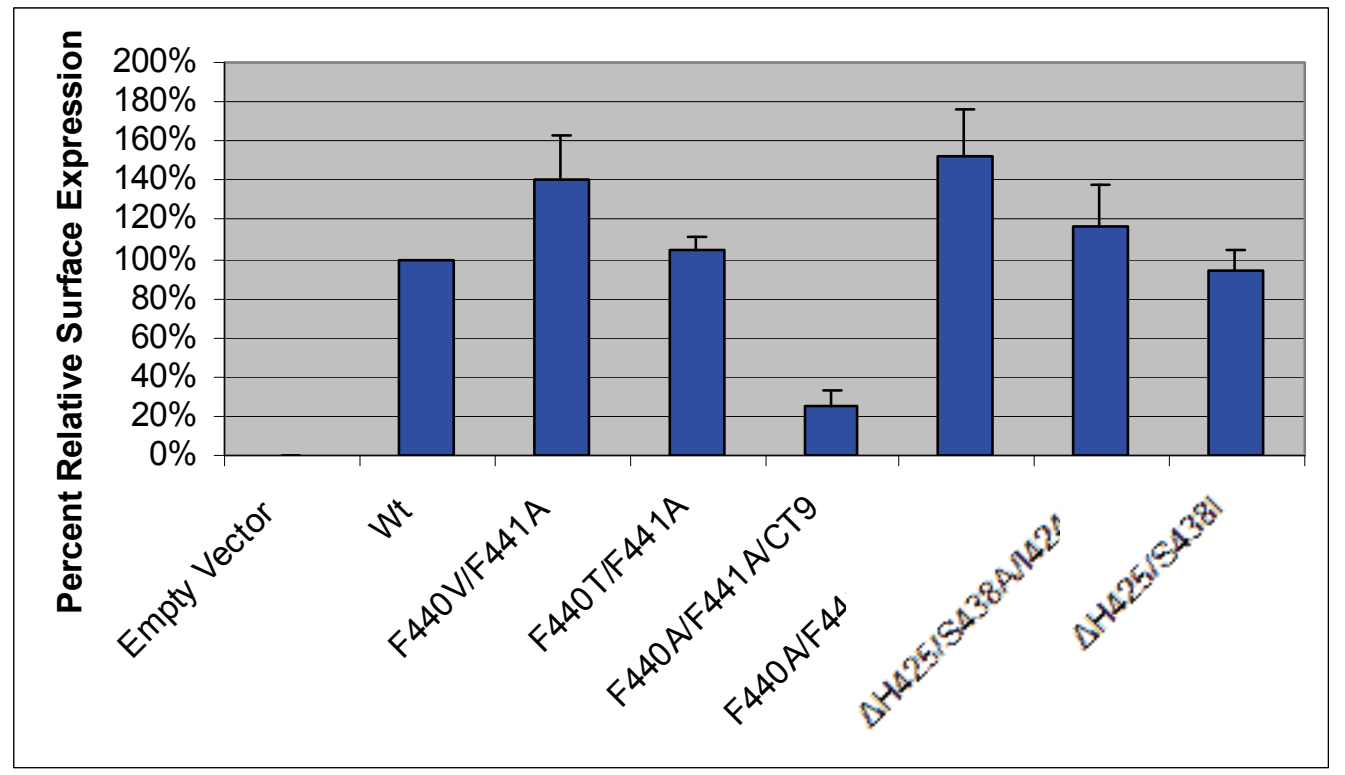

Figure 4-4. Surface expression in transiently transfected cells. Surface expression was measured by flow cytometry of cells transiently transfected with plasmids encoding the appropriate $\mathrm{G}$ mutant. Cells were fixed approximately 24 hours post transfection and stained using I1 G monoclonal antibody and a secondary antibody conjugated to FITC. 
fusion was reduced to below 6.0, I wanted to see if the additional mutations were able to overcome this shift. To ensure that the mutated $\mathrm{G}$ proteins were expressed at levels greater than or equal to that of wild type G protein, I transfected cells using less plasmid cDNA encoding wild type than the mutant $G$ proteins $(2 / 5$ the amount of $\mathrm{Wt} G$ as mutant $\mathrm{G}$ cDNA). The F440A/F441A/CT9 mutant was still greatly reduced as compared to wild type G. Unexpectedly, the $\Delta \mathrm{H} 425 / \mathrm{S} 438 \mathrm{I}$ mutant was also expressed only about $50 \%$ that of wild type. However, regardless of the reduced level of surface expression, significant cell-cell fusion could still be observed at pH 5.2 as well as pH 6.0 (Fig 4-5 and 4-6A). F440V/F441A and F440T/F441A both showed no cell-cell fusion at $\mathrm{pH} 6.0$, but when treated at $\mathrm{pH} 5.2$, a high level of fusion was then observed. Interestingly, the $\Delta \mathrm{H} 425$ mutants initially showed a decrease in the $\mathrm{pH}$ threshold for fusion, but when $\Delta \mathrm{H} 425$ acquired the S438I mutation or both S438I and I426S mutations, fusion was induced at pH 6.0 (Fig 4-5 and 4-6A). These data suggest the S438I mutation helps to overcome the requirement for a lower $\mathrm{pH}$ for fusion that results from either the $\Delta \mathrm{H} 425$ or F441A/F441A mutations.

\section{Discussion}

Vesicular stomatitis virus has widely been used to study viral evolution due to the rapid rate at which the virus acquires mutations during replication. RNA viruses have a very high mutation rate that is attributed to the error prone RNA dependent RNA polymerase. The mutation rates in RNA viruses have been found to be one mutation per genome per round of replication (Drake 1999). Since mutations are constantly arising, RNA virus populations are very heterogeneous. This heterogeneity among the viral populations (in particular RNA viruses) is referred to as "quasispecies". A rapid rate of mutation among RNA viruses likely enables the viruses to become more fit for infection in a constantly changing environment.

Studies have been aimed at determining the ability viruses to express foreign genes though multiple rounds of infection without mutations arising. VSV has served as an attractive candidate for gene therapy and therefore examining the rate of mutation in this virus has proven important. One such study identified the number of passages on cells in which VSV encoding CD4 could maintain CD4 expression without mutations arising within this gene. Experiments indicated that VSV expressing CD4 remained stable for 26 passages before a mutation arose that affected expression of the foreign gene (Quinones-Kochs, Schnell et al. 2001). Viruses that were more fit for infection (did not have the foreign gene expressed) outgrew the CD4 expressing population. However when VSV expressed the measles virus F protein in addition to the G protein, the virus showed a loss of $\mathrm{F}$ protein expression after the first passage. The authors hypothesized that the F protein affected some aspect of VSV growth and therefore the virus that was more fit for infection became predominant in the population (Schnell, Buonocore et al. 1996; Quinones-Kochs, Schnell et al. 2001). 
Figure 4-5. Cell-cell fusion activity. $6 \mathrm{~cm}$ plates of BHK-21 cells were transfected using $2 \mu \mathrm{g}$ of plasmid DNA encoding wild type $\mathrm{G}_{\mathrm{IND}}$ or $6 \mu \mathrm{g}$ of plasmid DNA encoding each of the mutated $G$ proteins. 2 hours post transfection the cells were trypsinized and plated onto $4 \times 35 \mathrm{~mm}$ plates. Approximately 24 hours post transfection the cells were rinsed one time and incubated in fusion media buffered to $\mathrm{pH} 7.0,6.0$, or 5.2 for $1 \mathrm{~min}$ at room temperature. The media was then replaced with DMEM containing 5\% FBS for 30 minutes. The cells were then photographed using a Zeiss Axiophot camera and Axiophot software. 


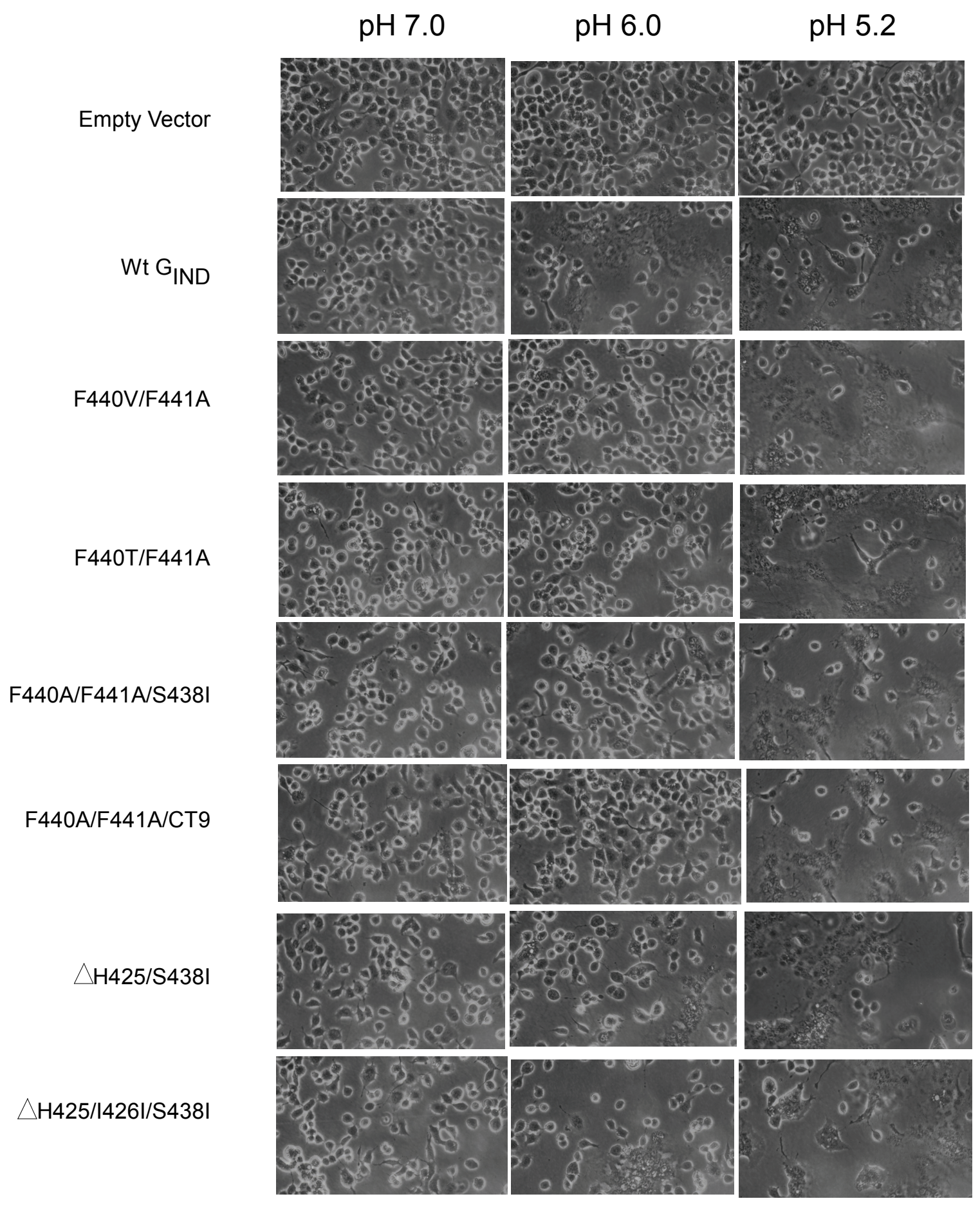


Figure 4-6. Quantitation of cell-cell fusion activity. (A) Cell-cell fusion activity was measured from the experiment in figure 4-5 by counting cells that had not fused in three separate fields of view per plate. Percentages were calculated based on the number of cells fused (in three separate fields of view) as compared with plates treated at neutral $\mathrm{pH}$ (7.0) and normalized to wild type by calculating percent fusion observed. (B) One of the plates from the transfection described in fig 4-5 was used to measure surface expression at $\sim 24 \mathrm{hrs}$ post transfection. Relative surface expression as a percentage of wild type as described in figure 3-5 is shown. 
A

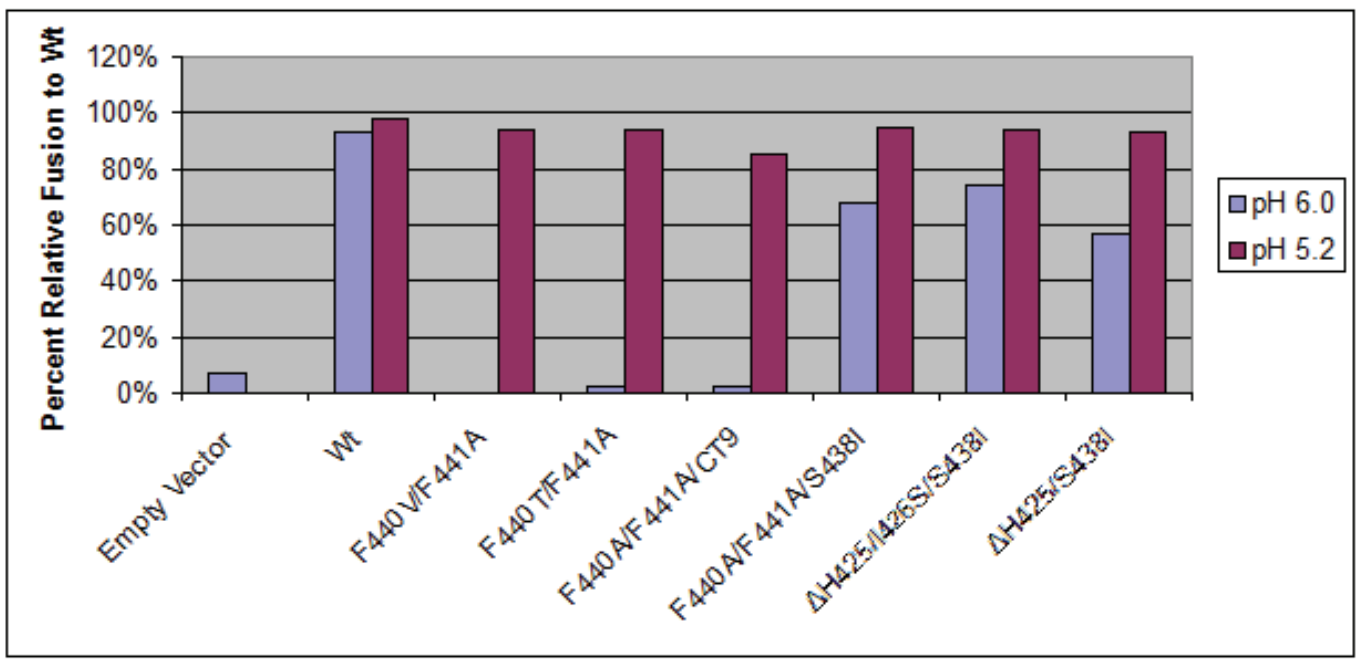

B

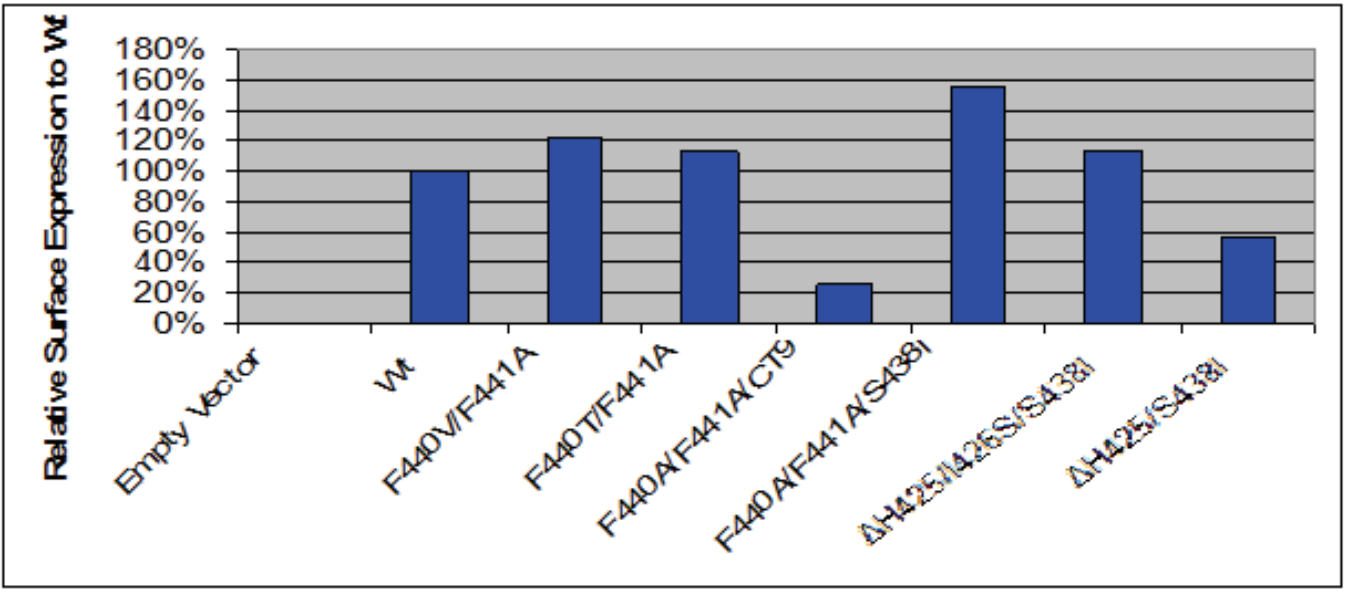


Chapter 3 was aimed at understanding the role of the membrane-proximal region of VSV G through the use of a mutational analysis. Two mutant viruses were recovered that upon passaging on BHK-21 cells began growing to significantly higher titers and forming larger plaques than what was seen from the original recovery supernatant. The $\mathrm{G}$ proteins expressed on these viruses acquired additional mutations from those originally constructed. Since mutations rapidly arose in these viruses I wanted to determine what enabled the viruses to grow and spread more readily than the original mutants $(\Delta \mathrm{H} 425$ and $\mathrm{F} 440 \mathrm{~A} / \mathrm{F} 441 \mathrm{~A}$ ). Both $\Delta \mathrm{H} 425$ and $\mathrm{F} 440 \mathrm{~A} / \mathrm{F} 441 \mathrm{~A}$ were reduced in cell surface expression and had a lower $\mathrm{pH}$ threshold for fusion (Fig 3-2, 3-4, 3-5) and therefore, I hypothesized that the additional mutations enabled the virus to overcome these defects, allowing for more efficient growth and spread.

Through the use of a standard plaque assay we were able to identify a number of other mutants within the recovery supernatant. We chose to use these mutants as tools to attempt to understand the importance of the F440, F441, and H426 residues and possibly identify other residues that participate in membrane fusion or play a role in efficient growth and spread of the virus. The mutant viruses that we observed in the respective recovery supernatants were $\Delta \mathrm{H} 425, \Delta \mathrm{H} 425 / \mathrm{S} 438 \mathrm{I}$ (also obtained from passage P5, $\Delta \mathrm{H} 425 / \mathrm{I} 426 \mathrm{~S} / \mathrm{S} 438 \mathrm{I}), \mathrm{F} 440 \mathrm{~V} / \mathrm{F} 441 \mathrm{~A}, \mathrm{~F} 440 \mathrm{~T} / \mathrm{F} 441 \mathrm{~A}, \mathrm{~F} 440 \mathrm{~A} / \mathrm{F} 441 \mathrm{~A} / \mathrm{CT}$, and $\mathrm{F} 440 \mathrm{~A} / \mathrm{F} 440 \mathrm{~A} / \mathrm{S} 438 \mathrm{I}$. Interestingly, the S438I mutation was observed in both the $\Delta \mathrm{H} 425$ and $\mathrm{F} 440 \mathrm{~A} / \mathrm{F} 441 \mathrm{~A}$ recovery supernatants indicating that mutation of this residue alone likely helps in overcoming the defects that cause the virus to be less infectious. Also, notably, we did not identify any virus with only the F440A/F441A mutation, which may indicate that these two residues are very important in producing infectious virus. Likewise, additional mutations only arose at position F440 but not F441 possibly suggesting this residue is more critical to successful infection. Experiments using cells transiently expressing the mutant $\mathrm{G}$ proteins were employed to address the role of $\mathrm{H} 425$, F440, and F441 since mutations arise so rapidly in the context of a viral infection.

Further experiments in this chapter revealed that the additional mutations, with the exception of F440A/F441A/CT9, enhanced the cell surface expression of the mutated $\mathrm{G}$ proteins to near wild type levels. Interestingly, previous studies pertaining to the role of the C-tail of VSV G in virus assembly examined truncation mutants in which one of those mutants was a $\mathrm{G}$ protein with a truncated C-tail of only 9 amino acids (CT9) (Whitt 1989). This mutant was also expressed on the surface at significantly reduced levels. Infectivity was measured by the ability of the mutant $\mathrm{G}$ protein to rescue infectivity of the tsO45 mutant that was described in chapter 1. A 10-fold reduction in titer was observed when the CT9 mutant was used to rescue infectivity of tsO45 as opposed to wild type $\mathrm{G}_{\mathrm{IND}}$. The authors conclude that the reduction in surface expression accounts for the reduction in viral titer (Whitt, Chong et al. 1989). The next step in characterization of these mutants was to examine fusion capacity.

Cell-cell fusion experiments revealed that the membrane fusion activity of the $\Delta \mathrm{H} 425 / \mathrm{S} 438 \mathrm{I}$ and $\Delta \mathrm{H} 425 / \mathrm{I} 426 \mathrm{~S} / \mathrm{S} 438 \mathrm{I}$ was restored to near wild type levels at both $\mathrm{pH}$ 6.0 and 5.2. Interestingly, in this experiment, the $\Delta \mathrm{H} 425 / \mathrm{S} 438 \mathrm{I}$ mutant was only expressed at approximately $60 \%$ that of wild type and still was able to fuse at a level 
similar to that of wild type. This finding suggests the level of surface expression is not the primary determinant for efficient fusion of these mutated G proteins. Alternately, the mutation may have produced a $\mathrm{G}$ protein that is a hyperfuser and therefore able to overcome reduced surface expression levels by fusing with greater efficiency. Likewise, the finding may also indicate a level of expression that is sufficient to drive near wild type levels of fusion. Further examination of levels of expression in correlation to fusion activity of $\mathrm{G}$ protein would be necessary to address these possibilities. The F440A/F441A/S438I mutant also showed a restoration in fusion at $\mathrm{pH}$ 6.0. The S438I mutation appears to enable the virus to overcome the decrease in threshold $\mathrm{pH}$ required for fusion to occur. Perhaps the added hydrophbicity of the isoleucine at this position allows for interaction with either the target membrane or the viral membrane during the fusion process, causing destabilization of the membrane and promoting membrane fusion.

Cell-cell fusion activity at $\mathrm{pH} 6.0$ was not observed to be restored in the other mutants examined; F440V/F441A, F440T/F441A, or F440A/F441A/CT9. Since these viruses likely outgrew the F440A/F441A mutant virus, some added benefit appears to have arisen with the additional mutations. Phenyalanine residues are able to interact with other aromatic amino acids containing free pi electrons. The two phenylalanines at positions 440 and 441 could have formed interactions with other aromatic residues that are nearby in the post fusion structure for stabilization. Without these phenylalanines, the protein may rely on other interactions to provide stability which allows for more efficient fusion. Perhaps the alanines mutate to valine or threonine respectively due to the larger size of these residues which in turn positions other residues within the protein in close proximity for interactions. Further studies would be helpful in addressing theses possibilities.

Surprisingly, F440A/F441A/CT9 was not enhanced in either cell surface expression or cell-cell fusion capacity. The cytoplasmic domain of viral fusion proteins such as Alphaviruses (Zhao, Lindqvist et al. 1994) and Retroviruses (Cosson 1996) have been shown to be important factors in the efficient budding of progeny virus. Since previous studies examining the length requirement for the C-terminus of VSV G indicated at least 9 residues are required for the efficient incorporation of $\mathrm{G}$ into virions (Whitt, Chong et al. 1989) the CT9 mutant should be incorporated efficiently. The question as to the advantage this rapidly acquired mutation provides still remains. One possibility is the shorter C-tail is better positioned to interact with the cell membrane which in effect aids in the membrane curvature required for budding of progeny virus. However, one would expect to have seen an enhancement in virus budding in the previous study using a CT9 mutant, so this is likely not the case. Further experimentation would be needed to identify the advantage gained by acquiring the CT9 mutation in the F440A/F441A encoding virus. 


\section{Chapter 5: General Discussion}

\section{Involvement of G Protein in VSV Infection}

Vesicular stomatitis virus is an enveloped virus that must undergo a fusion event mediated by the outer surface protein, $G$, to gain access into a host cell. Viral fusion in enveloped viruses has been widely studied, with Influenza HA being the first fusion protein to be extensively characterized (Wiley, Wilson et al. 1981; Wilson, Skehel et al. 1981). Viral fusion proteins are required for entry into the host cell and function by mediating the membrane merger event between the viral membrane and the host cell membrane. Crystal structure data for fusion proteins has provided much insight as to mechanisms by which these proteins may mediate viral entry, a critical step in the life cycle of the virus. However, since no crystal structure data is available for the membrane-proximal region of these proteins, little is understood in regard to the exact role of this region in membrane fusion. Previous mutational analyses of VSV G have suggested a direct contribution of the membrane-proximal region of the protein to the fusion and budding processes (Robison and Whitt 2000; Jeetendra, Robison et al. 2002; Jeetendra, Ghosh et al. 2003). I am proposing a model for the contribution of the membrane-proximal region of $\mathrm{G}$ in host cell entry of VSV.

VSV G Mediated Entry. Vesicular stomatitis virus enters host cells through receptormediated endocytosis (Matlin, Reggio et al. 1982). The glycoprotein, G, on the outer membrane of the virus binds the host cell through an unknown receptor (Coil and Miller 2004), is endocytosed by clathrin coated vesicles and transported through the endocytic pathway (Matlin, Reggio et al. 1982). Evidence from our lab (Mire 2008), as well as others, suggests the fusion event occurs within the acidic environment of the early endosomes while another group argues transport to late endosomes is required (Le Blanc, Luyet et al. 2005). Upon acidification of the endosome, a reversible conformational change in the $\mathrm{G}$ protein is triggered. The reversible nature of this conformational change is a unique feature of the $G$ protein that has not been observed in other viral fusion proteins (Roche and Gaudin 2002). Once the initial conformational changes occur, the fusion peptide is thought to insert into the target membrane allowing for further conformational changes that pull the two membranes together. A fusion pore is formed and the viral ribonucleocapsid is released into the host cell cytosol where replication takes place. The solution of $\mathrm{G}$ protein crystal structures of $\mathrm{G}$ in both pre- and post fusion forms (Roche, Bressanelli et al. 2006; Roche, Rey et al. 2007) resulted in the classification of a third group of fusion proteins. Fusion proteins that do not fit into class I or class II but have structural homology to VSV G in the post fusion structure are grouped into this class, as well. Further elucidation of the VSV G-mediated fusion mechanism hopefully will provide clues as to the entry processes of less understood viruses. 
Prototypic Class III Fusion Protein. The past few years have provided a wealth of groundbreaking research contributing greatly to our understanding of viral fusion. As mentioned, a new class of fusion proteins (class III) has been identified based on determination of the crystal structures of $\mathrm{G}$ in the pre- and postfusion forms (Roche, Rey et al. 2007) and their homology to the postfusion form of Herpes virus $\mathrm{gB}$ (Heldwein, Lou et al. 2006). More recently, the Baculovirus gp64 (Kadlec, Loureiro et al. 2008) and Epstein-Barr virus $\mathrm{gB}$ postfusion structures have been solved (Backovic, Longnecker et al. 2009) revealing similar postfusion structures to that of VSV G and therefore are grouped in this class. Since VSV G is the only protein in this new group of fusion proteins in which both the pre and postfusion crystal structures have been solved, it serves as the prototype. However, we still have a number of gaps in understanding the exact pathway of VSV G mediated membrane fusion. Intermediate structures of G protein in the transition from the pre-fusion to the postfusion state have yet to be identified and structural information is not available for the membrane-proximal region, leaving many unanswered questions. We are uncertain as to the exact contribution of the membrane-proximal region in achieving the structural transitions leading to membrane fusion or perhaps even in the actual membrane merger event itself. In an effort to further elucidate the membrane fusion pathway of VSV G, the prototypic class III fusion protein, I chose to employ a mutagenesis approach focusing on the membrane-proximal region to identify the possible role of specific residues within this highly conserved region.

\section{VSV G Mediated Membrane Fusion Model}

Based on the available structural data and our recent findings, we have developed a model for the events leading to VSV G mediated membrane fusion (Fig 5-1). VSV G trimers are embedded in the envelope of the virus and thought to sit on the surface of the virion forming "tripods" (Roche, Bressanelli et al. 2006) (Step 1). The fusion domains serve as legs of the tripod with the membrane proximal regions positioned on the interior. The first step in $\mathrm{G}$ mediated membrane fusion is likely the binding of $\mathrm{G}$ to a phospholipid or other ubiquitious molecule on the cell surface (Schlegel, Willingham et al. 1982; Carneiro, Bianconi et al. 2002; Coil and Miller 2004). Once bound to the cell surface the virus is internalized via receptor mediated endocytosis (Matlin, Reggio et al. 1982). At this stage in the fusion pathway $\mathrm{G}$ is likely still in the prefusion conformation that is believed to be stabilized by noncovalent interactions between the fusion domain and the membrane-proximal region (Roche, Bressanelli et al. 2006). As the $\mathrm{pH}$ decreases within the endosome a conformational change occurs in $\mathrm{G}$ that exposes the bipartite fusion loops, enabling them to be inserted into the target membrane (Step 2).

The next step is the clustering of $\mathrm{G}$ trimers at the fusion site. Previous reports in rabies virus indicate a requirement of 13 to $19 \mathrm{G}$ trimers for membrane fusion (Gaudin, Tuffereau et al. 1991). The sequestering of a number of fusion proteins is seen in other viruses such as SFV E1, which has been shown to form rings of 5 to 6 trimers (Gibbons, Reilly et al. 2004; Kielian and Rey 2006). Similarly, a need for clustering of fusion protein trimers has been observed in TBE E (Stiasny, Kiermayr et al. 2006). When only the $\mathrm{C}$-tail, transmembrane domain, and membrane-proximal region of $\mathrm{G}$ are expressed, 


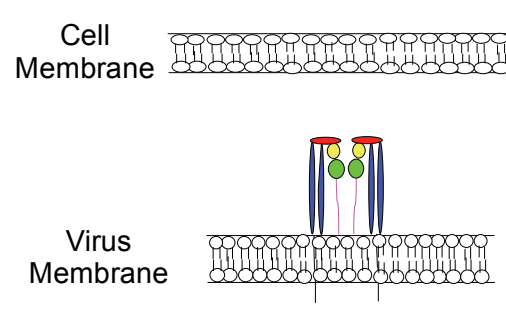

Step 5: Formation of Fusion Pore

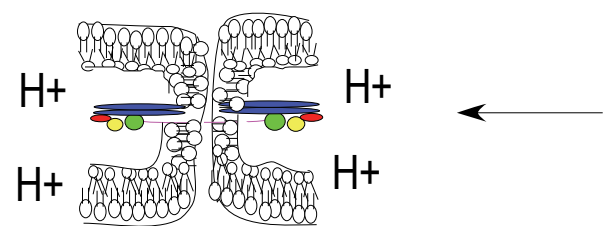

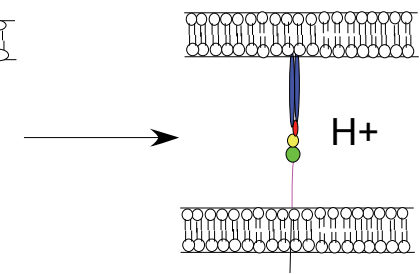

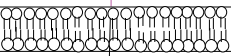
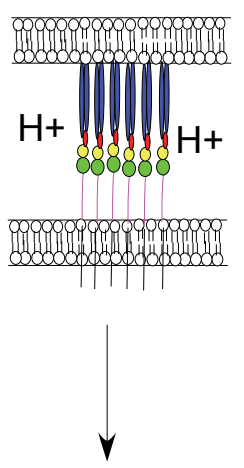

Step 4: Hemifusion Intermediate

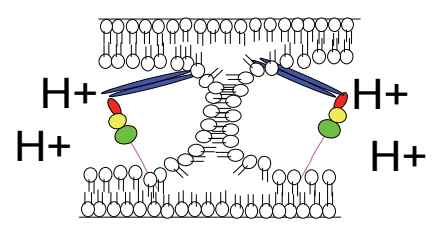

Figure 5-1. Model for VSV G mediated membrane fusion. (Step 1) G trimers sit on the virion surface like "tripods". This model shows the fusion domains (blue) on the interior of the trimer and extending downward toward the virion membrane. The Cterminal domain is extending out of the virion envelope and likely forming interactions with the fusion domain to stabilize the prefusion structure. (Step 2) Once exposed to the low $\mathrm{pH}$ environment of the endosome a conformational change occurs releasing the fusion peptide and allowing for insertion into the target membrane. (Step 3) G trimers cluster at the fusion site possibly through lateral interactions of the membrane-proximal domain. (Step 4) As the $\mathrm{pH}$ decreases in the endosome further conformational changes occur that pulls the two membranes together, forming a hemifusion intermediate. (Step 5) Protonation of specific histidine residues leading to the formation of salt bridges with acidic residues in close proximity "lock" the low $\mathrm{pH}$ structure in place, allowing for fusion pore formation. 
the truncated mutant is able to form trimers on the virion surface (Robison and Whitt 2000). The ability of this mutant to form trimers indicates that the residues within the truncated ectodomain can likely form interactions. Based on these findings, one hypothesis for a role of the membrane-proximal region of $G$ is to recruit enough $G$ trimers to the fusion site to allow for fusion. At this stage, the fusion protein is forming a "pre-hairpin intermediate" and is in an extended structure. The conformation of $\mathrm{G}$ then changes from the extended state that allows for insertion into the target membrane by folding back on itself, bringing the $\mathrm{C}$-terminal end and the fusion domain together. The dramatic conformational change pulls the two opposing membranes into close proximity causing the initial lipid mixing, or hemifusion (step 3).

Histidine protonation has been suggested to drive this low $\mathrm{pH}$-induced structural transition (Carneiro, Stauffer et al. 2003). Upon protonation of specific histidine residues, initial interactions are released, exposing the fusion loops. The protein then folds back on itself and the newly protonated histidines come into proximity with acidic residues in which they can form salt bridges. Formation of these interactions stabilizes this "hairpin" structure so that the highly unfavorable event, membrane merger, can occur (step 5). Histidine has a $\mathrm{pKa}$ of 6 indicating that when $\mathrm{G}$ is exposed to low $\mathrm{pH}$ this residue becomes protonated (Carneiro, Stauffer et al. 2003). The small pH range required for the conformational changes to occur suggests the protonation of only a few ionizable groups is required for the structural changes to occur in $\mathrm{G}$. I hypothesize that $\mathrm{G}$ undergoes the initial conformational changes driven by protonation of histidine residues, such as H148 and H149, (Carneiro, Stauffer et al. 2003) but that protonation of H423 perhaps "locks" this postfusion conformation long enough to allow for outer lipid mixing, then pore formation, leading to release of the nucleocapsid into the host cell cytoplasm. When H423 is deleted (in the mutant $\Delta \mathrm{H} 423 / \mathrm{P} 424 / \mathrm{H} 425$ ) no cell-cell fusion is observed. The mutated protein is still observed to undergo $\mathrm{pH}$ dependent conformational changes suggesting the residue is not critical for the low $\mathrm{pH}$ induced changes, but perhaps for maintaining the stability of the low $\mathrm{pH}$ form. The DDE motif examined in chapter 3 could possibly serve to interact with the newly protonated histidine residues to "lock" the protein in the post-fusion structure. The last step in the fusion process is the complete mixing of the inner and outer leaflets of the two membranes and formation of a fusion pore in which the viral RNP can pass through for release into the host cell cytoplasm.

\section{Rapid Acquisition of Growth Enhancing Mutations}

RNA viruses have a very rapid mutation rate due to the error prone RNA dependent RNA polymerase used for replication. This high rate of mutation likely enables the virus to adapt to a constantly changing environment. Vesicular stomatitis virus serves as an attractive candidate for gene therapy and therefore examination of the rate of mutation has been widely studied. Our findings suggest mutations made to the membrane-proximal region of the virus, producing less infectious virus, are rapidly compensated for through the incorporation of additional mutations. Some of these rapidly acquired mutations appeared to overcome the fusion defect of the original desired mutation (F440A/F441A/S438I, $\Delta H 425 / S 438 I$, and $\Delta H 425 / I 426 S / S 438 I)$. However, 
other mutations arose that showed the same fusion phenotype as was observed for the original intended mutant (F440V/F441A, F440A/F441A/CT9, and F440T/F441A).

These data indicate that the mutations made to the membrane-proximal region of the $\mathrm{G}$ protein affected another stage of the viral life cycle. The viruses with the same fusion defect as the F440A/F441A mutants were able to outgrow their respective parent virus indicating the mutation still provided some benefit, at a stage after the fusion event that enabled the virus to be more infectious. The original constructed mutation resulted in a decrease in the threshold $\mathrm{pH}$ required to trigger fusion between the virus membrane and the host cell endosomal membrane. Previous work in our lab has shown that mutations made to $\mathrm{G}$ protein causing a reduction in the $\mathrm{pH}$ at which fusion occurs resulted in production of less infectious virus (Fredericksen and Whitt 1995). The likely reason for the decrease in viral titers observed for those viruses expressing mutated $G$ proteins with a reduced $\mathrm{pH}$ threshold for fusion is the release of the RNP at a later time point in the endocytic pathway. As the virus traverses the endocytic pathway, the $\mathrm{pH}$ drops. When the $\mathrm{pH}$ reaches between 6.2 and 6.3 the viral membrane undergoes a fusion event with the host cell endosomal membrane, releasing the viral genetic information in to the cell cytoplasm where replication takes place. A G protein with mutations resulting in the requirement of a lower $\mathrm{pH}$ for fusion would cause the RNP to be released at a different point within the endocytic pathway. The fusion defect could possibly thereby have resulted in a replication, assembly, or budding defect. The additional mutations that arose could compensate for the fusion defect as was observed for the mutants that acquired the S428I mutation. However, the F440V/F441A and F440T/F441A mutants did not have restoration of fusion at the optimal $\mathrm{pH}$ for wild type $\mathrm{G}$ protein. These viruses outgrew the F440A/F441A mutant virus indicating the viruses may have mutated to overcome the possible replication, assembly, or budding defect that resulted from the decrease in the $\mathrm{pH}$ required for fusion. The rapid rate in which the additional mutations arise confirms our hypothesis that the membrane-proximal residues are critical to membrane fusion and infectivity of VSV.

\section{Role of GS in VSV Infection}

Studies involving GS have shown that this truncated G protein is present on the wild type VSV virion and can form trimers (Metsikko and Simons 1986; Robison and Whitt 2000). GS, when expressed independently, can bind host cells, induce hemifusion, and potentiate cell-cell fusion when co-expressed with a fusion protein that cannot mediate fusion on its own (Robison and Whitt 2000). Due to the interesting characteristics of this truncated $\mathrm{G}$ protein, questions have arisen in regard to its contribution to infection (if any). The mutational analysis conducted in chapter 3 revealed a $\mathrm{G}$ protein that, when D437, D438, and E439 are mutated to alanines, results in a reduction in cell-cell fusion activity. This phenotype, however, did not correlate with what was seen in the virus. The recombinant virus encoding this mutant $\mathrm{G}$ protein grew to titers similar to that of wild type and formed large plaques when examined by standard plaque assays. Immunoblots of purified virus revealed a significantly larger amount of a C-tail antibody reactive protein which, based on its size, represents GS, than what was seen in wild type VSV. We were unable to successfully immunoblot transiently 
transfected cells to determine if $\mathrm{G}$ is being cleaved in the context of a viral infection or if this same cleavage product can be detected in the transiently transfected cells. One possible explanation for the disconnect in data between the fusion assays performed on transiently transfected cells and the ability of the virus to grow and spread is the ability of GS to potentiate the fusion of viral fusion proteins that cannot fuse independently. Previous reports proposed a model, based on the ability of GS to bind cells, form trimers, and induce hemifusion, suggesting that GS interacts with the target membrane causing destabilization (Jeetendra, Robison et al. 2002).

A cleavage site for G, producing GS, has yet to be identified. Therefore, it is not known at what location in the cell $\mathrm{G}$ protein is truncated. Many viral fusion proteins are proteolytically cleaved during transport through the secretory pathway by furin. Furin is a calcium dependent serine endoprotease that cleaves just downstream of Arg - X(Lys/Arg) - Arg and is enriched in the Golgi. If the DDE mutant G protein is being cleaved by furin resulting in enhanced GS production, the truncated protein likely would be observed in the transiently expressing cells since the furin cleavage occurs in the secretory pathway. Therefore, any affect on fusion capacity would likely be observed in cells transiently expressing the mutant $\mathrm{G}$ protein. Another possibility could be cleavage occurring by enzymes within the acidic envoironment of the endosomes. Since the DDE mutant has a reduced $\mathrm{pH}$ threshold for fusion the virus would travel further on the endocytic pathway. The mutated $\mathrm{G}$ protein could be exposed to enzymes within the late endosomes/lysosomes that cleave G forming GS. This theory could explain the disconnect in data between cell-cell fusion assays using transiently transfected cells versus those infected with recombinant virus. Regardless of the means by which $G$ is cleaved, the experiments in chapter 3 suggest that the increased level of GS on the virion surface helps the virus overcome the fusion defect resultant from the D435A/D436A/E437A mutation. We developed a model suggesting how the GS protein could aid in the VSV G mediated fusion process.

Figure 5-2 depicts how GS could enhance fusion/entry of VSV G by either binding to and destabilizing the target membrane on the outside of the trimers (Fig 5-2A), or interacting with the viral membrane to cause destabilization (Fig 5-2B). Alternatively, GS could be positioned on the inside of the "tripod" and as the membranes are being pulled together the truncated protein could interact with the target membrane causing destabilization and in effect help in the membrane merger event (Fig 5-2C). However, our data merely suggests this possibility and further studies would need to be done to draw further conclusions.

\section{Future Experiments}

To further examine steps in the VSV G mediated vius-cell membrane fusion pathway it would be helpful to identify structural intermediates in the transition from the prefusion form to the low $\mathrm{pH}$ conformation. Identification of these intermediates could give further insight as to the contribution of the membrane proximal region. Determination of these intermediates in the structural rearrangements that lead to fusion 
Figure 5-2. Potential role of GS in VSV G mediated fusion. VSV G trimers are initially present on the virion surface as "tripods" in their prefusion form. Upon exposure to low $\mathrm{pH}, \mathrm{G}$ undergoes a reversible conformational change that initially exposes the fusion peptide and allows for insertion into the target membrane. (A) Once the fusion peptide has inserted into the target membrane it "folds back" on itself pulling the two opposing membranes together. One potential role of GS (shown in red) in VSV G mediated fusion is destabilization of the target membrane when the two membranes are initially being pulled together. (B) Alternately, GS could lay parallel to the virion membrane and interact with the viral envelope to enhance the membrane fusion activity of G. (C) GS could also participate by destabilizing the target membrane at the site where the two opposing membranes are being pulled together. 
A

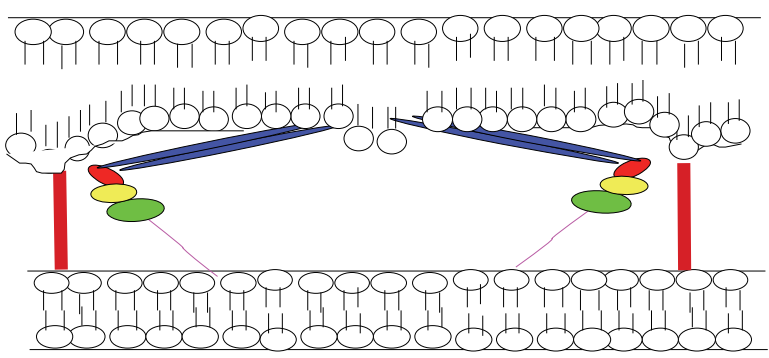

Cell

Membrane

Virus

Membrane

B

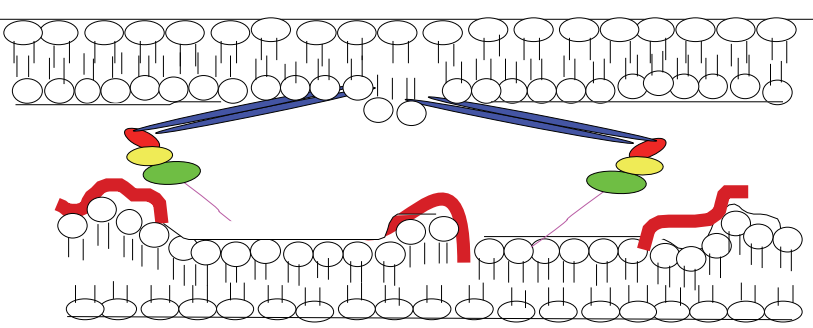

Cell

Membrane

Virus

Membrane

C

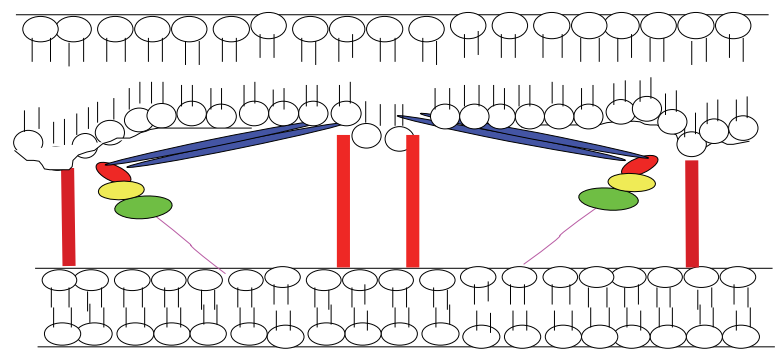

Cell Membrane

Virus

Membrane 
could also provide clues as to the pathway of the other newly characterized class III fusion proteins such as Herpes virus $\mathrm{gB}$, Baculovirus gp64, and Epstein-Barr virus $\mathrm{gB}$. A challenge in studying the transition from the pre- to postfusion conformational change in the $\mathrm{G}$ protein is the inability to detect intermediates with antibodies (as is seen in SFV E1, for example) Previous attempts at generating monoclonal antibodies to the membrane proximal region of $\mathrm{G}$ have been unsuccessful (personal communication with Mike Whitt). Perhaps peptide inhibitors could be designed directed toward the membrane proximal region to determine if structural transitions could be blocked by the interference of the peptides, as seen with PIV-5 F (Russell, Jardetzky et al. 2001).

Data in chapter 3 suggests a critical role of the conserved HPH motif (or just the histidines). An experiment that would help examine the hypothesis that these histidines are involved in stabilization of the post fusion structure would be to do a 3-color fusion assay with $\Delta \mathrm{H} 423 / \mathrm{P} 424 / \mathrm{H} 425$ (fusion defective) to detect if this fusion defective mutant is able to achieve hemifusion. If this mutant were able to achieve hemifusion it would support the idea that the histidines or the HPH motif is important to stabilization of the final, low $\mathrm{pH}$ conformation. Initial conformational changes would allow for insertion of the fusion peptide, further conformational changes would allow for hemifusion to be observed, however if the structure is not stabilized full fusion would not occur (as was observed in chapter 3). Since I propose the mutated residues in chapter 3 are important to the low $\mathrm{pH}$-induced conformational changes it would be helpful to do a trypsinsensitivity assay in which limiting amounts of trypsin is used to look at the stability of the conformational changes.

I also think that additional mutations in the membrane proximal region could provide more conclusive evidence regarding specific residues in this region. For example, H423 (the histidine proposed to form a salt bridge with D137) should be mutated to determine if this one histidine residue is critical to G-mediated membrane fusion. Likewise, my model for VSV G mediated membrane fusion suggests the possible role of hydrophobic residues. Further mutational analysis in which hydrophobic residues, such as F421, I426, L433, L439, and L446 are changed to alanines to identify if the hydrophobicity of this region plays a role in the virus-cell fusion pathway of G. Furthermore, it would be interesting to mutate the serine at position 438 (that was mutated to an isoleucine in several of the variants) to an isoleucine to see if an enhanced fusion or cell surface expression phenotype could be observed to explore the advantage of the amino acid change to virus entry. The mutants from chapter 3 should also be examined for their budding capacity at early time points and experiments should be done to measure the replication capacity (real time PCR could be used to measure this).

The D435A/D436A/D437A mutant provides the first possible evidence for a role for GS in the context of its natural expression on the virion surface. However, the data (in chapter 3) only suggests the possibility that GS functions to enhance fusion activity (possibly even more when environmental pressures are limiting the ability of the virus to grow and spread efficiently). Unfortunately, experiments in which detection of GS in cells transiently transfected with either wild type G or D435A/D436A/E437A were unsuccessful, leaving doubt as to the level of cleaved G (GS) on the cell surface in the 
context of transient expression. Optimization of this experiment should be explored by immunoprecipitating the protein from overexpressing cells. One problem in the experiment has been the amount of protein is very small making detection challenging. Likewise, when the experiment is done on cell lysates that have not been immunoprecipitated non-specific interactions are detected preventing visualization of GS.

An experiment that would help determine the proximity of GS on the virion (or cell) surface is the use of electonmicroscopy with immunogold labeling This suggestion is based on experiments done by Dr. Doug Lyles (Wake Forest University) that identified the localization of $\mathrm{G}$ in microdomains on the virion surface (Brown and Lyles 2003). This experiment would answer the question as to whether G and GS are even located in the same microdomains to determine if both proteins are even present at the fusion site simultaneously.

In conclusion, these studies have given further insight to the VSV G mediated membrane fusion pathway by identifying residues within the membrane-proximal region of which no structural information is available. Gaining a better understanding of the Gmediated fusion event also can give provide clues as to the mechanisms other class III fusion proteins utilize, in particular human pathogens such as herpes simplex EpsteinBarr viruses. 


\section{List of References}

Allison, S. L., J. Schalich, et al. (1995). "Oligomeric rearrangement of tick-borne encephalitis virus envelope proteins induced by an acidic pH." J Virol 69(2): 695700.

Bach, M., P. Bringmann, et al. (1990). "Purification of small nuclear ribonucleoprotein particles with antibodies against modified nucleosides of small nuclear RNAs." Methods Enzymol. 181: 232-257.

Backovic, M., R. Longnecker, et al. (2009). "Structure of a trimeric variant of the Epstein-Barr virus glycoprotein B." Proc Natl Acad Sci U S A 106(8): 2880-2885.

Balch, W. E. (1989). "Biochemistry of interorganelle transport. A new frontier in enzymology emerges from versatile in vitro model systems." J Biol Chem 264: $16965-16968$.

Berger, E. A. (1998). "And the best picture is--the HIV gp120 envelope, please!" Nat Struct Biol 5(8): 671-674.

Berger, E. A., P. M. Murphy, et al. (1999). "Chemokine receptors as HIV-1 coreceptors: roles in viral entry, tropism, and disease." Annu Rev Immunol 17: 657-700.

Bhella, R. S., S. T. Nichol, et al. (1998). "Structure, expression and phylogenetic analysis of the glycoprotein gene of Cocal virus." Virus Res 54(2): 197-205.

Bilsel, P. A. and S. T. Nichol (1990). "Polymerase errors accumulating during natural evolution of the glycoprotein gene of vesicular stomatitis virus Indiana serotype isolates." J Virol 64(10): 4873-4883.

Blumenthal, R., D. P. Sarkar, et al. (1996). "Dilation of the influenza hemagglutinin fusion pore revealed by the kinetics of individual cell-cell fusion events." $\underline{\mathrm{J} \text { Cell }}$ Biol 135(1): 63-71.

Bottomley, M. J., K. Salim, et al. (1998). "Phospholipid-binding protein domains." Biochim Biophys Acta 1436(1-2): 165-183.

Brown, E. L. and D. S. Lyles (2003). "Organization of the vesicular stomatitis virus glycoprotein into membrane microdomains occurs independently of intracellular viral components." J Virol 77(7): 3985-3992.

Brun, G., X. Bao, et al. (1995). "The relationship of Piry virus to other vesiculoviruses: a re-evaluation based on the glycoprotein gene sequence." Intervirology 38: 274282.

Bullough, P. A., F. M. Hughson, et al. (1994). "Structure of influenza haemagglutinin at the $\mathrm{pH}$ of membrane fusion." Nature 371: 37-43.

Carneiro, F. A., M. L. Bianconi, et al. (2002). "Membrane recognition by vesicular stomatitis virus involves enthalpy-driven protein-lipid interactions." J Virol 76(8): 3756-3764.

Carneiro, F. A., F. Stauffer, et al. (2003). "Membrane fusion induced by vesicular stomatitis virus depends on histidine protonation." J Biol Chem 278(16): 1378913794.

Carnell, L. and H. P. Moore (1994). "Transport via the regulated secretory pathway in semi-intact PC12 cells: role of intra-cisternal calcium and $\mathrm{pH}$ in the transport and sorting of secretogranin II." J Cell Biol 127(3): 693-705. 
Carr, C. M., C. Chaudhry, et al. (1997). "Influenza hemagglutinin is spring-loaded by a metastable native conformation." Proc Natl Acad Sci (USA) 94(26): 1430614313.

Chan, D. C., D. Fass, et al. (1997). "Core structure of gp41 from the HIV envelope glycoprotein." Cell 89(2): 263-273.

Chen, S. S. L., N. Ariel, et al. (1988). "Membrane anchors of vesicular stomatitis virus: characterization and incorporation into virions." J Virol 62: 2552-2556.

Chernomordik, L. V., G. B. Melikyan, et al. (1987). "Biomembrane fusion: a new concept derived from model studies using two interacting planar lipid bilayers." Biochim Biophys Acta 906(3): 309-352.

Choe, H., M. Farzan, et al. (1996). "The beta-chemokine receptors CCR3 and CCR5 facilitate infection by primary HIV-1 isolates." Cell 85(7): 1135-1148.

Coil, D. A. and A. D. Miller (2004). "Phosphatidylserine is not the cell surface receptor for vesicular stomatitis virus." J Virol 78(20): 10920-10926.

Corey, E. A., A. M. Mirza, et al. (2003). "Fusion deficiency induced by mutations at the dimer interface in the Newcastle disease virus hemagglutinin-neuraminidase is due to a temperature-dependent defect in receptor binding." J Virol 77(12): 69136922.

Corver, J., A. Ortiz, et al. (2000). "Membrane fusion activity of tick-borne encephalitis virus and recombinant subviral particles in a liposomal model system." Virology 269(1): 37-46.

Cosson, P. (1996). "Direct interaction between the envelope and matrix proteins of HIV1." Embo J 15(21): 5783-5788.

Crise, B., A. Ruusala, et al. (1989). "Oligomerization of glycolipid-anchored and soluble forms of the vesicular stomatitis virus glycoprotein." J Virol 63: 5328-5333.

Cross, K. J., S. A. Wharton, et al. (2001). "Studies on influenza haemagglutinin fusion peptide mutants generated by reverse genetics." EMBO J 20(16): 4432-4442.

Daniels, T. S., J. C. Downie, et al. (1985). "Fusion mutants of the influenza virus hemagglutinin glycoprotein." Cell 40: 431-439.

de Silva, A., I. Braakman, et al. (1993). "Posttranslational folding of vesicular stomatitis virus $\mathrm{G}$ protein in the ER: involvement of noncovalent and covalent complexes." $\mathrm{J}$ Cell Biol 120: 647-655.

de Silva, A. M., W. E. Balch, et al. (1990). "Quality control in the endoplasmic reticulum: folding and misfolding of vesicular stomatitis virus $\mathrm{G}$ protein in cells and in vitro." J Cell Biol 111: 857-866.

Decroly, E., M. Vandenbranden, et al. (1994). "The convertases furin and PC1 can both cleave the human immunodeficiency virus (HIV)-1 envelope glycoprotein gp160 into gp120 (HIV-1 SU) and gp41 (HIV-I TM)." J Biol Chem 269(16): 1224012247.

Demaurex, N., W. Furuya, et al. (1998). "Mechanism of acidification of the trans-Golgi network (TGN). In situ measurements of $\mathrm{pH}$ using retrieval of TGN38 and furin from the cell surface." J Biol Chem 273(4): 2044-2051.

Doms, R. W., D. S. Keller, et al. (1987). "Role for adenosine triphosphate in regulating the assembly and transport of vesicular stomatitis virus G protein trimers." J Cell Biol 105: 1957-1969. 
Doms, R. W., A. Ruusala, et al. (1988). "Differential effects of mutations in three domains on folding, quaternary structure, and intracellular transport of vesicular stomatitis virus G protein." J Cell Biol. 107: 89-99.

Doms, R. W. and D. Trono (2000). "The plasma membrane as a combat zone in the HIV battlefield." Genes Dev 14(21): 2677-2688.

Drake, J. W. (1999). "The distribution of rates of spontaneous mutation over viruses, prokaryotes, and eukaryotes." Ann N Y Acad Sci 870: 100-107.

Drake, J. W. and J. J. Holland (1999). "Mutation rates among RNA viruses." Proc Natl Acad Sci U S A 96(24): 13910-13913.

Durrer, P., Y. Gaudin, et al. (1995). "Photolabeling identifies a putative fusion domain in the envelope glycoprotein of rabies and vesicular stomatitis viruses." J Biol Chem 270(29): 17575-17581.

Earp, L. J., S. E. Delos, et al. (2005). "The many mechanisms of viral membrane fusion proteins." Curr Top Microbiol Immunol 285: 25-66.

Eckert, D. M. and P. S. Kim (2001). "Design of potent inhibitors of HIV-1 entry from the gp41 N-peptide region." Proc Natl Acad Sci U S A 98(20): 11187-11192.

Fredericksen, B. L. and M. A. Whitt (1995). Mutations affecting the $\mathrm{pH}$ threshold for vesicular stomatitis virus $G$ protein mediated membrane fusion. 14th Annual American Society for Virology Meeting, Austin, TX.

Fredericksen, B. L. and M. A. Whitt (1995). "Vesicular stomatitis virus glycoprotein mutations that affect membrane fusion activity and abolish virus infectivity." $\underline{\mathrm{J}}$ Virol 69: 1435-1443.

Fredericksen, B. L. and M. A. Whitt (1996). "Mutations at two conserved acidic amino acids in the glycoprotein of vesicular stomatitis virus affect $\mathrm{pH}$-dependent conformational changes and reduce the $\mathrm{pH}$ threshold for membrane fusion." Virology 217: 49-57.

Fredericksen, B. L. and M. A. Whitt (1998). "Attenuation of recombinant vesicular stomatitis viruses encoding mutant glycoproteins demonstrate a critical role for maintaining a high $\mathrm{pH}$ threshold for membrane fusion in viral fitness." Virology 240: 349-358.

Fuerst, T. R., E. P.L., et al. (1987). "Use of a hybrid vaccinia virus-T7 RNA polymerase system for expression of target genes." Mol Cell Biol. 7: 2538-2544.

Gallione, C. J. and J. K. Rose (1983). "Nucleotide sequence of a cDNA clone encoding the entire glycoprotein from the New Jersey serotype of vesicular stomatitis virus." J Virol 46: 162-169.

Gaudin, Y., P. de Kinkelin, et al. (1999). "Mutations in the glycoprotein of viral haemorrhagic septicaemia virus that affect virulence for fish and the $\mathrm{pH}$ threshold for membrane fusion." J Gen Virol 80 ( Pt 5)(Pt 5): 1221-1229.

Gaudin, Y., H. Raux, et al. (1996). "Identification of amino acids controlling the low-pHinduced conformational change of rabies virus glycoprotein." J Virol 70: 73717378.

Gaudin, Y., C. Tuffereau, et al. (1991). "Reversible conformational changes and fusion activity of rabies virus glycoprotein." J Virol 65: 4853-4859.

Gething, M. J., K. McCammon, et al. (1986). "Expression of wild-type and mutant forms of influenza hemagglutinin: the role of folding in intracellular transport." Cell 46: 939-950. 
Gibbons, D. L., B. Reilly, et al. (2004). "Purification and crystallization reveal two types of interactions of the fusion protein homotrimer of Semliki Forest virus." J Virol 78(7): 3514-3523.

Gravel, K. A. and T. G. Morrison (2003). "Interacting domains of the HN and F proteins of newcastle disease virus." J Virol 77(20): 11040-11049.

Hallenberger, S., V. Bosch, et al. (1992). "Inhibition of furin-mediated cleavage activation of HIV-1 glycoprotein gp160." Nature 360(6402): 358-361.

Harlan, J. E., P. J. Hajduk, et al. (1994). "Pleckstrin homology domains bind to phosphatidylinositol-4,5-bisphosphate." Nature 371(6493): 168-170.

Heinz, F. X. and C. Kunz (2004). "Tick-borne encephalitis and the impact of vaccination." Arch Virol Suppl 18(18): 201-205.

Heldwein, E. E., H. Lou, et al. (2006). "Crystal structure of glycoprotein B from herpes simplex virus 1." Science 313(5784): 217-220.

Helenius, A. and J. Kartenbeck (1980). "The effects of octylglucoside on the Semliki Forest virus membrane: evidence for a spike-nucleocapsid interaction." Eur J Biochem. 106: 613-618.

Hercyk, N., S. M. Horikami, et al. (1988). "The vesicular stomatitis virus L protein possesses the mRNA methyltransferase activities." Virology 163: 222-225.

Hernandez, L. D., L. R. Hoffman, et al. (1996). "Virus-cell and cell-cell fusion." Ann Rev Cell Dev Biol. 12: 627-661.

Huang, R. T., R. Rott, et al. (1981). "Influenza viruses cause hemolysis and fusion of cells." Virology 110(1): 243-247.

Hughson, F. M. (1997). "Enveloped viruses: a common mode of membrane fusion?" Curr Biol 7(9): R565-569.

Iverson, L. E. and J. K. Rose (1981). "Localized attenuation and discontinuous synthesis during vesicular stomatitis virus transcription." Cell 23: 477-484.

Iverson, L. E. and J. K. Rose (1982). "Sequential synthesis of 5'-proximal vesicular stomatitis virus mRNA sequences." J Virol 44: 356-365.

Jahn, R. and T. C. Sudhof (1999). "Membrane fusion and exocytosis." Annu Rev Biochem 68: 863-911.

Jayakar, H. R. and M. A. Whitt (2002). "Identification of two additional translation products from the matrix $(\mathrm{M})$ gene that contribute to vesicular stomatitis virus cytopathology." J Virol 76(16): 8011-8018.

Jeetendra, E., K. Ghosh, et al. (2003). "The membrane-proximal region of vesicular stomatitis virus glycoprotein $\mathrm{G}$ ectodomain is critical for fusion and virus infectivity." J Virol 77(23): 12807-12818.

Jeetendra, E., C. S. Robison, et al. (2002). "The membrane-proximal domain of vesicular stomatitis virus $\mathrm{G}$ protein functions as a membrane fusion potentiator and can induce hemifusion." J Virol 76(23): 12300-12311.

Kadlec, J., S. Loureiro, et al. (2008). "The postfusion structure of baculovirus gp64 supports a unified view of viral fusion machines." Nat Struct Mol Biol 15(10): 1024-1030.

Kampmann, T., D. S. Mueller, et al. (2006). "The Role of histidine residues in low-pHmediated viral membrane fusion." Structure 14(10): 1481-1487.

Kearney, C. M., J. Donson, et al. (1993). "Low level of genetic drift in foreign sequences replicating in an RNA virus in plants." Virology 192(1): 11-17. 
Kielian, M., S. Keranen, et al. (1984). "Membrane fusion mutants of Semliki Forest virus." J Cell Biol 98: 139-145.

Kielian, M. and F. A. Rey (2006). "Virus membrane-fusion proteins: more than one way to make a hairpin." Nat Rev Microbiol 4(1): 67-76.

Kim, J. H., L. Johannes, et al. (1998). "Noninvasive measurement of the $\mathrm{pH}$ of the endoplasmic reticulum at rest and during calcium release." Proc Natl Acad Sci U S A 95(6): 2997-3002.

Kim, J. H., C. A. Lingwood, et al. (1996). "Dynamic measurement of the pH of the Golgi complex in living cells using retrograde transport of the verotoxin receptor." $\underline{J}$ Cell Biol 134(6): 1387-1399.

Knipe, D. M., D. Baltimore, et al. (1977). "Maturation of viral proteins in cells infected with temperature- sensitive mutants of vesicular stomatitis virus." J Virol 21(3): 1149-1158.

Kuzmin, P. I., J. Zimmerberg, et al. (2001). "A quantitative model for membrane fusion based on low-energy intermediates." Proc Natl Acad Sci U S A 98(13): 72357240.

Lapham, C. K., J. Ouyang, et al. (1996). "Evidence for cell-surface association between fusin and the CD4-gp120 complex in human cell lines." Science 274(5287): 602605.

Lawson, N. D., E. A. Stillman, et al. (1995). "Recombinant vesicular stomatitis viruses from DNA." Proc Natl Acad Sci (USA) 92(10): 4477-4481.

Le Blanc, I., P. P. Luyet, et al. (2005). "Endosome-to-cytosol transport of viral nucleocapsids.[see comment]." Nature Cell Biology 7(7): 653-664.

Lecocq-Xhonneux, F., M. Thiry, et al. (1994). "A recombinant viral haemorrhagic septicaemia virus glycoprotein expressed in insect cells induces protective immunity in rainbow trout." J Gen Virol 75 ( Pt 7)(Pt 7): 1579-1587.

Lefrancois, L. and D. S. Lyles (1982). "The interaction of antibody with the major surface glycoprotein of vesicular stomatitis virus. I. analysis of neutralizing epitopes with monoclonal antibodies." Virology 121: 157-167.

Lefrancois, L. and D. S. Lyles (1982). "The interaction of antibody with the major surface glycorprotein of vesicular stomatitis virus. II. monoclonal antibodies to nonneutralizing and cross-reactive epitopes of Indiana and New Jersey serotypes." Virology 121: 168-174.

Lemmon, M. A. and K. M. Ferguson (2000). "Signal-dependent membrane targeting by pleckstrin homology (PH) domains." Biochem J 350 Pt 1: 1-18.

Lentz, B. R., V. Malinin, et al. (2000). "Protein machines and lipid assemblies: current views of cell membrane fusion." Curr Opin Struct Biol 10(5): 607-615.

Lescar, J., A. Roussel, et al. (2001). "The fusion glycoprotein shell of Semliki Forest virus: an icosahedral assembly primed for fusogenic activation at endosomal pH." Cell 105(1): 137-148.

Li, Y., C. Drone, et al. (1993). "Mutational analysis of the vesicular stomatitis virus glycoprotein G for membrane fusion domains." J Virol 67: 4070-4077.

Liao, M. and M. Kielian (2006). "Functions of the stem region of the Semliki Forest virus fusion protein during virus fusion and assembly." J Virol 80(22): 11362-11369. 
Liao, M. and M. Kielian (2006). "Site-directed antibodies against the stem region reveal low $\mathrm{pH}$-induced conformational changes of the Semliki Forest virus fusion protein." J Virol 80(19): 9599-9607.

Lyles, D. S., M. McKenzie, et al. (1992). "Subunit interactions of vesicular stomatitis virus envelope glycoprotein stabilized by binding to viral matrix protein." J Virol 66: $349-358$.

Lyles, D. S. and M. O. McKenzie (1998). "Reversible and irreversible steps in assembly and disassembly and vesicular stomatitis virus: equilibria and kinetics of dissociation of nucleocapsid-M protein complexes assembled in vivo." Biochemistry 37: 439-450.

Lyles, D. S., V. A. Varela, et al. (1990). "Dynamic nature of the quaternary structure of the vesicular stomatitis virus envelope glycoprotein." Biochemistry 29: 24422449.

Machamer, C. E., R. W. Doms, et al. (1990). "Heavy chain binding protein recognizes incompletely disulfide-bonded forms of vesicular stomatitis virus $G$ protein." $\underline{\mathrm{J}}$ Biol Chem 265: 6879-6883.

Maddon, P. J., A. G. Dalgleish, et al. (1986). "The T4 gene encodes the AIDS virus receptor and is expressed in the immune system and the brain." Cell 47: 333-348.

Maddon, P. J., J. S. McDougal, et al. (1988). "HIV infection does not require endocytosis of its receptor, CD4." Cell 54(6): 865-874.

Maeda, T. and S. Ohnishi (1980). "Activation of influenza virus by acidic media causes hemolysis and fusion of erythrocytes." FEBS Lett 122(2): 283-287.

Marriott, A. C. (2005). "Complete genome sequences of Chandipura and Isfahan vesiculoviruses." Arch Virol 150(4): 671-680.

Masters, P. S., R. S. Bhella, et al. (1989). "Structure and expression of the glycoprotein gene of Chandipura virus [published erratum appears in Virology 1990 Feb;174(2):630]." Virology 171(1): 285-290.

Mathieu, M. E., P. R. Grigera, et al. (1996). "Folding, unfolding, and refolding of the vesicular stomatitis virus glycoprotein." Biochemistry 35(13): 4084-4093.

Matlin, K., H. Reggio, et al. (1982). "The pathway of vesicular stomatitis entry leading to infection." J Mol Biol 156: 609-631.

Matlin, K. S., H. Reggio, et al. (1982). "Pathway of vesicular stomatitis virus entry leading to infection." J Mol Biol 156(3): 609-631.

McClure, M. O., M. Marsh, et al. (1988). "Human immunodeficiency virus infection of CD4-bearing cells occurs by a pH-independent mechanism." EMBO J 7(2): 513518.

Melikyan, G. B., R. M. Markosyan, et al. (2000). "Evidence that the transition of HIV-1 gp41 into a six-helix bundle, not the bundle configuration, induces membrane fusion." J Cell Biol 151(2): 413-423.

Melikyan, G. B., W. D. Niles, et al. (1993). "Influenza virus hemagglutinin-induced cellplanar bilayer fusion: quantitative dissection of fusion pore kinetics into stages." J Gen Physiol 102(6): 1151-1170.

Melikyan, G. B., W. D. Niles, et al. (1993). "Influenza hemagglutinin-mediated fusion pores connecting cells to planar membranes: flickering to final expansion." J Gen Physiol 102(6): 1131-1149. 
Metsikko, K. and K. Simons (1986). "The budding mechanism of spikeless vesicular stomatitis virus particles." EMBO J. 5: 1913-1920.

Mire, Chad E., "Investigation of the vesicular stomatitis virus matrix protein: uncoating and assembly" (Ph.D. dissertation, University of Tennessee Health Science Center, 2008), 44-56.

Miyauchi, K., Y. Kim, et al. (2009). "HIV enters cells via endocytosis and dynamindependent fusion with endosomes." Cell 137(3): 433-444.

Nieva, J. L., R. Bron, et al. (1994). "Membrane fusion of Semliki Forest virus requires sphingolipids in the target membrane." Embo J 13(12): 2797-2804.

Odenwald, W. F., H. Arnheiter, et al. (1986). "Stereo images of vesicular stomatitis virus assembly." J Virol 57: 922-932.

Porotto, M., M. Murrell, et al. (2005). "Influence of the human parainfluenza virus 3 attachment protein's neuraminidase activity on its capacity to activate the fusion protein." J Virol 79(4): 2383-2392.

Qin, Z. L., Y. Zheng, et al. (2009). "Role of conserved histidine residues in the low-pH dependence of the Semliki Forest virus fusion protein." J Virol 83(9): 4670-4677.

Quinones-Kochs, M. I., M. J. Schnell, et al. (2001). "Mechanisms of loss of foreign gene expression in recombinant vesicular stomatitis viruses." Virology 287(2): 427435.

Rebecchi, M. J. and S. Scarlata (1998). "Pleckstrin homology domains: a common fold with diverse functions." Annu Rev Biophys Biomol Struct 27: 503-528.

Reithmeier, R. A. (1995). "Characterization and modeling of membrane proteins using sequence analysis." Curr Opin Struct Biol 5(4): 491-500.

Rigaut, K. D., D. E. Birk, et al. (1991). "Intracellular distribution of input vesicular stomatitis virus proteins after uncoating." J Virol 65: 2622-2628.

Robison, C. S. and M. A. Whitt (2000). "The membrane-proximal stem region of vesicular stomatitis virus G protein confers efficient virus assembly." J Virol 74: 2239-2246.

Roche, S., S. Bressanelli, et al. (2006). "Crystal structure of the low-pH form of the vesicular stomatitis virus glycoprotein G." Science 313(5784): 187-191.

Roche, S. and Y. Gaudin (2002). "Characterization of the equilibrium between the native and fusion-inactive conformation of rabies virus glycoprotein indicates that the fusion complex is made of several trimers." Virology 297(1): 128-135.

Roche, S., F. A. Rey, et al. (2007). "Structure of the prefusion form of the vesicular stomatitis virus glycoprotein G." Science 315(5813): 843-848.

Rose, J. K., L. Buonocore, et al. (1991). "A new cationic liposome reagent mediating nearly quantitative transfection of animal cells." BioTechniques 10: 520-525.

Rose, J. K., R. F. Doolittle, et al. (1982). "Homology between the glycoproteins of vesicular stomatitis virus and rabies virus." J Virol 43: 361-364.

Rose, J. K. and C. J. Gallione (1981). "Nucleotide sequences of the mRNA's encoding the vesicular stomatitis virus $\mathrm{G}$ and $\mathrm{M}$ proteins determined from cDNA clones containing the complete coding regions." J Virol 39: 519-528.

Rose, J. K., W. J. Welch, et al. (1980). "Vesicular stomatitis virus glycoprotein is anchored in the viral membrane by a hydrophobic domain near the $\mathrm{COOH}$ terminus." Proc Natl Acad Sci USA 77: 3884-3888. 
Rose, J. K. and M. A. Whitt (2001). Rhabdoviridae: the viruses and their replication. Field's Virology. D. Knipe and P. M. Howley. Philadelphia, Lippincott Williams \& Wilkins. 1: 1221-1244.

Roussel, A., J. Lescar, et al. (2006). "Structure and interactions at the viral surface of the envelope protein E1 of Semliki Forest virus." Structure 14(1): 75-86.

Ruigrok, R. W., N. G. Wrigley, et al. (1986). "Electron microscopy of the low pH structure of influenza virus haemagglutinin." Embo J 5(1): 41-49.

Russell, C. J., T. S. Jardetzky, et al. (2001). "Membrane fusion machines of paramyxoviruses: capture of intermediates of fusion." Embo J 20(15): 4024-4034.

Salminen, A., J. M. Wahlberg, et al. (1992). "Membrane fusion process of Semliki Forest virus. II: cleavage-dependent reorganization of the spike protein complex controls virus entry." J Cell Biol 116(2): 349-357.

Salzwedel, K., J. T. West, et al. (1999). "A conserved tryptophan-rich motif in the membrane-proximal region of the human immunodeficiency virus type 1 gp41 ectodomain is important for Env-mediated fusion and virus infectivity." J Virol 73(3): 2469-2480.

Schlegel, R., M. C. Willingham, et al. (1982). "Saturable binding sites for vesicular stomatitis virus on the surface of Vero cells." J Virol 43(3): 871-875.

Schnell, M. J., L. Buonocore, et al. (1996). "The minimal conserved transcription stopstart signal promotes stable expression of a foreign gene in vesicular stomatitis virus." J Virol 70(4): 2318-2323.

Schnell, M. J., J. E. Johnson, et al. (1997). "Construction of a novel virus that targets HIV-1-infected cells and controls HIV-1 infection [see comments]." Cell 90(5): 849-857.

Schubert, M., J. D. Keene, et al. (1980). "Site of the vesicular stomatitis virus genome sqecifying polyadenylation and the end of the L gene mRNA." J Virol 34: 550559.

Seksek, O., J. Biwersi, et al. (1996). "Evidence against defective trans-Golgi acidification in cystic fibrosis." J Biol Chem 271(26): 15542-15548.

Shokralla, S., R. Chernish, et al. (1999). "Effects of double-site mutations of vesicular stomatitis virus glycoprotein $\mathrm{G}$ on membrane fusion activity." Virology 256(1): 119-129.

Skehel, J. J. and D. C. Wiley (1998). "Coiled coils in both intracellular vesicle and viral membrane fusion." Cell 95(7): 871-874.

Skehel, J. J. and D. C. Wiley (2000). "Receptor binding and membrane fusion in virus entry: the influenza hemagglutinin." Annu Rev Biochem 69: 531-569.

Smith, A. E. and A. Helenius (2004). "How viruses enter animal cells." Science 304(5668): 237-242.

Spiropoulou, C. F. and S. T. Nichol (1993). "A small highly basic protein is encoded in overlapping frame within the $\mathrm{P}$ gene of vesicular stomatitis virus." $\mathrm{J}$ Virol 67: 3103-3110.

Stadler, K., S. L. Allison, et al. (1997). "Proteolytic activation of tick-borne encephalitis virus by furin." J Virol 71(11): 8475-8481.

Stein, B. S., S. D. Gowda, et al. (1987). "pH-independent HIV entry into CD4-positive T cells via virus envelope fusion to the plasma membrane." Cell 49(5): 659-668. 
Steinhauer, D. A., J. C. De La Torre, et al. (1989). "High nucleotide substitution error frequencies in clonal pools of vesicular stomatitis virus." J Virol 63(5): 20632071.

Stiasny, K., S. Kiermayr, et al. (2006). "Cryptic properties of a cluster of dominant flavivirus cross-reactive antigenic sites." J Virol 80(19): 9557-9568.

Stiasny, K., C. Koessl, et al. (2003). "Involvement of lipids in different steps of the flavivirus fusion mechanism." J Virol 77(14): 7856-7862.

Swinteck, B.D. and D.S. Lyles (2008). "Plasma membrane microdomains containing vesicular stomatitis virus $M$ protein are separate from microdomains containing $G$ protein and nucleocapsids." J Virol 82(11): 5536-5547.

Takada, A., C. Robison, et al. (1997). "A novel system for functional analysis of Ebola virus glycoprotein." Proc Natl Acad Sci USA 94: 14764-14769.

Takimoto, T., G. L. Taylor, et al. (2002). "Role of the hemagglutinin-neuraminidase protein in the mechanism of paramyxovirus-cell membrane fusion." J Virol 76(24): 13028-13033.

Thomas, D., W. W. Newcomb, et al. (1985). "Mass and molecular composition of vesicular stomatitis virus: a scanning transmission electron microscopy analysis." J Virol 54: 598-607.

Trkola, A., T. Dragic, et al. (1996). "CD4-dependent, antibody-sensitive interactions between HIV-1 and its co-receptor CCR-5." Nature 384(6605): 184-187.

Wahlberg, J. M., R. Bron, et al. (1992). "Membrane fusion of Semliki Forest virus involves homotrimers of the fusion protein." J Virol 66: 7309-7318.

Weissenhorn, W., A. Dessen, et al. (1997). "Atomic structure of the ectodomain from HIV-1 gp41." Nature 387(6631): 426-430.

Wengler, G. and G. Wengler (1989). "Cell-associated West Nile flavivirus is covered with E+pre-M protein heterodimers which are destroyed and reorganized by proteolytic cleavage during virus release." J Virol 63(6): 2521-2526.

White, J., K. Matlin, et al. (1981). "Cell fusion by Semliki Forest, influenza and vesicular stomatitis virus." J Cell Biol 89: 674-679.

White, J. M., S. E. Delos, et al. (2008). "Structures and mechanisms of viral membrane fusion proteins: multiple variations on a common theme." Critical Reviews in Biochemistry \& Molecular Biology 43(3): 189-219.

Whitt, M. A., L. Buonocore, et al. (1991). "Membrane fusion activity, oligomerization, and assembly of the rabies virus glycoprotein." Virology 185: 681-688.

Whitt, M. A., L. Chong, et al. (1989). "Glycoprotein cytoplasmic domain sequences required for rescue of a vesicular stomatitis virus glycoprotein mutant." J Virol 63: $3569-3578$.

Wild, C., J. W. Dubay, et al. (1994). "Propensity for a leucine zipper-like domain of human immunodeficiency virus type 1 gp41 to form oligomers correlates with a role in virus-induced fusion rather than assembly of the glycoprotein complex." Proc Natl Acad Sci USA 91(26): 12676-12680.

Wiley, D. C. and J. J. Skehel (1987). "The structure and function of the hemagglutinin membrane glycoprotein of influenza virus." Ann Rev Biochem 56: 365-394.

Wiley, D. C., I. A. Wilson, et al. (1981). "Structural identification of the antibodybinding sites of Hong Kong influenza haemagglutinin and their involvement in antigenic variation." Nature 289(5796): 373-378. 
Wilson, I., J. Skehel, et al. (1981). "Structure of the hemagglutinin membrane glycoprotein of Influenza virus at 3 A resolution." Nature (London) 289: 366-373.

Wilson, I. A., J. J. Skehel, et al. (1981). "Structure of the haemagglutinin membrane glycoprotein of influenza virus at 3 A resolution." Nature 289(5796): 366-373.

Wu, H., D. G. Myszka, et al. (1996). "Kinetic and structural analysis of mutant CD4 receptors that are defective in HIV gp120 binding." Proc Natl Acad Sci U S A 93(26): 15030-15035.

Wu, M. M., M. Grabe, et al. (2001). "Mechanisms of pH regulation in the regulated secretory pathway." J Biol Chem 276(35): 33027-33035.

Wyatt, R. and J. Sodroski (1998). "The HIV-1 envelope glycoproteins: fusogens, antigens, and immunogens." Science 280(5371): 1884-1888.

Zagouras, P. and J. K. Rose (1993). "Dynamic equilibrium between vesicular stomatitis virus glycoprotein monomers and trimers in the Golgi and at the cell surface." $\underline{J}$ Virol 67: 7533-7538.

Zagouras, P., A. Ruusala, et al. (1991). "Dissociation and reassociation of oligomeric viral glycoprotein subunits in the endoplasmic reticulum." J Virol 65: 1976-1984.

Zhang, L. and H. P. Ghosh (1994). "Characterization of the putative fusogenic domain in vesicular stomatitis virus glycoprotein G." J Virol 68: 2186-2193.

Zhang, X. L., J. R. Wang, et al. (2003). "[Expression, purification and identification of recombinant SARS coronavirus membrane protein]." Sheng Wu Hua Xue Yu Sheng Wu Wu Li Xue Bao (Shanghai) 35(12): 1140-1144.

Zhao, H., B. Lindqvist, et al. (1994). "A tyrosine-based motif in the cytoplasmic domain of the alphavirus envelope protein is essential for budding." EMBO J 13: 42044211.

Zhu, P., J. Liu, et al. (2006). "Distribution and three-dimensional structure of AIDS virus envelope spikes." Nature 441(7095): 847-852.

Zilberstein, A., M. D. Snider, et al. (1980). "Mutants of vesicular stomatitis virus blocked at different stages in maturation of the viral glycoprotein." Cell 21(2): 417-427.

Zimmerberg, J., R. Blumenthal, et al. (1994). "Restricted movement of lipid and aqueous dyes through pores formed by influenza hemagglutinin during cell fusion." $\underline{\mathrm{J} \text { Cell }}$ Biol 127(6 Pt 2): 1885-1894. 


\section{Vita}

Elizabeth Lane Matheny was born in Bluefield, West Virginia on September 16, 1981 and primarily grew up in Ft. Myers, Florida. She graduated from high school in May of 1999 and accepted a full tennis scholarship to attend The University of South Carolina Aiken where she majored in biology. Upon graduation in May of 2003 with a BS in biology from The University of South Carolina Aiken she enrolled at The University of Tennessee Health Science Center in the department of Molecular Sciences. Subsequently, she joined the lab of Michael A. Whitt, Ph.D. for her doctoral research. Lane expects to graduate with a Ph.D. in Molecular Biology in December 2009. 